Andrews University

Digital Commons @ Andrews University

2020

\title{
Music Notation-to-Color Synesthesia and Early Stages of Music Education: A Grounded Theory Study
}

Eduardo Sola Chagas Lima

Andrews University, solachagas@andrews.edu

Follow this and additional works at: https://digitalcommons.andrews.edu/dissertations

Part of the Curriculum and Instruction Commons, and the Music Education Commons

\section{Recommended Citation}

Sola Chagas Lima, Eduardo, "Music Notation-to-Color Synesthesia and Early Stages of Music Education: A Grounded Theory Study" (2020). Dissertations. 1722.

https://digitalcommons.andrews.edu/dissertations/1722

https://dx.doi.org/10.32597/dissertations/1722

This Dissertation is brought to you for free and open access by the Graduate Research at Digital Commons @ Andrews University. It has been accepted for inclusion in Dissertations by an authorized administrator of Digital Commons@ Andrews University. For more information, please contact repository@andrews.edu. 


\begin{abstract}
MUSIC NOTATION-TO-COLOR SYNESTHESIA AND EARLY STAGES OF MUSIC EDUCATION:

A GROUNDED THEORY STUDY
\end{abstract}

by

Eduardo Sola Chagas Lima

Chair: Anneris Coria-Navia 


\section{ABSTRACT OF GRADUATE RESEARCH}

Dissertation

Andrews University

School of Education

\section{Title: MUSIC NOTATION-TO-COLOR SYNESTHESIA AND EARLY STAGES OF MUSIC EDUCATION: A GROUNDED THEORY STUDY}

Name of Researcher: Eduardo Sola Chagas Lima

Name and degree of faculty chair: Anneris Coria-Navia, Ed.D.

Date completed: April 2020

\section{Problem}

Synesthesia is a neurological condition characterized by over-abundant neural connectivity between commonly highly specialized areas of the brain. The developmental form of the condition often results in automatic and consistent cross-sensory associations between perceived stimuli and commonly unrelated brain regions. This research contemplates the specific form of music notation-to-color synesthesia and its impact on early stages of music education. Synesthetes with this mode of the condition tend to involuntarily yet consistently associate music-notational concepts with colors, thus rendering their assimilation of these concepts unique and individualized. The purpose of this study is to determine the extent of these individualized experiences from original narratives. 


\section{Method}

This study entails a grounded theory qualitative approach, through which 12 from participants were interviewed cross-culturally ( 7 featured nationalities). All participants were adults with music notation-to-color synesthesia who experienced music instruction in a Western cultural context. Data collection methodology involved a written survey, inperson (or live Zoom) interviews, and shared document analysis. Qualitative analytical methodology was used via coding strategies to discover surfacing themes, emerging issues, and commonalities among the narratives.

\section{Results}

Five overarching categories of commonalities were identified in this study. Firstly, participants shared generalities of synesthetic perceptions of music notation involving color, such as their awareness about their condition, the qualities of their experiences, the conceptual basis of their associations, among other characteristics. Interviewees also alluded to the mechanisms involved in the perception of music notation, such as the positive impact of their music notation-to-color synesthesia on memory as well as the negative implications of synesthetic incongruence. The spatial location of synesthetic perceptions varied among participants. Interviewees reported projecting on the page of music and associating in their "mind's eye"-two common themes in the literature. Some participants, however, have also mentioned a middleground location that does not fit only one of these categories.

Finally, this study analyzed themes relating to the implications of this form of synesthesia for music education, with attention to awareness on the part of educators, 
instructional intentionality, validation, reinforcement of student individuality, and conscious use of the condition. Moreover, other themes and future research possibilities were analyzed.

\section{Conclusion}

This study arrived at two grounded theory models. The first comprises a grounded theory of the experiences shared by participants. This theoretical model articulates the salient themes, such as positive and negative traits of notation-to-color perceptions and spatial location of perceptions. In special, this theory argues for a tendency for conceptually-based notation-to-color synesthesia among participants.

The second grounded theory model advanced in this research entails an educational approach that would benefit awareness and intentionality in addressing students with music notation-to-color synesthesia. It discusses philosophical foundations, a theoretical framework, and methodological considerations that may transform how music notation-to-color students are accounted for in curricula.

The study concludes by offering pedagogical suggestions derived from the methodological considerations. Firstly, it advances a linear process for identification, verification, and addressing of synesthesia. Secondly, it proposes the elimination of excessive notational information and gradual learning as initial strategies that could benefit music notation-to-color synesthetes in learning new notational elements. 
Andrews University

School of Education

\title{
MUSIC NOTATION-TO-COLOR SYNESTHESIA AND \\ EARLY STAGES OF MUSIC EDUCATION: A GROUNDED THEORY STUDY
}

\author{
A Dissertation \\ Presented in Partial Fulfillment \\ of the Requirements for the Degree \\ Doctor of Philosophy
}

by

Eduardo Sola Chagas Lima

April 2020 
(C) Copyright by Eduardo Sola Chagas Lima 2020 All Rights Reserved 


\title{
MUSIC NOTATION-TO-COLOR SYNESTHESIA AND \\ EARLY STAGES OF MUSIC EDUCATION: \\ A GROUNDED THEORY STUDY
}

\author{
A dissertation \\ presented in partial fulfillment \\ of the requirements for the degree \\ Doctor of Philosophy
}

by

Eduardo Sola Chagas Lima

APPROVAL BY THE COMMITTEE:

Chair: Anneris Coria-Navia

Member: Jay Brand

External: Michael Haverkamp

\section{Member: Sean Day}

College of Education and International

Services, Dean Alayne Thorpe
Date approved 


\section{TABLE OF CONTENTS}

LIST OF ILLUSTRATIONS ..................................................................... viii

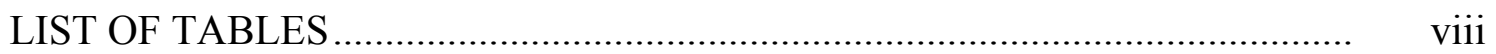

LIST OF ABBREVIATIONS .................................................................. ix

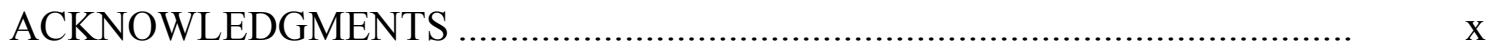

Chapter

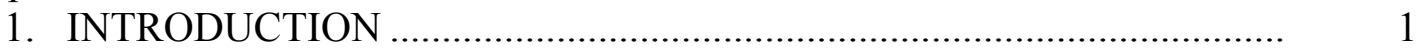

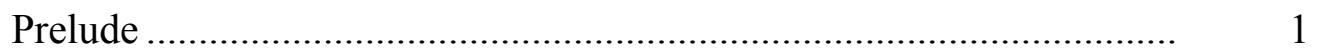

Statement of the Problem........................................................................ 6

Purpose of the Study ………………………..................................... 11

Research Questions........................................................................... 11

Research Approaches...................................................................... 12

Qualitative Approach ............................................................... 12

Role of the Researcher................................................................ 12

Conceptual Framework ...................................................................... 13

Methodological Procedures ......................................................... 14

Strategies for Validation and Evaluation ........................................ 17

Narrative Structure of the Dissertation ............................................ 18

Rationale and Significance of the Study .............................................. 19

Limitations/Delimitations ..................................................................... 19

Limitations .................................................................... 19

Delimitations...................................................................... 22

Definition of Key Terminology ........................................................ 22

Chapter 1 Summary ........................................................................ 23

2. HISTORICAL CONTEXT ................................................................ 25

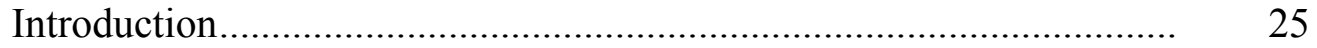

Background ................................................................................ 26

Synesthesia and Differentiated Education ............................................ 28

Differentiated Education and the American Curriculum....................... 31

Early Evidences of Differentiated Education ................................. 32

1920s-1960s: Further Evidences of Individuality in Education ..... 35

1960s-Present: Radical Changes..................................................... 39

A Place for Synesthesia in Education ................................................... 42 
Conclusory Thoughts on the American Curriculum........................... 45

Centrality of Music Notation ............................................................ 46

The Evolution of Notation in Western Culture....................................... 47

Music Notation and the Present Research ........................................ $\quad 50$

Closing Remarks ......................................................................... 52

Chapter 2 Summary ..................................................................... 53

3. LITERATURE REVIEW ............................................................. 54

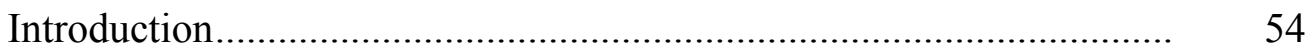

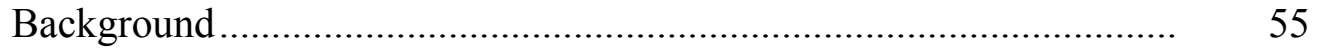

Thematic Review of Extant Literature.............................................. 56

Synesthesia Testing/Verification ............................................... 57

Synesthesia and Education .................................................... 59

Music-to-color Synesthesia ...................................................... $\quad 60$

Visual-to-visual Synesthesia: Grapheme-to-color Synesthesia ...... 65

Synesthetic Memory ............................................................ 68

Synesthetic Color and Memory...................................... $\quad 70$

Advantages of Synesthetic Memory ................................... 71

Synesthetic Incongruence ................................................... $\quad 72$

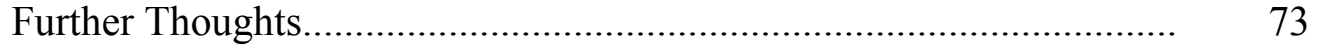

Chapter 3 Summary ................................................................... 74

4. METHODOLOGY ….......................................................................... $\quad 75$

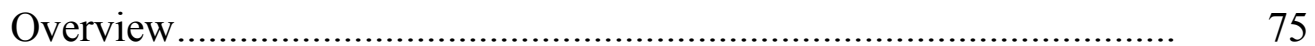

Research Sample......................................................................... 77

Research Population ....................................................................... 79

Research Design and Structure .................................................... 80

Data Collection Methods .................................................................. 82

Data Analysis and Synthesis.......................................................... 85

Ethical Considerations ............................................................... 88

Trustworthiness and Validation ................................................... 89

Triangulation.................................................................... 89

Role of the Researcher............................................................. 9

Recapitulation of Research Significance ............................................ 91

Chapter 4 Summary ..................................................................... 91

5. GENERALITIES OF PERCEPTION OF MUSIC NOTATION .............. 92

Overview ............................................................................. 92

Demographics ............................................................................. 93

Quality of Perception .................................................................... 97

Awareness (About One's Synesthesia) .............................................. 103

Late Discovery .......................................................................... 105

Other Modes of Synesthesia ......................................................... 106 
Perfect Pitch ................................................................................ 107

Conceptual Basis ........................................................................... 110

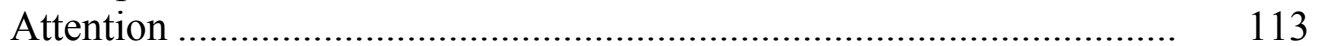

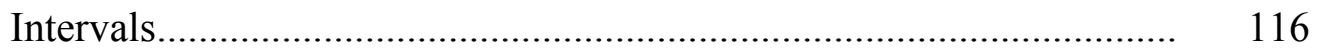

Romanticizing (of Synesthesia) ....................................................... 117

Difficulty in Recalling Experience ..................................................... 118

Multisensory Experiences vs. Synesthesia ………………………….... 119

Chapter 5 Summary ....................................................................... 121

6. MECHANISMS OF PERCEPTION OF MUSIC NOTATION ………....... 122

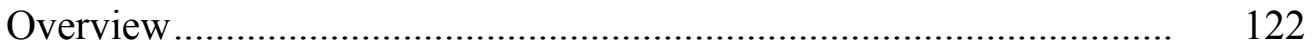

Positive Aspects of Synesthesia.............................................................. 123

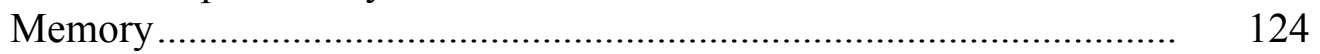

Improvisation ........................................................................ 129

Negative Aspects of Synesthesia ..................................................... 131

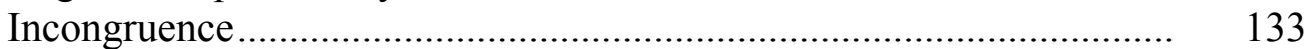

As a Source of Annoyance.......................................................... 133

Between Clefs ........................................................................... 135

Between Fingerings and Pitches .................................................. 137

Further Insights ......................................................................... 139

Chapter 6 Summary ........................................................................ 141

7. LOCATION OF PERCEPTION OF MUSIC NOTATION ……………...... 142

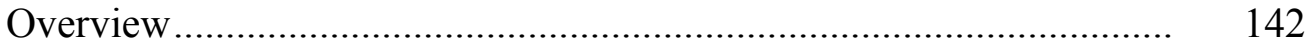

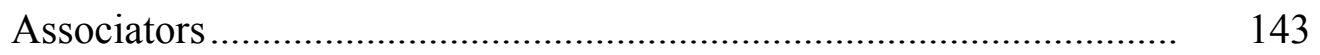

Projectors ..................................................................................... 144

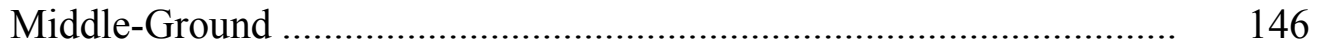

Chapter 7 Summary ……………………………….......................... 149

8. IMPLICATIONS FOR EDUCATION ……............................................... 151

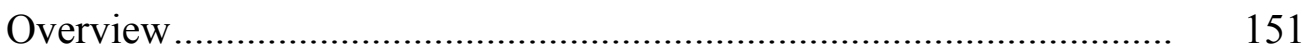

Awareness (on the Part of Educators)................................................. 152

Teacher Intentionality ................................................................... 155

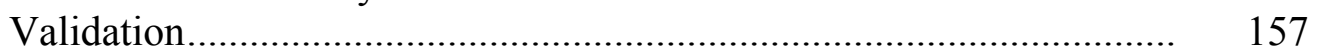

Reinforcement of Individuality ......................................................... 160

Memorizing.................................................................................. 163

Creativity and Imagination ............................................................. 167

Community ............................................................................ 168

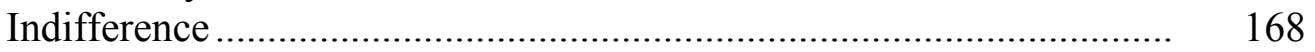

Chapter 8 Summary …………………………………..................... 169 
Overview

Positive Attitude Towards Research .................................................. 171

Researcher-Synesthete Relatability ................................................... 174

Further Studies ......................................................................... 176

Terminology Frequency..................................................................... 177

Chapter 9 Summary ......................................................................... 179

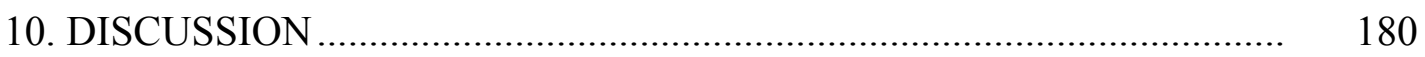

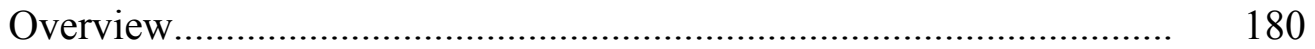

Grounded Theory of Perception ........................................................... 181

Theory Overview ………………….......................................... 181

Notation-to-color Perception Traits ............................................... 182

Location of Association.............................................................. 184

Conceptual Basis ........................................................................ 185

Positive and Negative Traits........................................................ 186

Grounded Theory of Educational Approach......................................... 187

Theory Overview ……………………………………........ 187

Phase 1: Philosophical Foundation......................................... 188

Awareness........................................................... 188

Intentionality........................................................... 190

Phase 2: Framework ............................................................... 191

Priority for Individuality............................................... 191

Validation and Encouragement ...................................... 192

Phase 3: Methodological Considerations ................................ 193

Chapter 10 Summary ………………………………........................ 195

11. PRACTICAL IMPLICATIONS ……………………............................. 196

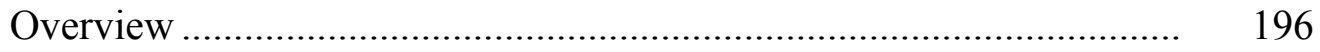

Individualized Instruction................................................................ 197

One-on-one Music Instruction ...................................................... 203

Reality: the Classroom Music Teacher ......................................... 204

Eliminating Excessive Notational Information ................................... 206

Gradual Learning for Transfer .......................................................... 208

Zone of Proximal Development (ZPD) ........................................ 209

Chapter 11 Summary ................................................................ 211

Closing Thoughts ......................................................................... 212

Appendix

A. RECRUITMENT LETTER ……………………………………..... 219 
B. INFORMED CONSENT DISCLAIMER/FORM.................................. 222

C. SURVEY AND SEMI-STRUCTURED INTERVIEW PROTOCOLS 225

D. INTERVIEW FLOWCHART............................................................ 227

E. CODING CATEGORIZATION/HIERARCHY ……………………..... 229

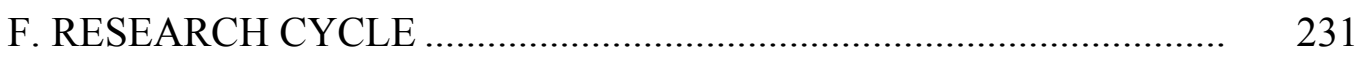

G. IRB APPROVAL ……………………………………………... 233

H. THEORETICAL PLAN: PERCEPTION ……………………….......... 235

I. THEORETICAL MODEL: EDUCATIONAL APPROACH ................. 237

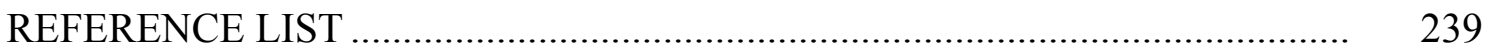

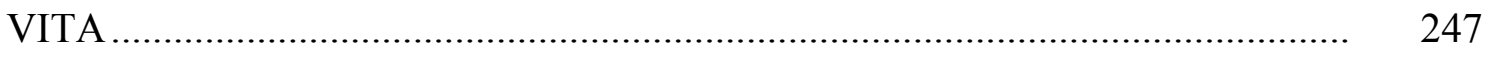




\section{LIST OF ILLUSTRATIONS}

1. My Synesthetic Perception ........................................................................ 2

2. Elaboration of Rachlin's (2005) Representation of Müller's Law ..................... 5

3. Comparison of Different Neumatic Notations ................................................. 48

4. Gustav Mahler, Symphony No. 5, Mov. 1, "Trauermarsch”............................... 50

5. Ludwig van Beethoven, Sonata No. 12, Op. 36, Mov. 1 …………………….... 51

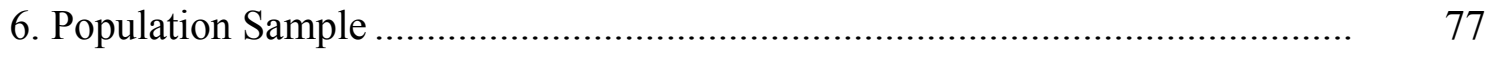

7. Ethnic Distribution of Participants.................................................................... 97

8. An Example of Debbra's Perception of Different Pitches.................................. 136

9. James' Perception of Music Notation ............................................................. 150

10. The Color Associations of Kailey’s Student.................................................... 162

11. Heidi's Color Codes Used to Learn Guitar................................................... 166

12. Terminology Frequency Word Cloud Obtained from Narratives...................... 178

13. Location of Association Continuum .............................................................. 184

14. Instructional Intentionality in Practice ....................................................... 200

15. Vygotsky's (1987) Zone of Proximal Development (ZPD) ............................. 210

\section{LIST OF TABLES}

1. Preliminary Survey Partial Results by Participant................................................ 94

2. Level of Education and Level of Music Education by Participant ..................... 95 


\section{LIST OF ABBREVIATIONS}

$\begin{array}{ll}\text { ADHD } & \text { Attention Deficit Hyperactivity Disorder } \\ \text { ASA } & \text { American Synesthesia Association } \\ \text { ASCD } & \text { Association for Supervision and Curriculum Development } \\ \text { AS-UK } & \text { United Kingdom Synesthesia Association } \\ \text { fMRI } & \text { Functional Magnetic Resonance Imaging } \\ \text { IASAS } & \text { International Association of Synesthetes, Artists, and Scientists } \\ \text { IRB } & \text { Institutional Review Board } \\ \text { MRI } & \text { Magnetic Resonance Imaging } \\ \text { NIH } & \text { National Institutes of Health } \\ \text { ZPD } & \text { Zone of Proximal Development }\end{array}$




\section{ACKNOWLDGMENTS}

Primarily, I would like to thank God for strength and endurance. I thank my parents Marcia and Edinei for their unwavering support. My fiancée Shania Wollmann was fundamental in her patience and encouragement throughout the writing of this

dissertation - thank you. I would also like to thank my advisors Sean Day and Jay Brand for their recommendations and my external examiner Michael Haverkamp. In special, I would like to thank the chair of the dissertation committee, Anneris Coria-Navia, for her ongoing mentorship throughout my work, for believing in me, and for always treating me as a colleague.

Thank you to Andrews University for providing quality instruction and facilitating substantial funding for my studies through different avenues. I would like to thank Burman University for the financial support; in special, thank you to my colleagues Nicole Bartolay and Noble Donkor for making funding possible.

Finally, I could not forget to express gratitude to the participants in this qualitative research who dedicated their time and attention in sharing their experiences with me, thus making this study possible. Thank you for your insightful contributions and for cheering me on in my endeavor to understand this mode of synesthesia. It is my hope that this research goes a long way helping the next generation of synesthetes and inspiring further studies. 


\section{CHAPTER 1}

\section{INTRODUCTION}

\section{Prelude}

My tenth sonata is a sonata of insects.

Insects are born from the sun...

they are the sun's kisses...

How unified world-understanding is when you look at things this way. In science all is dis-unified, not made into one.

It is analysis, not synthesis.

-Alexander Scriabin (Bowers, 1996)

In a highly science-geared society, with its priority for scientific methods that are still heavily Newtonian-Cartesian in nature, mechanistic, and reductionist, we find ourselves as educators facing exceptions to established pedagogical norms that constantly challenge our traditionalized music-teaching methodologies. Although the semiotics of music documentation has been crystallized into norms integral to a growingly universal — albeit heavily Westernized — notational system, perceptions and expressions of music can still vary drastically from one person to another. Everyone, to a greater or lesser extent, perceives music differently, but synesthetes with music-related forms of the condition experience music in a unique way. Synesthesia connected to music notation, in particular, adds one or more extra layers of meaning to this notated language, in terms of what it has to communicate through its symbols and graphic concepts. Figure 1 loosely 
represents how I perceive a hypothetical musical passage written in modern notation, since early stages of music education, as extracted from a scholarly paper I published a few years ago (Lima, 2015) addressing the phenomenology of my music perception. Because of my synesthetic perception, notated musical concepts (as well as other graphic symbols, such as numbers and letters) are automatically and involuntarily associated with a specific color.

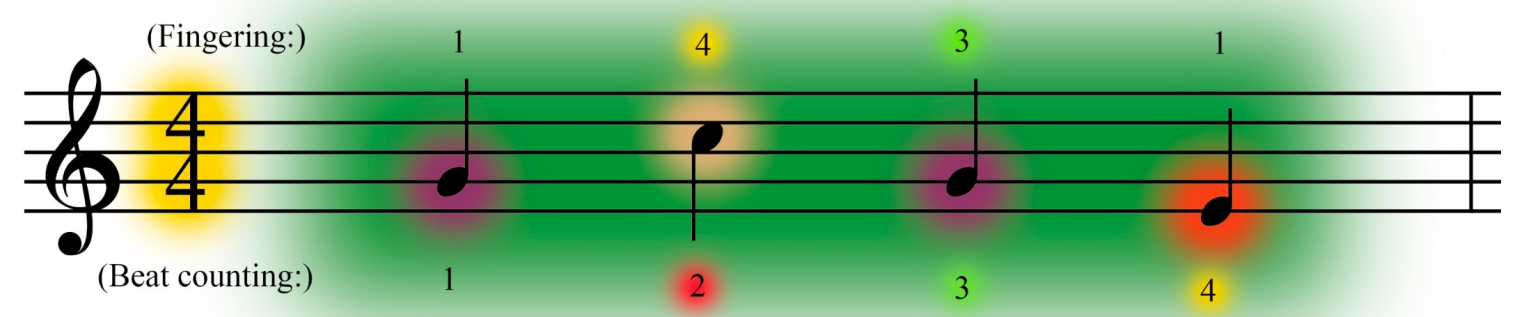

Figure 1. My synesthetic perception, adapted from Lima, (2015).

In fact, the uniqueness and individuality of my experience have often challenged established music-pedagogical methodologies as ineffective throughout my music instruction. At times, due to the overload of information and frequently conflating color associations, my learning of music was wearying. At other times, my music notation-tocolor synesthesia has been advantageous when it comes to my musical memory and improvisational/compositional skills. Music notation-to-color synesthesia has always informed who I am and what I do as a music learner, musician, and music instructor. It has informed my experience during my learning stages and played a role in my early 
music education. My perception has posed challenges as well as added facilities that put my experience in stark contrast with that of "normal", non-synethete peers, adding unique qualities to it.

This dissertation proposal contemplates developmental synesthetes' experiences of the automatic association of color and notated musical concepts throughout early stages of music instruction. Developmental synesthesia is the congenital form of a neurological condition that causes cross-talk between typically specialized areas of the brain, often resulting in concurrent perceptual sensations as automatic responses to various inducing stimuli (Simner \& Hubbard, 2013).

In discussing the causes of synesthesia, Ward (2013) identifies proximal and distal (or ultimate) features that, combined, may lead to the manifestation of developmental synesthesia. Among the proximal causes, the author alludes to structural differences in a synesthete's brain—leading to more abundant neural connections in comparison to the non-synesthetic brain (Ward, 2013, p. 58). A second proximal cause mentioned by Ward (2013) is functional differences found in synesthetes, entailing neural pathways that are present in all brains, but inhibited in non-synesthetes (p. 59).

Since proximal features cannot be considered as singular causes of synesthesia, Ward (2013) also proposes two distal (or ultimate) causes. Firstly, he alludes to the genetic component, in attesting to the pervading nature of synesthesia among families (p. 61). The author proposes that this genetic component can lead to a failure to prune synaptic connections between temporarily connected brain areas in the transition from childhood to adulthood. This points to the developmental nature of congenital forms of synesthesia. Ward (2013) also suggests, additionally, that there might be a genetically- 
caused overgrowth of synaptic connections in synesthetes' brains in combination with a failure to prune them throughout brain development (p. 61-62). The second distal cause discussed by Ward (2013) is the environmental factor. He proposes that the synesthesia may only manifest if environmental factors such as exposure to literacy, cultural constructs, among other concepts, are involved in this developmental process (Ward, 2013, p. 62).

Synesthesia may also be conceptualized as an exception to Johann Müller's “law of specific never energies". Müller helped coin this theory in the nineteenth-century, although it shows Cartesian roots, and is still studied and used today in psychology (Rachlin, 2005, p. 43). The "law" proposes that there are no commonalities between the quality of a perceived object and the actual sensorial perception of that object. Perception is, ultimately, mediated by sensorial organs and the neural pathways that they involve (Rachlin, 2005, p. 43). Because this research involves the perception of visual inputs in the form of music notation, this theory is worth discussing in further depth.

Figure 2 exemplifies Müller's law, in an elaboration of the graphic representation of the perceptual process of visual inputs proposed by Rachlin (2005). The author suggests that, more commonly, the perception of a visual concept, when passing through the respective sensorial organ, and processed in the mind, yields a unique and specific sensation. In the context of this research, according to Rachlin (2005), a musical note (A, for instance), as represented in a visual concept notated on a page of music, would be processed in the brain as " $\mathrm{x} \rightarrow \mathrm{x}$ " " and ultimately cause the sensation " $\mathrm{X}$ " that the brain would associate with the idea of that note. Müller's law would remain consistent for any another note: $\mathrm{B} \rightarrow \mathrm{y} \rightarrow \mathrm{y}^{1} \rightarrow \mathrm{Y}$, and so forth. 


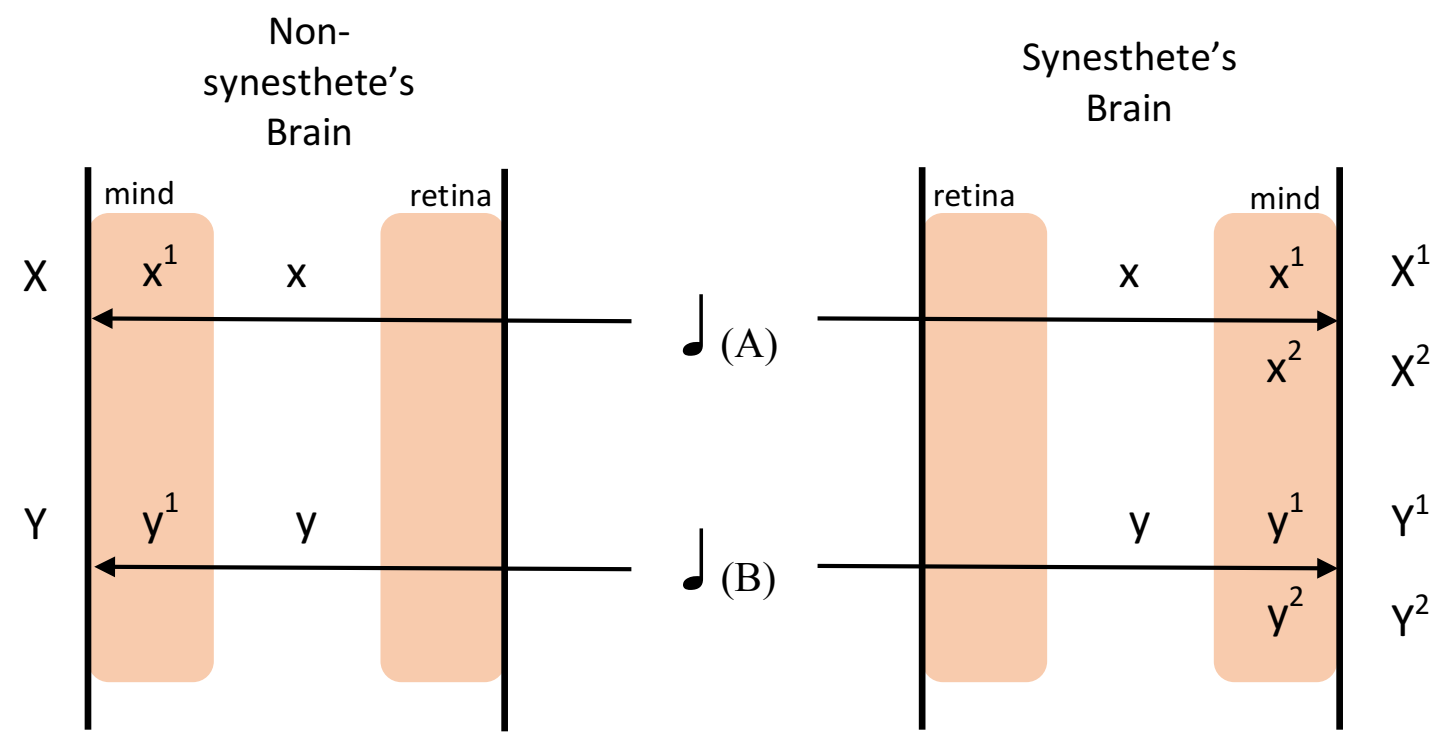

Figure 2. Elaboration of Rachlin's (2005) representation of Müller's law (p. 42. 44).

Synesthesia seems to pose an exception to this law in that it may elicit two or more sensations associated with a perceived concept. A given note (A), in this case, may be perceived by the appropriate sensorial organ and elicit multiple sensations: $\mathrm{A} \rightarrow \mathrm{x} \rightarrow \mathrm{x}^{1}$ $\rightarrow \mathrm{X}^{1}$; or $\mathrm{A} \rightarrow \mathrm{x} \rightarrow \mathrm{x}^{2} \rightarrow \mathrm{X}^{2}$; or $\mathrm{A} \rightarrow \mathrm{x} \rightarrow \mathrm{x}^{\mathrm{n}} \rightarrow \mathrm{X}^{\mathrm{n}}$. The same would be true for another note (B): $\mathrm{B} \rightarrow \mathrm{y} \rightarrow \mathrm{y}^{1} \rightarrow \mathrm{Y}^{1}$; or $\mathrm{B} \rightarrow \mathrm{y} \rightarrow \mathrm{y}^{2} \rightarrow \mathrm{Y}^{2}$; or $\mathrm{B} \rightarrow \mathrm{y} \rightarrow \mathrm{y}^{\mathrm{n}} \rightarrow \mathrm{Y}^{\mathrm{n}}$. In a nutshell, perceived concepts can elicit multiple sensations and may, in fact, involve more than one brain area (Ward, 2013). In the context of this research, the synesthetic perception of a visual input, such as music-notational element or concept, may elicit more than one ultimate sensation (heretofore called concurrent sensations).

Concurrent synesthetic sensations are normally consistent throughout a synesthete's lifetime (Ward, 2013) and it is hypothesized here that it may pose challenges and advantages in the process of music-learning. More specifically, this dissertation 
includes individuals with notational concept-based music-related synesthesia and explores the quality of their experience, in describing how their perception of modern music notation may have impacted positively or negatively their learning of music.

This dissertation aims to approach both these challenges and facilities in more detail by analyzing individual narratives and accounts of these unique experiences. In collecting narratives cross-culturally from individuals who experience notation-to-color synesthesia or correlated forms of the condition and analyzing this data by means of qualitative methodology, this research proposes potential music-pedagogical methodologies that could optimize music learning on the part of synesthetes during early stages of their music education. It also mentions current standard methodologies that could be avoided or substituted in teaching these individuals effectively. In hypothesizing that music synesthesia affects the learning of music significantly, this research evaluates how these narratives intersect, revealing their commonalities and discrepancies.

\section{Statement of the Problem}

Although the term "music synesthesia" is used rather loosely in the literature to describe cross-sensory cognitive processes that involve music or music-related elements, there is a myriad of other forms of synesthesia that may have no direct impact on the perception of music. In fact, modes of the conditions such as touch-to-flavor, odor-toshape, or pain-to-color synesthesia, to name a few of the vast array of synesthetic possibilities, would have no direct impact on the perception of music and the cognition involved in musical activities, but others such as grapheme-to-color or number-to-color may. This research looks specifically at individuals with notation-based music-related synesthesia, that is, the mode of the condition that impacts the perception and cognitive 
processing of modern music notation. More specifically, it involves individuals that have music notation-to-color synesthesia (a visual-to-visual) form of music synesthesia. It also considers other music-related and non-music-related forms of the condition that may impact the perception of music notation tangentially. In other words, the focus of this research is the experiences of synesthetes with music notation-to-color synesthesia, with attention to other synesthetic experiences they may have that influence their notation-tocolor perception.

As the results of this research will show, most of the participants interviewed for this study manifested multiple modes of synesthesia. Beyond experiencing notation-tocolor synesthesia, these individuals reported other forms of the condition, some of which are music-related, some of which are not. Although the focus of this study is notation-tocolor due to the centrality of music notation in teaching music-related concepts, their notation-to-color synesthesia interacted with these other music-related forms of the condition. Several participants drew upon other forms of their synesthesia, especially grapheme-to-color, to further explain the mechanisms of their music notation-to-color mode. There is some attention in this research to these other modes whenever they suggest a connection with the notation-to-color form or have been a vehicle for participants to explain their experience. Some of the narratives included in the results of this research point to these other forms, many of which are music-related.

Day (2008) suggests at least ten types of music-to-color synesthesia (p. 283) other than notation-to-color, such as timber-to-color, heard pitch-to-color, etc. While the focus in this dissertation remains on music notation-to-color and the graphic elements involved in the documentation of Western music, other forms of synesthesia may interact with it. 
Denying this interaction and rejecting portions of the collected narratives that allude to these other modes would not have adequately accounted for these experiences thoroughly. When other tangential forms of synesthesia are mentioned in this study, they are referred to as such within their context. The potential for synesthesia to be considered as an exception to Müller's law discussed above — due to the poly-modal perceptual nature - stands as another argument for a consideration of tangential modes of synesthesia that may impact notation-to-color directly.

As I have suggested, certain modes of synesthesia can affect the perception of music notation dramatically. Expectedly, such experiences are both frequent and recurrent for developmental synesthetes (Ward, 2013) that manifest notation-based forms of synesthesia and who are engaged in the learning music. Yet, these experiences have not been specifically studied to-date in terms of how they affect perception qualitatively from individual to individual. Although some studies have approached the topic, as I will outline below in the literature review, they are still few and the scope rather narrow in terms of exploring the quality of synesthetic perceptions of music systematically and cross-culturally.

Because synesthesia is estimated to affect roughly four percent of the population, according to recent studies (Cytowic, 2018; Simner et al., 2006; Simner \& Hubbard, 2013), music education approaches to this condition would greatly benefit children and adults who experience early stages of learning in this unique way and are, more specifically, undertaking music as an object of study. Notation-to-color synesthesia is but one of the many music-related forms of synesthesia, but, given the centrality of notation in Western music education as a way to document and diffuse music discourses, 
systematic research in this direction is important. There is a great need in current research to collect narratives describing these experiences through qualitative methodologies in order to start mapping out future endeavors to understand the impact of synesthesia on music pedagogy in early stages of music instruction. At present, general studies on music synesthesia are mostly quantitative and within evidence-geared disciplines, such as neuroscience and psychology, although attention from disciplines such as musicology, music education, and instruction have grown significantly throughout recent years (Jewanski, 1999; Itoh et al., 2017). While this study accounts only for an initial contribution to the understanding of how synesthesia may impact the perception of music notation, it fosters this needed awareness about first-hand experiences and how they might change the quality of one's music-learning.

Extant scholarly literature has covered specific modes of developmental synesthesia, such as grapheme-color synesthesia. A capital example of this type of study is Mroczko-Wasowicz and Nikolic's article (2013) in the Oxford Handbook of Synesthesia, which explores colored alphabet letters across languages spoken by bilingual synesthetes. In fact, several of the articles in this comprehensive volume have sparked new approaches and new directions in research, such as the present study. As for firsthand accounts of music synesthesia in a narrative style, there are few samples currently available. A noteworthy example is evidenced in Day's (2013) account of synesthesia, where the author describes in detail his own synesthetic experience of music.

The scope of scholarly literature that explores issues pertaining to synesthetic perceptions of music notation is rather small. Although there is great attention in research to grapheme-color synesthesia, the association of color to music-related concepts is scant, 
despite the potential cross-overs and connections between these two forms of the condition. Another complicating factor in regards to studies that address synesthetic perceptions of music notation is that, when juxtaposed and compared, several of these researches use different terminologies and nomenclatures, thus rendering the interpretation of potential documented cases a difficult task to undertake when studies are compared or used as basis for future research.

Moreover, the priority for first-hand, phenomenological accounts such as the one evidenced in Day's (2013) article, is rare to find, thus pointing to the significant need for a well-structured and systematic collection of narratives and reports. Approaches such as Day's (2013) may also heavily rely on self-narratives solely—autobiographical descriptions of experience from the point of view of the researcher. However, a qualitative exploration and sampling of these experiences among the population at large is still in need of further documentation. As the analytical portions of this study will show, my personal involvement with the research from the perspective of a synesthete is also an element to consider in this research process. Although partaking of the condition may pose a research bias, at first glance—which I acknowledge in more detail belowthe involvement with participants, the intentionality in the process of data collection and interpretation, and the depth of narrative resulting from interactions with synesthetes have been instrumental in how rich the collected narratives proved to be. While I do not include my own experience among the collected data, the results of this study point to the importance of a researcher who participates in the condition/experience in allowing for participants to share theirs in a more detailed manner. 


\section{Purpose of the Study}

This doctoral dissertation research is a grounded theory study of synesthetic experiences of music notation during early stages of music education by means of narratives collected cross-culturally. While this study relies on similarities between music notation-color synesthesia and grapheme-color synesthesia as documented in the extant literature, it is exclusively based on empirical data collected throughout the research proper. With this in mind, it seeks to juxtapose narratives describing the first-hand experience of synesthetes when exposed to notated music concepts in order to start mapping out how this phenomenon affects music students, thus addressing this lacuna in the literature. This research examines these specific experiential processes of music synesthesia based on introspection and narrative description, looking for potential intersections, meanings, and emerging commonalities with the intent of unveiling details related to synesthetic experiences of music notation for further research within music education.

\section{Research Questions}

This grounded theory study focuses on the following three overarching questions:

1. How are music notation-to-color associations experienced by synesthetes?

2. What possible roles might music notation-to-color synesthetic experiences play in early stages of music education?

3. What are alternative ways in which music notation can be taught to synesthetes?

It also considers two sub-questions:

1. Is there some indication of consistency in narratives collected cross-culturally? 
2. What are the resonating points and similarities in these collected experiences?

\section{Research Approaches}

\section{Qualitative Approach}

This qualitative study comprises a grounded theory approach that analyses narratives outlining synesthetic experiences of music notation during early stages of their music education, with the intent of formulating a theory about trends in perception that may inform new music-educational pedagogies. These narratives reflect experiences through introspection and recollection on the part of interviewed participants with and afforded a juxtaposition of different responses in search for both resonant as well as divergent points. This study focuses most of its attention on intersections and emerging themes, utilizing identification of recurring patterns in these detailed narratives.

\section{Role of the Researcher}

I, the researcher, have conducted semi-structured interviews employing a basic protocol. I have organized collected narratives and coded identified themes using the traditional qualitative procedures outlined in the chapter of this dissertation dealing with methodology (Saldaña, 2016). It is important to note that, in conducting interviews and designing this study, this research maintained awareness about my own biases throughout the research process, through the use of bracketing techniques and an overall inductive and abductive, rather than deductive approach (Bloomberg \& Volpe, 2019). As this dissertation will show throughout the following chapters, I have cherished heightened reflexivity and conscious introspection in all stages of this study-in that I am, essentially, a part of this researched group of synesthetes. I have consciously bracketed 
my experience and prioritized the original narratives of the participants involved in this study. Creswell (2018) sees this process of conscious bracketing and reflexivity as an asset rather than a bias in qualitative research, although quantitative inquiry considers it as a potential bias (p. 40). He suggests that it attests to levels of credibility that would not be possible otherwise. Narratives are, nevertheless, reproduced in an intact form. Chapters 5 through 9 - the analysis portion of the dissertation—quotes verbatim directly from narratives. These quotes are also substantially available in this dissertation in considerable length in support of the conducted interpretation of results.

Moreover, I have not included my own narrative among the analyzed data. While I do understand the overarching mechanisms of synesthetic perceptions as a synestheteas one of this study's participants cleverly pointed out - the experiences of the participants interviewed are qualitatively different from mine. Yet, in seeking to understand the shared commonalities and differences arising between the narratives, I have realized that these experiences are not entirely foreign to me. The combinatory role of researcher and the researched can be refreshing and purpose-driven in a phenomenon such as this; a phenomenon that can only be qualified (perhaps even quantified) through introspection and reported narrative. The results of this study will show the foundational influence of a synesthete-researcher on participants' feeling of comfort and safety in sharing rather personal reflections on their own experiences with someone who understands them.

\section{Conceptual Framework}

Designing a conceptual framework for a qualitative study that involves a grounded theory approach may not only pose challenges but, in a way, it also defeats the 
purpose of the approach itself. In a grounded theory study, the conceptualization is crafted as the research process develops. Qualitative studies and research proposals of this nature usually offer a conceptual framework that accompanies the research's procedures, analytical methods, evaluation strategies, and the overall nature of the study, which I debrief in detail below.

\section{Methodological Procedures}

This research accounts for individuals with developmental synesthesia who manifest music notation-color types of the condition. Developmental synesthesia affects approximately four percent of the population (Cytowic, 2018; Simner et al., 2006; Simner \& Hubbard, 2013). This research counts on an individual-based approach with a crosscultural perspective. A homogeneous group of 12 individuals participated in this research cross-culturally. Access to participants was multifaceted throughout this research, involving personal acquaintances I made throughout the years, volunteer synesthetes who take part in the online-based community of available on Sean Day's "Synesthesia List", and other synesthetes who were recruited through social media, chiefly among members of synesthesia communities on Facebook. Both the international "Synesthesia List" as well as social media-based communities of synesthetes count on the prompt, active participation and contribution to research on the part of individuals around the globe.

The sampling goal was set between 10 and 15 individuals. While the research recruitment yielded 22 interested participants, only 12 qualified as true music notation-tocolor synesthetes that went through the entire data collection process. The interview protocols and study descriptions were distributed to the group at large and are discussed in more detail in the methodology chapter of this dissertation. Interviews were conducted 
and recorded in English (the common language of participants in the group at large) in person or via Zoom. Nuances in choice of words, sentence construction, etc., were observed among non-native speakers through the usage of alternative terminology and alternative conceptual translations. Gesture, inflection, and demeanor were taken into account throughout the interview and informed the choice for either in-person or video recorded interviews. These non-verbal aspects proved to be often just as essential elements of gathered qualitative data in a study of this nature, in terms of expressing and accessing experiences more accurately.

As for budgeting strategies, both the "Synesthesia List" as well as social mediabased communities count on synesthetes that are highly cooperative and willing to volunteer for research of this nature. This study did not incur any extra expenses or expenditure in relation to this grounded study, except for a complimentary Amazon.com gift card in the amount of USD $\$ 25.00$ sent to every participant engaging in the complete interview process, as a token of appreciation for their devoted time. I applied for and received a grant in aid of research from the Office of Research and Creative Scholarship at Andrews University to defray the costs of the participants' appreciation gift card.

Data was collected based on an interview protocol exploring participants' lived experiences and information was stored, organized, and categorized electronically through digital files (recorded web-based video interviews, written narrative scripts, iconography, etc.). Qualitative data was stored, organized, and categorize with the assistance of NVivo software. Data analysis was carried out manually, although computer-based analytical strategies generated by NVivo were used for research validation. 
The collected detailed narrative descriptions feature first-person accounts by the individuals participating in this study. Participants - all of whom were 18 years of age or older - described their synesthetic experience of music notation during early stages of their music education, with attention to overall perceptions, congruence/incongruence, and its effect on their educational process. Participants also offered thoughts on how methodology could have made learning more viable, thus suggesting ample room for further research. The objective in collecting narrative descriptions was to offer a glimpse into the actual synesthetic experiences of music notation during early stages of their music education to promote growing awareness about the need of new pedagogical methodologies tailored for synesthetes in future studies.

This research used coding as an analytical method. As a grounded study, it proposed a cyclical approach to coding based on frequent revision, reinterpretation, and recurring reviews of established codes (Saldaña, 2016). This research also understands coding as a "translation" process; therefore, accounting for reflexivity as a fundamental aspect of this cycle. In particular, it recognizes the researcher's biases and other potential interfering elements. The analysis of collected data was based on the identification of common themes in the collected narrative interviews, along with a categorization (and subcategorization) of identified themes.

This process was combined with code annotations throughout the interview process and with memo-ing and journaling strategies that collected and organized the researcher's thoughts and coding insights during all stages of inquiry, envisioning a refined approach and assuring the highest possible degree of accountability and accuracy in "translated" information (Saldaña, 2016). Analytic memos were used in the creation 
and organization of coding categories throughout the analysis process. Furthermore, this study prioritized the threefold cyclical systematic approach to coding procedures, in which codes are proposed and cyclically revised, eclectic coding is considered, and codes are again proposed and revised (Saldaña, 2016).

\section{Strategies for Validation and Evaluation}

This research advances a multifaceted approach to validation, evidenced in (1) the systematic approach to processes that takes place in the synesthetic experience of music notation in early stages of music education. It also takes the role of the researcher into deeper consideration, in that it (2) accounts reflexively for the researcher's own experience of synesthesia, along with the potential biases and other aspects of interference that may interact with the research process and its ultimate outcomes. As previous sections of this introduction have outlined, this study (3) relies heavily on memo-ing strategies throughout the research in combination with (4) coding models that bear direct impact and significance for the theoretical model at hand.

Additionally, the researcher has (5) provided visual representations of the theoretical mechanics involved in the overarching argument, by means of diagramming and graphing and, finally, designed this research to (6) identify future directions in scholarly inquiry, in that it entails groundwork in upholding these individual narratives as examples of the variety and complexity of synesthetic experiences of music notation in such foundational stages of music education. 


\section{Narrative Structure of the Dissertation}

This study is divided into eleven chapters. Following this introduction, it comprises a historical contextualization of the topic (chapter 2), a comprehensive literature review (chapter 3), an overview of the methodological strategies used for data collection and analysis (chapter 4), and a written report outlining the five categories of coded narratives organized in five independent sections (chapters 5 through 9). The study also contains an interpretation of the collected and analyzed data as well as the proposition of two resulting grounded theories (chapter 10). It includes visual representations of these theories through the use of diagrammed graphs that show the articulation of the working mechanics between the ideas presented. Finally, this study suggests practical implications deriving from the theoretical considerations achieved in the research (chapter 11).

Although this introduction advances the research problem in question in light of a general overview of the study and its design, the second chapter elaborates on the historical context of synesthesia in North American education from a theoretical perspective, also exploring the centrality of music notation as a learning tool. This portion of the research both contextualizes and supports the rationale of this dissertation, outlined in the next section. The ensuing literature review features a thematic survey of the extant literature on synesthesia that pertains to the topic of this study. The dissertation goes on to present methodologies in terms of data gathering, coding, memo-ing, and other analytical strategies involved in the study. In the portions of this document entailing analytical findings, attention is devoted specifically to passages of the original narratives included in the study. The final portions of the study feature a thorough discussion of the 
results, research findings, and outcomes as well as the researcher's conclusory notes. Furthermore, grounded theories are presented in the closing parts of this dissertation, signaling practical implications and potential areas for future research.

\section{Rationale and Significance of the Study}

Synesthetic experiences are unique and benefit from approaches that are intended as universally applicable while preserving the individuality of these experiences and the idiosyncrasies of every person's perception. The grounded theory design was selected for this research due to its consistent sampling of narratives involving a phenomenon that needs systematic qualitative documentation. The aforementioned lack of attention to specific cases of synesthetic experiences of music notation within music education attests to the importance of this study. Similarly, the current lack of extensively collected samples of first-hand narratives from among the population cross-culturally and qualitatively also attests to the importance of this study in mapping out synesthetic experiences of music notation in what pertains to music education both within the present study and in future research endeavors.

\section{Limitations/Delimitations}

\section{Limitations}

Among the limitations of this study, three stand out more prominently. Firstly, the number of individuals with music notation-color synesthesia may be relatively small in the community of accessible synesthetes cross-culturally. However, it still proved adequately-sized for a grounded theory study. Besides, the number of individuals fitting within the intersection between those with music notation-color synesthesia and those 
who have had reportable music training was slightly diminished and fairly difficult to assemble into a researchable population. Nonetheless, 12 individuals were found who met those criteria. This carries implications for potential replications of this grounded study. Despite these difficulties, this research has not found other major impediments or impediments in accessing this group of individuals.

Literature has also challenged the reliability of narratives on the part of adults when asked to recall childhood experiences. Participants were asked to recall rather early memories of events that elapsed in their childhood. Documented difficulty in recalling experiences or imprecision in reporting those memories has been accounted for in literature in connection with trauma, such as memories connected to sexual abuse and sexual hysteria (Loftus \& Ketcham, 1994; Ofshe, 1994). In acknowledging this limitation, it is also important to note that synesthetic experiences of color are not traumatic to this degree. In fact, as the results of this research will show, most participants attest to the positivity of synesthetic experiences. Sedikides and Skowronski (2020) have attested to the lasting nature of positive memories over negative memories.

This research was designed to feature the perspectives of adult synesthetes for specific reasons (as opposed those of children). There was an overall desire to select individuals who did not discover their synesthesia accidentally throughout their music education or not at all until later in life. Several participants, in fact, have attested to the late discovery of the condition. In this sense, these participants can more candidly and informedly voice their positive and negative experienced. In fact, these adults' lived experiences as well as their music education process likely took place approximately twenty or more years in the past, a time during which synesthesia research was still 
slowly growing. In other words, adult participants are more likely to have interacted with their own condition without awareness and intervention on the part of their educators and could, therefore, voice specific educational concerns and needs for change in a more intact manner. Most importantly, they could do so from their own perspective. Participants younger than 18, on the other hand, may have lived during a time of more pervading synesthesia awareness and a greater diffusion of literature (observed in the last twenty years) and have less compelling experiences that signal educational change. This study also prioritized a large enough number of years of synesthetic experience on the part of participants, so that they could draw upon specific examples and lived situations. As this research will reveal, participants have outlined in compelling ways their experienced need for recognition, validation, and awareness in terms of their music education.

Moreover, studies indicate that synesthesia is consistent and automatic (Ward, 2013). The synesthetic experiences of adult participants (in this case music notation-tocolor associations) have remained the same throughout their life time. Although studies indicate that synesthetes do not necessarily have a better memory than non-synesthetes (Rothen \& Meier, 2010), cross-sensory communications and the potential emotional value attached to them (Van Campen, 2009) may render these experiences particularly memorable and accurately recalled.

Finally, individuals on both the Synesthesia List as well as social media are selfdeclared synesthetes. As the literature reviewed in this study indicates (chapter 3), synesthetes participating in research are often self-reported and are confirmed to possess the condition through a verification of consistency and automaticity of their synesthetic 
associations. Specific measures were taken in this research to overcome this difficulty and ensure participants' truthfulness in regards to their associations. Participants were tested throughout the interview in terms of the consistency and automaticity of their responses. Ultimately, nonetheless, self-reported information is recurrent in qualitative research designs. In specific, grounded theory studies rely primarily on narratives collected from individuals who are believed on reasonable grounds to belong to a target group.

\section{Delimitations}

This study approaches the intersectional narratives of persons above the age of 18 years, who have developmental synesthesia (featuring music notation-to-color), and that also went through the experience of musical training, regardless of gender, nationality, race, or ethnicity. The study does not encompass, therefore, the population of synesthetes under the age of 18 or adult synesthetes that have not had formal training in music education. The reason for this delimitation is rooted in the aforementioned ability of older synesthetes to recall on their synesthetic experiences of music notation during a time in which synesthesia research was under foundational development (Lovelace, 2013; Jewanski, 2013).

\section{Definition of Key Terminology}

This section clarifies some of the key terminologies in the context of this study. Synesthesia is used in this research to specifically denote developmental synesthesia, as opposed to accounting for other modes of the condition acquired temporarily or later in life, such as pharmacologically or as a result of sensory loss (such as the case of the onset 
of blindness), for example. Developmental synesthesia refers to cross-sensory neural communication grounded in a genetic component, thus resulting in structural and functional differences throughout brain development. These differences are generally consistent into adulthood and brain maturation and remain part of a synesthete's experience for a lifetime. In this sense, the synesthetic associations among the adults interviewed for this study have remained, reportedly, consistent throughout their childhood and into their adult life.

The binary inducer-to-concurrent is used frequently in this study to denote the original perceptual stimuli that trigger synesthesia and the cross-sensory response that results from that original stimulus, respectively. The primary example of this binary is found in the very title of this study: music notation-to-color synesthesia. Other forms of synesthesia involving music may be referred to as pitch-to-color, or timbre-to-texture, to name a few further examples.

Moreover, music-specific terminology used throughout this study consists of universally acknowledged and basic musical concepts - especially those belonging to Western traditional music notation. Any deviations from this norm are explained locally in its immediate context.

\section{Chapter 1 Summary}

This study aims at collecting the experiences of color-related music-notation synesthesia in early stages of music education, with the intent of analyzing trends and commonalities that could change the way music teachers engage with instructing to those who manifest notation-to-color synesthesia. This study will also point to gaps in the literature, addressing ways in which music can be taught differently to synesthetes, thus 
ensuring the best learning outcomes. In this sense, this research approaches

differentiation in pedagogical techniques in the teaching and learning of music by a specific group of individuals. 


\title{
CHAPTER 2
}

\section{HISTORICAL CONTEXT}

\section{Introduction}

\author{
Educational efforts should play to children's strengths... \\ and those with synesthesia need to be educated differently. \\ -Maureen Seaberg (2011)
}

The present chapter serves as a theoretical extension to the first chapter of this dissertation. It addresses the historical place of synesthesia as a neurological condition among American curriculum reform scholarship as well as the centrality of music notation in Western music education. Given the fact that the present study is one of the first systematic researches conducted to-date specifically on music notation-based synesthesia and music education, such historical contextualization and overview are paramount in understanding the approach to current scholarly publications that mention this form of the condition.

This historical contextualization is also fundamental in situating this study's rationale. In other words, it is important to comprehend first how synesthesia as a neurological condition gained recognition and space in education and educational research before addressing the specificity of a particular mode of synesthesia in music education. 
This first part of the chapter involves a historical overview and situates synesthesia (in its broad manifestation) as discussed in curriculum-related literature, arguing that research on synesthesia — and more specifically music synesthesia—itself is only possible to conceive of through the historical lenses of American curriculum reform, as taking place in the twentieth century. The second part of this chapter contextualizes the historical place of modern music notation within the rather broad scope of Western music, attesting to its centrality in documenting musical discourses since the seventeenth century.

\section{Background}

From the standpoint of differentiated education, the history of American educational reform, as evidenced in the struggles felt between the end of the nineteenthcentury and present times, can be understood in terms of child individuality. Just as the role of the teacher undergoes significant metamorphoses during this century-long timespan - from the truth-holder whose function is to infuse knowledge into empty vessels so vividly described in fictional prose by Charles Dickens in the opening chapter of Hard Times (1854) — so does the role of the student change considerably. The role of the learner, along with the nature of his/her engagement in the schooling system, undergoes radical transformations; from the status of mere receptacles to that of volatile beings, with their individual needs, wants, backgrounds, struggles, strengths, and, ultimately, unique story. Throughout the long twentieth century, we can clearly see how child individuality, as a concept, experiences shifts, as the elasticity of social and educational theories, in their political, economic, anthropological intersectionalities, affect the status of the individual student as a unique being. 
Although awareness about individuality, as a consequence of awareness about difference, becomes more noticeable in this recent history of the American curriculum, it is fair to conclude that this gradual reformative work is still at play today. In fact, in the very essence of curricular reformative endeavors, one can feel a promise for continued reform and change, as society itself changes. Even within the same geographical and political jurisdiction, such as the United States of America as a country, it is possible to behold great need for an acknowledgment of individuality in various areas of cognition in education. Although we have observed greater inclusion of those challenged by major learning deficiencies and disabilities, as some refer to them, there are various differentiations in perception that have not been adequately accommodated within mainstream educational pedagogies yet.

That is much the case with synesthesia - a neurological condition that has been attracting growing attention from researchers across various disciplines presently. Etymologically meaning a "union", or "joining”, of the senses, synesthesia poses a necessity of further research in education, since it has already proven to affect life in particular, idiomatic, and idiosyncratic ways for those who have the condition. Many synesthetes, like myself, have gone through the earlier stages of the schooling process in silence, dealing with their strife for a thorough grasp of mainstream understandings that completely rule out the peculiarities that inform their exceptional perception of the world.

In this research, I contemplate the aforementioned aspects of the struggle for the American curriculum as played out in history with attention to the quest for differentiated education as a strife for student identity. In search of a place for synesthesia within differentiated education in present times, this research discusses how the history of 
American curriculum reform has allowed for individuality along its dramatic play. Amid the coexistence of aspects of positivity and disillusionment in the history of the American curriculum field, there can be found much hope for inclusivity of individuality as a strong ally to differentiation awareness.

\section{Synesthesia and Differentiated Education}

Multisensory connections have permeated literature and philosophical speculations from ancient Greece and throughout cosmological and mystical understandings of its manifestations in the Middle Ages and Renaissance (Jewanski, 2009; Lima, 2019). Early modern attempts to describe potential connections between the senses, such as Isaac Newton's endeavors to prove perceptual connections between sound waves and color, were not uncommon as science, as we know it, developed in the Enlightenment (Jewanski, 2009; Lima, 2019). Yet synesthesia only gained its first formal medical account in a publication by George Sachs's, in 1812. In this document—his medical doctoral dissertation at the University of Erlangen, Germany—Sachs offers a full description of his own synesthesia, thus looking at it from a medical perspective for the first time in history. This account is considered today by the medical community to be the first report that addresses and describes the condition by means of "scientific" methodology, because it starts exploring the neural mechanisms that are involved in synesthetic perception (Jewanski, 2009).

Since then, synesthesia has grown in prominence as a topic of academic inquiry throughout several areas of knowledge, especially the neurosciences, medicine, psychology, and experiential philosophy. With the increase of technology and the

employment of MRI (magnetic resonance imaging) and fMRI (functional magnetic 
resonance imaging) in research, synesthesia has also been emancipated from popular disbelief and discredit, now being recognized as a neurological condition in need of official recognition (Hubbard, 2007, p. 193). As such, discussions on the impact of synesthesia on everyday life, its potential influences on perceptual processes, behavioral response, creativity, memory, to name a few, have only multiplied in scholarly discourse, as far as allowing for synesthesia to figure today among worldwide conferences and scholarly publications. The establishment of the American Synesthesia Association (ASA), in the United States, the United Kingdom Synesthesia Association (UK-SA), and the International Association of Synesthetes, Artists, and Scientists (IASAS), among several other associations worldwide, have also attested to an evident leap in the amount of cross-disciplinary research around the globe, highlighting synesthesia's relevance as a topic in across various disciplines and shedding light on how synesthetes perceive the world around them.

The adjective developmental is often used in conjunction with the term synesthesia itself to denote its most common phenotypical manifestation: consistency of the phenomenon throughout brain development into adulthood. Developmental synesthesia is distinct from alternative forms of the condition—often called acquired synesthesia — which are commonly attributed to sensory loss (e.g., long-term onset of blindness), pharmacological induction (with drugs such as LSD, for instance, which has been said to simulate synesthetic effects in users temporarily), and induced during altered states of consciousness. Research on the genetic components of developmental synesthesia has also shown that the phenotypical manifestation of the condition skips generations (Asher \& Carmichael, 2013). 
Although synesthesia has proven to affect children's perception and implications for education have been frequently pointed out in available literature, there is still much work to be done in terms of making these more broadly known and refined. A mode that may require specialized methodologies, refined teaching techniques, and, hence, may require a special place in differentiated education. While other neurological conditions have been extensively addressed on the part of scholarly research throughout the history of the American curriculum, synesthesia has been largely left aside as a matter for future speculation. To be sure, various statistic studies have revealed a potentially significant incidence of synesthesia in the population (Simner at al., 2006). These have been drawing the attention of educators in America and abroad, but, at its best, synesthesia remains a topic crying out for ample research work.

Maureen Seaberg states, “educational efforts should play to children's strengths (...) and those with synesthesia need to be educated differently" (Seaberg, 2011, p. 174). Her plea for heightened awareness about synesthesia and other perceptual differentiations is noteworthy in the context of education. I concur with Seaberg (2011) that it is about time synesthesia should be considered more consistently in education, given its dramatic impact on learning. Seaberg's (2011) tone is scholarly but speaks to the general public in the form of loose activism that promotes awareness about differentiation. This is to say that, as far as perceptual differentiations are concerned (as well as the potential learning modes they entail), education and instruction remain now in as much need of constant, recurring review as they were throughout the long twentieth century. It is with this in mind that I set to explore the historical foundation for synesthesia in the American curriculum and instruction. 
Synesthesia is phenomenologically defined (Sagiv \& Frith, 2013, p. 1), meaning that its study relies heavily on individual experience. As I have suggested in the introduction to this paper, in this survey of the American curriculum, the common, leading thread will be a search for child individuality and individualized experience. I will argue that an understanding of differentiated education throughout the history of the American curriculum, as laid out in the following portions of this paper, allow for the ultimate historical placement of synesthesia as a topic in need of urgent attention if it is regarded in light of this tumultuous historical documentation.

At this juncture, three paramount research questions start to form: (1) cannot the historical struggle over the American curriculum be understood in phenomenological terms?; (2) is not what is at stake in this discussion, ultimately, the child's individual experience? As I explore potential answers to these difficult questions, I hope to bring to light the historical context that allows for a consideration of synesthesia in present times, which brings me to my main and final research question: (3) why has synesthesia not been fully addressed in education yet?

\section{Differentiated Education and the American Curriculum}

In searching for a place for synesthesia in education, this section chronologically explores instances in the American curriculum that suggest implementations of differentiated education - implementations that sprang up as the main reformative movements in education played out and interacted with one another at the beginning of curricular reform, as observed in the 1890s. It is crucial to keep in mind that many of these instances are not examples of differentiation as we understand it today, but rather 
point to how instructional/curricular distinction, segregation, and specialization were infused into educational policies over time. In this sense, I would like to reiterate my priority for individuality as a common thematic thread throughout the ensuing subsections.

\section{Early Evidences of Differentiated Education}

Difference and differentiated education were, to some extent, always present in the American curriculum's reformative process. Yet the agendas behind such specializations point to wide fluctuations when it comes to their purpose and raison d'être. One of the first cases of differentiated education that stands out prominently at the dawn of curriculum reformation is one connected to the social efficiency movement taking place at the opening of the twentieth century. With the earnest effort to wipe waste out of education, there came along the inevitable consequence of segregation according to social class and social rank. It followed that education must be differentiated to reach the student and prepare him/her for society. However, there is no attention, at least at this point, to the student's interest, especially as a child. In fact, there was no such thing as childhood as far as a socially efficient education was concerned; rather, in John Franklin Bobbitt's words, "education is primarily for adult life, not for child life" (Kliebard, 2013, p. 38).

Behind Bobbitt's ideology, as one of the major proponents of social efficiency as a movement, education should be differentiated as long as it served the primary and fundamental purpose of the movement: that of establishing and perpetuating a synergistic social order. Kliebard's (2004) states: 
Individual variation in ability had, of course, been recognized well before Bobbitt's time, but Bobbitt was now asserting that the curriculum be carefully adapted to each "class of individuals" as part of the drive for the elimination of inefficiency in education. People, after all, should not be taught what they would never use. That would be a waste. In order to reduce waste, educators had to institute a process of scientific measurement leading to a prediction as to one's future role in life. (p. 84)

In other words, predestination according to class or social rank was determinant in the process of differentiation.

Similarly, with the consequential successful advent of vocational education (Kliebard, 2004), we can also see curricular distinction and differentiation in connection to the then economically less favored classes, such as African Americans and the Native Indigenous populations. All these reformative efforts, nevertheless, had a common goal; they were still destined to serving society directly, rather than inspired by the learner's experience and potential interest. It follows that there is still no clear suggestion of the child's "self" in education, or his/her individualized experience. The child's identity is still defined by its purpose and role within a system.

On the other hand, the genuine effort of developmentalists, compounded with G. Stanley Hall's "pseudoscientific" and psychological approaches to the child's mind, began to allow education to witness an alternative to traditionalized curriculum approaches. Essentially, the fair assumption that the child sees the world differently from an adult started to bring about implications for curriculum, instruction, and teaching methodologies. However, there is little attention to how one child may differ from another child in the way he/she sees the world in a more holistic sense. Therefore, although the child's interest is considered, her/his individuality within the schooling process is still questionable. The very question of gender felt in the dichotomy between 
boyhood (as a reflection of manhood) vis-à-vis girlhood (as a reflection of womanhood) within the schooling system at this time attests to problems in differentiation.

It is paramount to highlight aspects of differentiated education at this historical moment, such as the growing awareness about women's labor training and women's rights in a society that was still largely informed by gender-specific social roles, as well as gender-specific education and professional placement. Hall, however, proposes gender segregation from early stages of education. According to Kliebard (2004):

A strong believer in hereditary determinism, Hall (1911) advocated for differentiated instruction based on innate endowment and even urged separate schools for "dullards" in the elementary grades. Segregation by sex, according to Hall (1903), should begin at the outset of adolescence since marked divergence among the sexes begins suddenly "in the pubescent period - in the early teens".

Hall noted with some alarm that, although young girls adopted ideals associated with their own sex, statistical studies had shown that, thereafter, girls began to adopt the ideals of males, citing the concern of one writer that "we shall soon have a female sex without a female character", Hall, while not opposing coeducation per se, advocated some segregation within the high school in order to ensure "the full and complete development" of both sexes (p. 41). Hall's position on gender segregation sounds rather radical, but does make sense in the context of gender-specific social roles, especially if in light of the ideals fostered by social efficiency proponents.

Further indications of early differentiated education are evidenced in the Home Project teaching approach. As a response to the strict tenets of social efficiency, home project philosophy (later leading to the Experience Curriculum), allowed for children's individuality to be seen as a more tangible aspect of the educational process; one that starts bearing significance in curriculum design itself. The potential for a revitalized 
curriculum starts to lie within the child, thus creating space for growing awareness about the child's interests as an individuated being. The implications of this shift in philosophy (as a new phenomenon) were of utmost importance for the immediate future of differentiated education.

In this context, I will briefly turn to some of Dewey's writings (ranging from 1902 to 1934), as I believe his thoughts on the experience of the educational process are noteworthy in pointing to a brighter future much ahead of his time. In elaborating on the nature of the educational experience on the part of the pupil in Democracy and Education (1916), Dewey grants the student the ability to experience as an individual being (Dewey, 2008, p. 163) - that is still a fresh concept at the time. Along the same lines, he also proposes that the child can only learn through practical experience (Dewey, 1902, p. 5), that is, through his/her senses. Perception and practical engagement alone can afford the development of empathy and relatability on the part of the child. Ultimately, there can be education through individual experience (Dewey, 1934, p. 98). It was thoughts like this that started paving the way to a brighter future: one that would take a closer look at existential phenomenology, in the second half of the century, and that would make it possible for individuality to be more consistently integrated into curriculum studies.

\section{0s-1960s: Further Evidences of Individuality in Education}

As we look ahead in the history of the American curriculum, it is possible to identify groundbreaking social changes that contribute to the evolution of differentiated education and the present discussion of student individuality. Herbert Kliebard, in focusing on the first half of the twentieth century in his The Struggle for the American 
Curriculum (2004), points directly to several of these changes. In overlapping historically in content, at mid-century, with J. Dan Marshall et al.'s book-which, in turn, focuses on the second half of this history to present times - these authors' combined efforts highlight the wild changes and conflict that took place in society, especially at mid-century. How did the awareness about (and priority for) the child's individual experience continued to evolve and advance from the 1920s to the early 1960s? What social factors informed this evolution as laid out in the final chapters of Kliebard's (2004) comprehensive historical analysis and the chronologically sequential points raised in the first portions of Marshall et al. (2007)? How does social meliorism and progressive education inform potential advancements in differentiated education?

One major realization lies in George Counts's recognition that education (as it stood in the 1920s and 1930s), along with its standardizations resulting from an industrial society, perpetuated social evils, rather than promoting meaningful social change. In this context, perhaps one of the most significant evidence of growing attention to the child's individuality as we look forward in history is Counts's Dare the School Build a New Social Order? (2013) manifesto, which, despite its still socially geared approach, does acknowledge the student's individual experience. Counts, however, recognizes a developing priority for progressive and experimental education as intrusive to the child's individuality. In Kliebard's discussion of the "hybridization" of the curriculum, as it took new and various directions, he acknowledges the implications of both the growth of student individuality as well as educational individualization itself (Kliebard, 2004, p. 177), which, expectedly, would pose challenges for a still epistemologically standardized way to look at educational processes - at least at a national level. 
For John Dewey and Boyd Bode, on the other hand, the role of education is to simply "make aware", rather than to inculcate social meliorism in the child as a means for eradicating social evils and other consequences of the contemporary society (Kliebard, 2004, p. 166). The idea of "making aware" as the basis of the educational process foreshadows, much ahead of its time, what Paulo Freire (2013) would identify the student's gift of choice decades later, in Pedagogy of the Oppressed. Awareness—as an opportunity for freedom of will—stands at the core of student individuality and identity. Much along the same lines as Dewey and Bode, Harold O. Rugg's priority for making students think for themselves (Kliebard, 2004, p. 168) becomes a major landmark in my search for individuality. While it resonates with Counts's propositions in that they aim at a common social goal, Rugg's rationale stands out and goes beyond in that he sees individuality as a potential for social meliorism (Kliebard, 2004, p. 170).

In moving on to the momentous social changes occurring during the war and in the ensuing postwar (1940s) it is possible to see a growing eagerness to behold student's individual abilities and potentials as elements that can be developed (through education) to serve a society that finds itself in need of adaptations, adjustments, and, ultimately, actual change in education (Kliebard, 2004, p. 205). A growing concern is evidenced as to how the individual can serve society and what the role of education is in this process (Kliebard, 2004, p. 206). In the endeavors laid out in the Paideia Proposal (Adler, 2013), for instance, it is possible to realize how quality education for all implies inevitable negligence of difference, thus demanding a more careful consideration of equality as opposed to equity in education. The ideology behind this distinction has been overlooked in the past and is still a matter of debate and concern among educators. 
The short-lived principles of the original Paideia Proposal were faded to failure due to its linear approach to quality, in that it ignored the implications of equality versus its more inclusive and thorough counterpart: equity. Quality in education, as a concept, first approached in opposition to quantity, envisioned that every student should have access to the same opportunity in terms of quality education. The problem with that approach is that quality for all automatically suggests equality. Yet, giving the students the same amount does not account for how much they may need to succeed, given their intrinsic differences and their individuality. In this sense, while all students demand and need the same amount of educational attention, priority, and investment, each student's needs may be ontologically different from another's. Hence, this desired universal, systemic quality in education can only come into being through differentiation (equity) rather than standardization (equality). Ultimately, the student's experience, along with her/his individual abilities and background, begins to matter more (Kliebard, p. 264).

In discussing what should inform objectives in curriculum development, Marshall et al. (2007) also offer insight on what is really at stake in the 1940s and 1950s: a threefold struggle between the demands of society, the primacy of man's knowledge, and student individuality (Marshall at al., 2007, p. 26-27). By the 1950s, individuality had become a considerably salient concern in curriculum theory. Bruner's (1960) priority for maximizing understanding and his/her ability to explain learned material in his/her own words, are also clear evidences of a more tangible student identity in the classroom setting. Yet, the cultural shock and dramatic revolution education underwent with the Civil Rights movement was still to be felt fully in the following decades. 


\section{0s-Present: Radical Changes}

Perhaps the most significant social factor growing in intensity from the $1960 \mathrm{~s}$ through the 1980s was the heightened awareness about civil rights. According to Marshall et al. (2007), this awareness resulted in "new subcultures of difference" (p. 70), featuring the gradual liberation of the individual from society (although the media sought to unify people into a thoughtless mass), an over glorification of the individual, segregating of groups into social tribes, and bringing to light concepts of individuality. Who is the individual? What does it mean to be individual? (Marshall et al., 2007, p. 71). This struggle resulted in a generalized strife for racial and gender equality, as evidenced in the intense activism and sexual liberation demonstrated by various groups belonging to multifaceted forms of feminism and gay movements, for instance.

The study of continental philosophy coincides with this social upheaval. Phenomenology had been in the bake in continental Europe during the first half of the twentieth century. Although American curricularists almost completely ignored it at the time, the study of European existential philosophy is considered to have finally made its way into curriculum studies during the 1960s (Magrini, 2016, p. 3). Pioneer work such as Edmund Husserl's (1964) On the Phenomenology of the Consciousness of Internal Time (first published in 1928), Martin Heidegger's (1962) Being in Time (first published in 1927), Maurice Merleau-Ponty's (1962) Phenomenology of Perception (first published in 1945), and Jean-Paul Sartre's (1992) Being and Nothingness (first published in 1943), to name a few prominent figures, was suddenly at the disposal and under the scrutiny of American curriculum theorists. As early as 1962, the Association for Supervision and Curriculum Development (ASCD) released a yearbook that shows evidence of growing 
interest in phenomenology (Marshall et al., 2007, p. 62). This could also be regarded, in this context, as an alternative to the then standing behaviorist psychological approach and its powerlessness in the face of the struggles regarding civil rights and education of marginalized populations. There was a need for strategies that permitted students to go after their own goals, to acknowledge their aptitudes, and prioritize their interests. This look into existentialism was promising in that it started to afford even the marginalized minorities to be composed of a collection of individuals with interests, hopes, and dreams.

Previous attempts to allow students to pursue personal interests, to demonstrate the ability to choose, to have a sense of belonging, and to feel entitled to express themselves creatively (Marshall, 2007, p. 63), had already started to equip the younger generation with a notion of self. Expectation gradually lied on students to foster the ability to evaluate their own progress (Marshall et al., 2007, p. 65). According to Marshall et al. (2007), Jerome Bruner's Toward a Theory of Institution (1966) and Goodlad's School, Curriculum, and the Individual (1966) also account for the importance of the student's individuality in the making of the curriculum and in the building of the educational process. This developing sense of self is also echoed in different ways across the field. For instance, in asking herself rhetorical questions pertaining to her own experience as a teacher, her goals, her personal struggles, and her place in education in New Priorities in the Curriculum, Louise Berman, begins to indicate that individuality is not only restricted to students but also informs the teachers as unique beings, as well as all those that are involved in the educational process (Marshall, 2007). 
This shift from development to an understanding of the curriculum as empirical process did not fully appear until the 1970s (Marshall et al., 2007, p. 104). McDonald's description of the interactions taking place within the individual as well as between the individual and the environment in Curriculum Theory (1971), starts to uncover theoretically the phenomenological mechanisms that elapse in the process of education (Marshall et al., 2007, p. 117). In special, William Pinar's (1974) profound inquiries featured in Heightened Consciousness, Cultural Revolution, and Curriculum Theory offer ample space for phenomenological approaches. Indeed, his subsequent, emerging works on self-awareness culminated in the development of a prominent theory that is most significant when it comes to individuality, now known as Autobiographical Theory (Pinar, 1994). Pinar proposes that one teaches best from what/who one is; similarly, one learns best from what/who one is. In this sense, a synesthete-researcher or a synestheteteacher may be in a desirable condition to conduct research such as the present study or designing educative methodologies for synesthetes. With Pinar (1994), one's essence, individuality, and experience become a priority. In this context, any and every autobiography is a biography worth reading, since these collective experiences of the world, as metanarratives, inform curriculum making. In fact, they are agents of formation, transformation, evolution, adaptation, flexibility, and inclusivity in every aspect of education.

Autobiographical theory, with its phenomenological grasp, resonates with Paulo Freire's (2013) then-contemporary Pedagogy of the Oppressed (1972). Freire equates awareness, or self-awareness, to the ability to choose, or "having the freedom of choice". To be aware is to be free. Freedom, then, becomes the basis and vehicle for a fair, 
inclusive, equitable education (Freire, 2013). Thus, it is not surprising that the phenomenology of education remains until today a topic of debate and investigation, due to the subjective nature of the very pedagogical process and its dependence on introspection and self-awareness. In recapitulating that synesthesia is phenomenologically defined and in admitting that it relies heavily on introspection (despite the so-called "scientific" technology that can be used to diagnose it), the intensifying inquiry into continental phenomenology that still permeates scholarly literature in sociology, psychology, and neuroscience alike, invite a thorough exploration of this topic presently also on the part of education.

\section{A Place for Synesthesia in Education}

Although synesthesia is a verifiable neurological condition and can be identified through laboratory tests, it is phenomenologically defined, as I have suggested throughout this paper. As a condition that affects one's perception of the surrounding world, it is impossible to quantify and qualify synesthesia if not through introspection and individual account. Growing awareness about synesthesia could not be possible until the advent of continental philosophy and its infusion into American curriculum-making and theorizing. Phenomenology, in particular, started to exert a more significant influence on curriculum and curriculum studies well into the second half of the twentieth century. Thus, it is expected that synesthesia stays out of pedagogical discussions up until then, on the one hand. On the other, this raises the question as to why synesthesia has not yet gained more prominent attention in scholarly literature in education, given its aforementioned dramatic impact on perception and learning. 
When these advancements in differentiated education and student individuality are put together in a historical and, therefore, chronological perspective, it is possible to see a lack of epistemological alignment of the vigorous development between continental philosophy (which took place, in its most part, during the first half of the twentieth century) and the thorough educational investigation of these philosophies on the part of the American education. Educational theories/movements in America during the first half of the twentieth century were, in a rough sense, epistemologically ignorant of these theories and how radically they would influence education and inform change in the years to come. When Pinar and others started to build more solidly on existentialism and phenomenology (1970s onwards), continental philosophy was already quite established and advanced.

The first bricks of continental philosophy, especially as they involve existentialism and phenomenology, along with the ideas coined by some of the aforementioned major proponents, were in the bake and developing during the first half of the century; that is, in parallel with educational theories that seem to have ignored them almost completely on American soil. Having Edmund Husserl as the philosophical basis for subsequent inquiries, works such as Martin Heidegger's (1962) Being in Time and Maurice Merleau-Ponty's (1962) Phenomenology of Perception would influence North American philosophy in many respects, including education and curriculum theory.

This lack of alignment answers in part my main and final research question: synesthesia has not been addressed before because of the very impossibility of its consideration prior to the 1970s. Besides, given the slow, arduous, strenuous journey of individuality, as it plays out in American curriculum history, it is clear that questions of 
personal experience still remain a matter for educational consideration. The advent and settlement of phenomenology across most contemporary disciplines today clearly sets the stage for a closer look at synesthesia in education as a unique perceptual form.

In drawing upon my personal experience as a synesthesia scholar in the last few years, I can attest to the fact that the main peer-reviewed journals and books on synesthesia coming out of the press do not count on a substantial representation of pedagogical and educational approaches. One can possibly hear the loud cry coming from various disciplines for more detail on the implications of synesthesia for education, as perfectly echoed in Seaberg's (2011) affirmation, which I restate at this point due to its timeliness: "educational efforts should play to children's strengths (...) and those with synesthesia need to be educated differently" (Seaberg, 2011, p. 174); but this work has not been consistently carried out and remains open-ended. With that in mind, I feel both inspired and motivated in concluding that the present search for a place for synesthesia has been a successful one. It seems that the time and place to research synesthesia in education is now and here.

Current literature does not attribute this gap on the part of educational research to low incidence of synesthesia among the population (Hubbard, 2007). On the contrary, research on the impact of synesthesia on teaching and learning has been frequently encouraged across different disciplines due to its significant bearing on perception and, consequently, on the adaptations it instigates when it comes to teaching methodologies and pedagogical techniques. Neither does extant literature blame this hiatus in scholarly output on the fact that synesthesia does not classify currently as a mainstream form of learning disability. Rather, in acknowledging the perception of synesthetes, researchers 
have fostered a thorough consideration of synesthesia as a unique way to engage with the world both in and outside the classroom. In fact, literature has often alluded to the need for universal fairness in relation to any form of differentiated perception (Seaberg, 2011). Hence, the relevance of synesthesia research can be supported both by current streams in scholarly activity and by the historical perspective discussed in the present paper.

\section{Conclusory Thoughts on the American Curriculum}

The study of synesthesia may pose various challenges for education in regards to teaching methodologies, pedagogical techniques, and especially, for curriculum development, design, and implementation. Established methodologies often require revision and prove inadequate when used with synesthetes. Nevertheless, the history of American education has shown that differentiated methodologies have been incorporated all along. It is hard to assume that adaptations would not be made as synesthesia becomes part of this history. Conversely, I expect this kind of research endeavor to entail a slow process of implementation, due partially to the novelty of the theme itself within education, and the time required to test the effectiveness of new methodologies as they are designed and become available to teachers. Awareness about synesthesia is still growing; significant progress has been made in the last decade. I expect this expanding awareness to be of a positive force in the inclusion of synesthesia in curriculum studies in this historical context. 


\section{Centrality of Music Notation}

In changing gears from this historical survey of synesthesia in connection with American curriculum and instruction, I turn to another foundational element involving the rationale for this dissertation. This rationale is very much grounded in the centrality of music notation as a form of documentation and diffusion of music discourse in Western society. Notation is, in particular, used in music education, to teach students basic principles of music theory and practice that are foundational to what is understood as music-making. Although other forms of non-Western music notation exist and are significant within their geographical contexts — which have been extensively explored from musicological and ethnomusicological perspectives - a standardization of the European notational system established during the Baroque period can be observed globally since the seventeenth century. This standard has been used to document both concert/art music as well as other types of musical manifestations, such as folkloric and popular music. Expectedly, formal (as well as much informal) music education nowadays relies on this notational system to teach music and music-related concepts. Students are almost invariable required to master the notational system to some extent as a main skill in the music-educational process.

As a crystalized notational system resulting from the evolution of the neumatic notation of the ninth century, to the mensural notation of the Late Middle Ages and Renaissance, to the established notational system of the Baroque, current music documentation relies on a 400 -year-old procedure. This procedure involves specific pitches (sound frequency), durations, volumes, among several other expressive and timber-based qualities. In the paragraphs that follow I outline the birth of notation as a 
historical necessity to control music documentation and performance, spread works by prolific composers, and to educate individuals in the art of music-making.

\section{The Evolution of Notation in Western Culture}

The earliest systematically documented music in Western culture appears around the ninth century in connection with Gregorian antiphons and responds (Taruskin, 2010, p. 888), in the context of Medieval Catholic music designed for liturgy. At first, notation was neumatic (diastematic) and entailed symbols usually placed above a written Latin text. Neumatic or diastemic notation comprises the "breadth" as the music-notational unit. In this sense, neumes are the smallest units of music notation and were used in a variety of ways and combinations. Neumes usually remained associated with specific syllables.

Primarily, neumatic notation was conceptualized systematically out of a rather political endeavor to unify musical practices in the empire, thus making sure they were performed similarly (Taruskin, 2010). Secondarily, it was developed to provide a means to document and thus immortalize a large liturgical repertoire practiced in the Catholic church that was failing to survive without local modifications, especially in geographically isolated portions of the Roman territory. Of course, this failure is due to the ephemeral and temporal nature of sound. The until then oral basis of music transmission between generation was naturally prone to differentiation precisely because of this ephemerality. Hence, although a secondary necessity, the endeavor to document music eventually became a primary concern, as written resources multiplied. Taruskin (2010) suggests that one of the most prominent reasons for this systematization of 
documentation is connected to the need for a mnemonic device that consists of an alternative to oral tradition (p. 957).

Medieval notation of liturgical chant, thus, unified the Roman Catholic kingdom in terms of music production and performance within the dominion of the church throughout Central Europe. While many variations were still observed across different regions, neumatic notation was vastly practiced in Europe at large with some similarities. A study shows the interchangeable relationship between these different neumes (University of Basel), reproduced in figure 3.

\begin{tabular}{|c|c|c|c|c|c|c|c|c|c|}
\hline Names & punctum & virga & pes & clivis & torculus & porrectus & climacus & scandicus & quilisma \\
\hline Modern equivalent & - & $\bullet$ & ? & 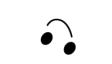 & 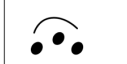 & $\because$ & $\bullet$ & $\overbrace{}^{\circ}$ & \\
\hline $\begin{array}{l}\text { French Square } \\
\text { Notation }\end{array}$ & a & n & & h & $\operatorname{mon}$ & & ( & $\boldsymbol{a}$ & \\
\hline St Gall & - - & & & & & & & & \\
\hline Messine & $n-$ & 1 & & $\eta \approx$ & $\bigwedge_{i N}$ & $V \approx N$ & $: \stackrel{N}{N}$ & & \\
\hline Breton & - & & & $7:$ & .74 & $V$ & : & & \\
\hline Aquitanian & - - & r & & : & 2 & & : & & \\
\hline Palaeo-Frankish & - - & & & $17:$ & $\bigcap$ & $\checkmark$ & $\because$ & . & \\
\hline Beneventan & - & 1 & & 17 & 1 & & $i$ & & \\
\hline
\end{tabular}

Figure 3. Comparison of different neumatic notations (University of Basel). 
Although this syllabic connection and the location of placement above the text gave some indication as to the duration and height of different notes, these were imprecise in that notation of time and specific pitches had not yet been coined. Guido d'Arezzo, an Italian monk, developed a system of lines to assist his choirboys (Taruskin, 2010, p. 2392) in performing specific pitches. These lines were retained historically due to their efficacy in distinguish pitches and eventually developed into a prototypic version of the five-line staff in modern notation. These lines were color-coded to facilitate memorization and identification on the part of his students, featuring specific colors for specific pitches (Bent et al., 2014; Van Waesberghe, 1951). The precision of pitch notation was, hence, developed both in connection to color as well as education- both central elements approached in this research. As the analysis portion of this research will indicate, color and pitch were, reportedly, one of the most pervading commonalities among the interviewed notation-to-color synesthetes.

Subsequently, the inclusion of music among the seven liberal arts, alongside arithmetic, geometry, and astronomy (the quadrivium) allowed for mathematicians to develop a more sophisticated notational system, associated with the Ars Nova movement (Taruskin, 2010, p. 4767). This new system allowed for a more precise notation of durations in terms of rations and other mathematical relationships. Although still highly imprecise in notating time graphically, this type of mensural notation remained the norm until the late Renaissance.

Baroque notation, established and virtually still the same notation used in Western society since the seventeenth century, developed from mensural notation, allowing for an even more precise and elegant way to notate music. Figure 4 shows a passage from the 
first edition of the conducting score for Gustav's Mahler's (1904) Symphony No. 5, exemplifying the complexity of notation and the precision of detail communicated from composer to performer.

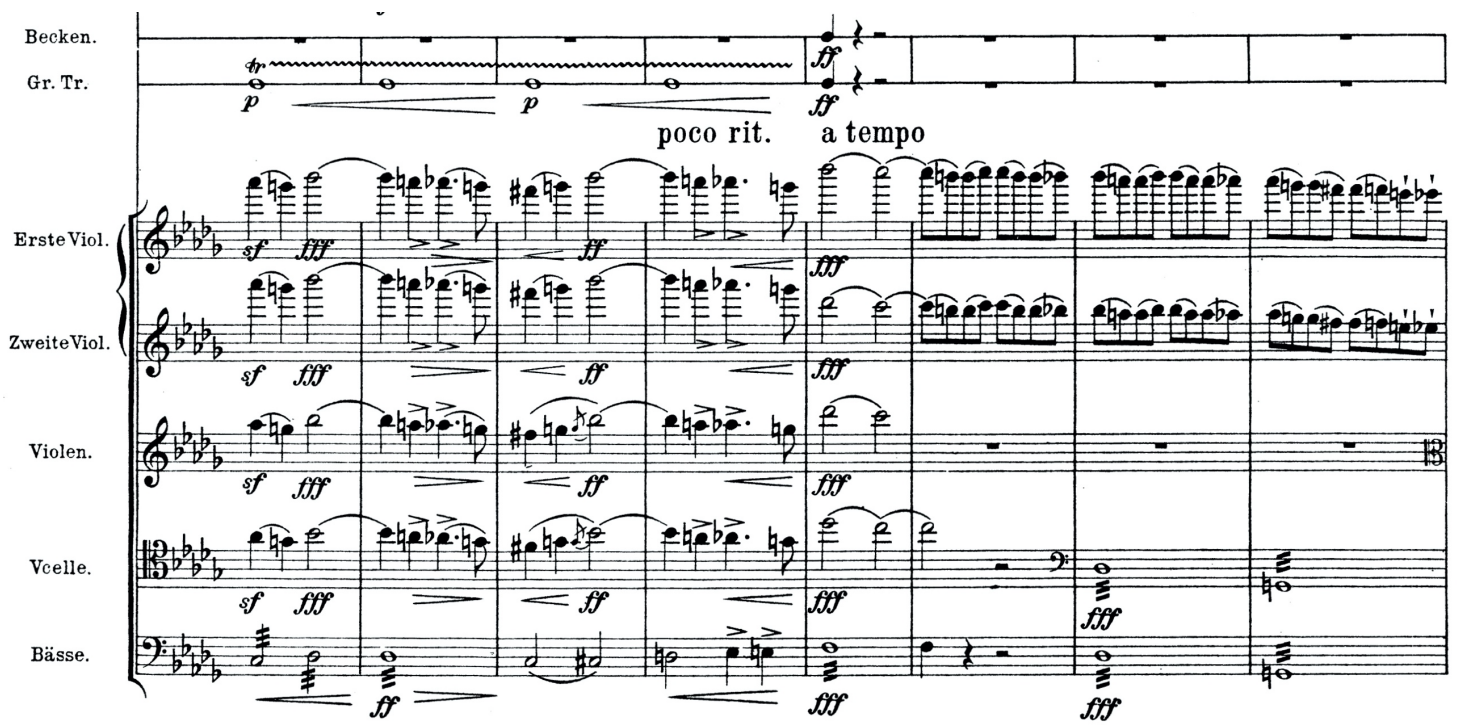

Figure 4. Gustav Mahler (1904), Symphony No. 5, Mov. 1, “Trauermarsch” (p. 28).

\section{Music Notation and the Present Research}

The elements of notation involved in the present research comprise a variety of notational symbols, which, in turn, denote specific concepts, several of which are featured in the example shown in figure 4. Music notation can exact elements such as pitch (height or frequency) of sound, dynamics of sound (volume or variation in volume), duration of sound, timber of sound, to name a few. This dissertation considers this broad spectrum of notational elements, rather than pitches alone. Although the majority of participants in this research have reported synesthetic experiences of color as resulting from exposure to specific musical pitches (whether or not mediated by absolute pitch), an 
array of other elements notated on a page of music also elicited synesthetic concurrent sensations. As the analytical portions of this dissertation will explore, participants spoke of several other notational elements inducing the synesthetic sensation of color, such as clefs, tempo indications, time signatures, dynamic markings, rests, breath marks, rhythms, ranges, intervals, harmonics, among others. Figure 5 shows these concepts as they might appear on a page of music.

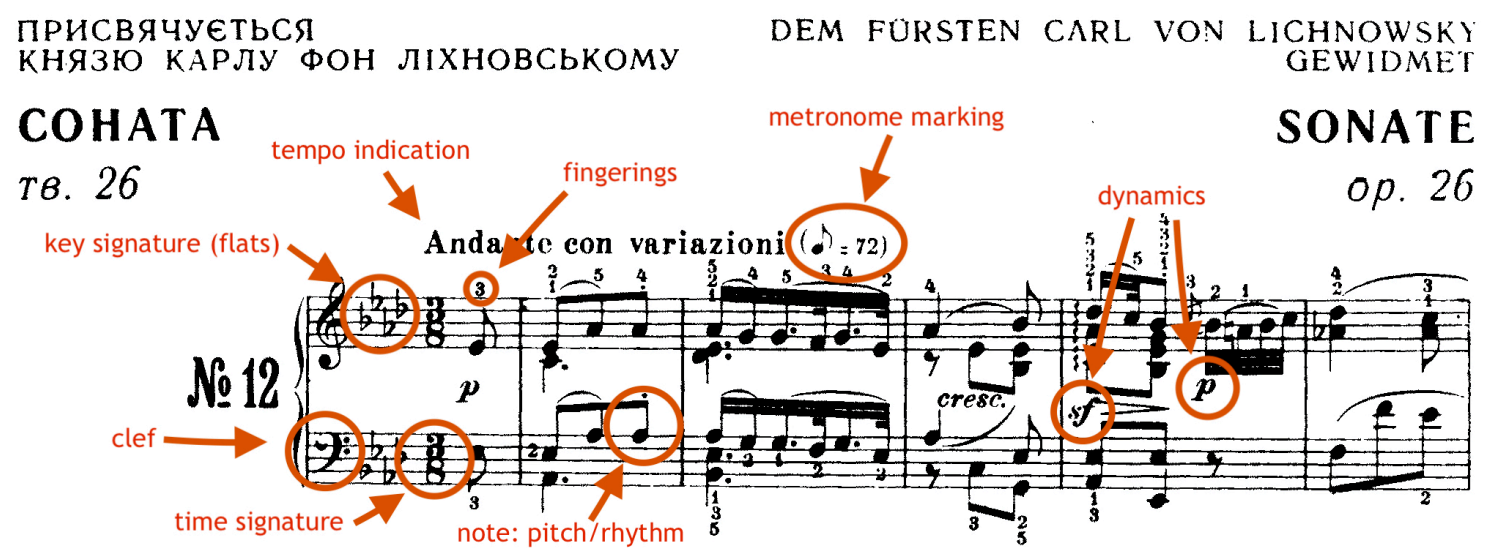

Figure 5. Ludwig van Beethoven (1923), Sonata No. 12, Op. 36, Mov. 1 (p. 195).

As Figure 5 suggests, some of these concepts are notated in music-notational specific symbols, such as pitches, rests, clefs, and key signatures (featuring flats, in this example), to name a few. Others are notated in Italian terms featuring graphemes of the alphabet, such as tempo indication, dynamics, etc. Others still, feature numbers, as in the case of fingerings, time signature, and metronome markings. Besides those, there are several other elements in the page that appear in writing involving graphemes and numbers, such as the title of the piece (in both Russian and German, in this edition), the number of the sonata, and the opus to which it belongs. 
Current music notation is not limited to the elements shown in figures 3 and 4 , however. As the findings of my cross-cultural ground theory study demonstrate in later portions of this dissertation, any of these concepts may be perceived synesthetically depending on the mode of the condition a synesthete has. Each of these and other symbols denote a specific concept and synesthesia often involves an automatic response to a concept when cognitively identified. The findings of this research also point to the conceptual basis of music notation-to-color synesthesia, although the extent and quality of the perceptual is very much unique to each individual. Some traits in the synesthetic perception of this type of music notation are, however, common and show remarkable similarity across participants, such as the aforementioned association of the concept of pitch and color.

\section{Closing Remarks}

Before delving into specifics on the methodology and analysis involving gathered qualitative data, the literature review in the next chapter discusses instances of synesthetic perception documented and explored in scholarly literature on synesthesia. Some of these instances involve music directly while others involve non-music-related, yet applicable cases, such as grapheme-to-color and number-to-color synesthesias-two well-documented forms of the condition that feature symbol-to-color synesthesia. It is paramount to understand these direct and indirect potential applicabilities as discussed in current literature before assumptions about the collected data can be made. 


\section{Chapter 2 Summary}

In this chapter, I have situated synesthesia and, in particular, music synesthesia within the field of education, curriculum, and instruction, point out to the very possibility and scholarly place for a study of this kind in relation to literature in sister-fields. This chapter also explores the centrality of music notation to music education in a Western, albeit growingly global, context, pointing to the importance of the present study's focus. 


\section{CHAPTER 3}

\section{LITERATURE REVIEW}

\section{Introduction}

First, synesthesia is phenomenologically-defined.

-Noam Sagiv \& Chris Frith (2013)

Glaser and Strauss (1967) suggest that a literature review should not be conducted prior to a study of this kind in order to maximize the impact of the findings. Yet, I kept two other considerations in mind in crafting the research questions, purpose, and significance of the study. Synesthesia is a developing field in many respects and much of the literature currently available poses applicabilities as well as intentional references to further research. Ignoring these instances would not be desirable from the perspective of the significance of the study in light of currently available findings. Therefore, a comprehensive but thorough literature review was conducted in designing the goals and expectations for this study as well as the methodological procedures to address them. Rather than obscuring the findings of the present research and dissertation, this literature illuminates the reported results exactly because a study of this kind is still much needed at present. This review of literature distinguishes other forms of synesthesia from the specific mode approached in this study, namely music notation-to-color synesthesia. 
The literature review conducted for this study addresses extant scholarship pertaining to the topic of developmental synesthesia and its impact on music education. Attention is given to literature that bears significance to notation-to-color synesthesiathe main focus of this dissertation. This chapter aligns with a formal structure common to a qualitative study, albeit rather extensive for a grounded theory approach, which usually features a short literature review. It entails a survey of reputable scholarly publications related to the present topic, most of which were written within the last twenty years (with a few exceptions).

\section{Background}

Allusions to notation-to-color synesthesia or how it impacts music perception often surface tangentially in scholarly literature. This review gathers information from a variety of sources, with the intension of providing consistent scholarly support for the hypotheses, design, and assumptions advanced in the present study. This literature review is organized around six major themes that pertain directly to this dissertation topic, in terms of their applicability to notation-to-color synesthesia and music education. Only literature that bears direct relevance to aspects involved in this study—including the challenge that synesthetic incongruence poses for the perception of notation and music education, discussed in the analysis and results—-have been selected for this review. These six themes are ordered in this literature review as follows: (1) synesthesia testing/verification; (2) synesthesia and education; (3) music synesthesia; (4) visual-tovisual synesthesia (with attention to grapheme-color synesthesia); and (5) synesthetic memory and (6) synesthetic incongruence. It is rather difficult, if at all possible, to 
explore the role of notation-to-color synesthesia in music education without exploring each of these areas and understanding the processes of diagnosis and its mechanisms.

Furthermore, music synesthesia is not addressed consistently as a concept across scholarly articles, which poses an additional challenge to a survey of that mode of the condition as addressed in the literature. The methodology chapter offers a distinction between alternative meanings of "music synesthesia" as a concept by approaching it in a systematic way. That being said, all of the items discussed in this literature review become fundamental for a thorough understanding of this lack of a clear conceptual discrepancy present in extant research as well as the more refined distinctions proposed by this study. In proposing a clearer, more accurate conceptualization of music synesthesia, this research acknowledges this preliminary gap in the literature and offers a unique perspective on that mode of the condition.

\section{Thematic Review of Extant Literature}

The following paragraphs analyze available literature that bears direct relevance to developmental synesthesia and elementary stages of music education with respect to each of the aforementioned six thematic areas, respectively. These six thematic niches address scholarly work that contributes directly to the study and understanding of developmental synesthesia, its mechanisms, and, in special, its impact on music and music education. Most of the items analyzed in this section were written within the last twenty years. The exceptions lie mostly within the theme of music synesthesia and auditory-visual modes of synesthesia, given the scarcity of scholarly literature on those subjects. Therefore, the sources chosen for this analysis remain the most authoritative and up-to-date scholarship in the field. 


\section{Synesthesia Testing/Verification}

The educational focus of this research and the pedagogy-oriented motivation of this study both bear implications for the "diagnosis" of synesthesia in potential students. Since the term diagnosis implies the conceptualization of synesthesia as a condition akin to a disease or abnormality, the terms testing and verification were selected as alternatives for this review. While formal and informal tests for synesthesia are available nowadays, some of them can prove expensive and of difficult access, such as functional magnetic resonance imaging (fMRI) scans. The latter can identify the cross-activation of normally individualized and specialized brain regions, thus quantifying the presence of some forms of synesthetic connections. This research and its implications for education do not explore costly testing alternatives for synesthesia diagnosis such as fMRI scans, especially in that in identifying the presence of cross-activation, they fail to provide further insights on the quality of individual synesthetic manifestation as an experience.

In a survey of the validity of short-term testing in relation to long-term testing for synesthesia, Carmichael et al. (2015) explore cost-effective verification alternatives based on the battery of tests that account for synesthetic experience. This modality of the test compares to previously used methods for synesthesia diagnosis, arriving at similar testing results in comparison to its long-term counterpart (Carmichael et al., 2015). The express speed in which such tests can be carried out is also advantageous when it comes to a pedagogical approach to synesthesia. In researching how the condition affects early stages of music education, it is more fruitful to identify and address the condition as early as possible in the educational process in order to afford teachers an opportunity to adapt their instructional material to the needs of the student. Long-term testing alternatives 
based on observation and recurrent assessment would also produce palpable evidence of synesthesia throughout the course of this educational process, however, albeit within a longer time span.

There are a plethora of methods for diagnosing grapheme-color synesthesia. Rothen et al. (2013) recapitulate these methods and consider how they may be adapted to sequence-space synesthesia. Since there is no scholarly work to-date on different testing methodologies for all possible conceptualizations of music synesthesia alluded to above, the present research reviews some of the same methodologies mentioned by the authors (Rothen et al., 2013) and their potential applicability to music-related forms of synesthesia, especially the mode that concerns this dissertation: notation-to-color.

In considering music-related forms of synesthesia-especially relationships between note-names and colors discussed in this research—neuroanatomical bases for tone-color relationships (Hänggi et al., 2008) and neuroimaging of synesthetic mechanisms between pitch and color (Neufeld et al., 2012) are also investigated thoroughly, but bear a tangential relevance to the present research. This tangential relevance is owed to the aforementioned insufficiency of quantitative approaches to synesthesia to explain the experiential impact of an essentially phenomenological condition on real-life circumstances. Besides, the costly nature of some of these quicker procedures to test synesthesia poses a further hindrance to replications of verification processes among larger sectors of the population—especially schools. In this sense, this study prioritizes testing for consistency of synesthetic perception by means of qualitative tools, such as the procedure employed in this research. 
Synesthesia and Education

Seaberg (2011) voices the need for differentiated education for synesthetes in acknowledging the significance of the condition when it comes to perception. Her approach to synesthesia and education is addressed comprehensively within the second chapter of this dissertation. In Seaberg's (2011) book, synesthesia is mentioned only briefly in relation to education and within the scope of scholarly literature on the condition, but the dramatic need for research in education is explored quite expressively in that the author recognizes that synesthetes perceive and experience the world in unique ways (Seaberg, 2011). The implications that differentiated perceptions bring to learning processes are alluded to in her book and addressed in terms of the urgency of such research-work in allowing synesthetes to learn effectively and transfer knowledge in as optimal a way as their non-synesthete peers.

In an instance of synesthesia research related directly to learning, Witthof and Winawer (2013) explore the impact of grapheme-color synesthesia on perception and processing of information. The authors use a quantitative method, however, and test participants on their ability to process congruent and incongruent synesthetic perceptions (Witthoft \& Winawer, 2013). This study does not bring about anything particularly novel to scholarship, in that many other studies have addressed the same issue in the past. Besides, it once more quantifies synesthetic experiences, as is often the case in scientific approaches to synesthesia, without exploring its experiential implications. A qualitative study in combination with this research would have yielded more nuanced and useful results when it comes to teaching and instruction. 
Simner and Bain (2018) discuss grapheme-color synesthesia in terms of its origins and prevalence among school-aged children. They allude to the enduring aspects of letter-color associations (Simner \& Bain, 2018), thus indicating the impact they may have in learning and suggesting how they may affect instructional practice. This quantitative study by Simner and Bain (2018) also discusses the fixation of letter-color association in relation to age, accounting for percentages and incidence among the synesthete population.

\section{Music-to-color Synesthesia}

There are instances of synesthetic perception that involve an auditory inducing stimulus and a visually-defined synesthetic concurrence. Though less accounted for in scholarly literature than the grapheme-color mode of synesthesia discussed in detail below, auditory-to-visual forms of synesthesia are rather prominently discussed (Goller et al., 2009; Ward et al., 2006). However, it is important to note the distinction between music synesthesia and other auditory-visual types of synesthesia. This distinction is paramount in conceptualizing the target form of synesthesia approached in this study: notation-to-color and its highly conceptual basis.

Although relatively few in comparison to other modes of synesthesia, music-color synesthesia is discussed rather prominently in the literature. The aforementioned terminological and nomenclature-related inconsistencies across the literature in approaching different conceptions of synesthesia are sometimes conflating and may generate a degree of confusion in studying the condition. Although this dissertation does not focus on conceptualizing all possible different forms of music synesthesia, it does focus on notation-to-color and, hence, makes an intentional distinction between the latter 
and other different modes of the condition that are referred to in literature. The following paragraphs discuss some terminological issues in relation to the conceptual basis of synesthesia advanced in this research.

One of the recurring themes in the current literature is the discussion of whether or not semantic meaning has a role in determining the concurrent sensation associated with an inducing stimulus. Curwen (2018) aligns methodologically with the present study in suggesting that music synesthesia may be purely conceptual. The author alludes to the term "ideasthesia", coined in recent years (Gsöllpointner, Schnell, \& Schuler, 2016), to explain that it is the musical concept, rather than a heard note that may induce a concurrent synesthetic color. The notion that music synesthesia has multiple modalities discussed in the methodology section of this paper builds on the argument that looking at synesthesia conceptually is desirable not only in music synesthesia research (Curwen, 2018), but in other endeavors to understand the condition.

The distinction between different music-related stimuli suggested in the methodology of this study has also been suggested in earlier studies (Day, 2008). Day (2008), for instance, suggests that, if one takes color alone as an example of concurrent sensation, there at least ten types of music-related synesthesia. In other words, according to Day (2008), there are at least ten different types of inducing stimuli that are musicrelated and can potentially induce a concurrent color sensation. That being said, if the concurrent color remains the same for a number of different stimuli, it is very likely that music-color synesthesia is ultimately conceptual. In other words, it is the idea (or concept) of a note or musical symbol that induces the color and not necessarily a particular frequency or pitch (at least as far as pitch-to-color synesthesia is concerned). 
De Thornley Head (2006), in discussing specifically the music-to-color mode of synesthesia that has a definite pitch as an inducer, proposes the opposite. The synesthetic association between pitch and color accounts for a more complex perceptual mechanism than mere correlations between lightness and intervallic relations discussed elsewhere (Hubbard, 1996). While acknowledging the reality of synesthetic concurrent colors, the author suggests that the study's subjects had color matches for heard tones that were independent of semantic mediation. The author discusses interference of pitch-color synesthesia with perfect pitch as a mediating facilitator in the process of synesthetic perception, suggesting that semantic knowledge of a note through absolute pitch is irrelevant (De Thornley Head, 2006). This perspective poses challenges, since matching pitches with colors (or matching pitches with note names) could denote one and the same thing in terms of pitch recognition: absolute pitch (even if any two enharmonic pitches may elicit different concurrent sensations, given their conceptual discrepancy). I am skeptical as to the validity of this research in light of the presently discussed conceptual nature of synesthesia. In other words, there might be an intersection of absolute pitch and synesthetic perception both working at a conceptual level, since the recognition of frequency would be as automatic as the color sensation, from this perspective.

De Thornley Head (2006) also argues that note names and concurrent colors do not interfere with one another for absolute-pitch synesthetes (p. 172), which is a problematic conclusion considering that both pitch and color would always be consistent in association with pitch (even considering the enharmonic implications mentioned above or different tuning standards). While absolute pitch and synesthesia are not always concurrently present in an individual's experience, there might be a genetic linkage 
between the two separate conditions and potential phenotypic overlap (Gregersen et al., 2013). Relationships between absolute pitch and pitch-color synesthesia are discussed elsewhere in the literature (Rogers, 1987), but are tangential to the topic of this dissertation.

Lacey et al. (2016), in comparing synesthetic associations between sound and visual concurrent sensations and cross-modal perceptual experiences in non-synesthetes, affirm that semantic meaning plays a central role in determining synesthetic associations because these lies outside synesthetic experiences themselves. In other words, synesthetic experiences are "post-perceptual" (Lacey et al., 2016) and require the semantic recognition of an inducing stimulus. This idea resonates with the propositions found in Day (2008) and Curwen (2018), while refuting the argument proposed by De Thorney Head (2006).

Itoh et al. (2017), while also resonating with Day (2008) and Curwen (2018) in regards to the role of semantic meaning (the name of a note, for instance) in eliciting a synesthetic response, offers an interesting perspective. Sir Isaac Newton attempted to trace a parallel between the notes of a musical scale (pitches) and the color spectrum. In a letter from 1675, Newton (Newton \& Turnbull, 1959) states:

As the harmony \& discord of Sounds proceed from the proportions of the aereall vibrations; so may the harmony of some colours, as of Golden \& blew, \& the discord of others as of red \& blew proceed from the proportions of the aethereall. And possibly colour may be distinguisht into its principal Degrees, Red, Orange, Yellow, Green, Blew, Indigo, and deep violet, on the same ground, that Sound within an eighth is graduated into tones. (p. 178).

Not only was his theory disproved in that there is no known physical correlation between optical and sound waves in comparing a musical scale to a color spectrum (rainbow), but synesthesia literature shows that color associations do not depend upon "real" potential 
relationships between sound and color. Rather, they differ from synesthete to synesthete (Jewanski, 2009). Therefore, the idea that a relationship between specific colors and the seven note-names of a C-major scale has a significant incidence among synesthetes (Itoh et al., 2017) is at least doubtful. Itoh et al. (2017) also discuss potential synesthetic relationships between scale degrees and brightness.

This study regards music as having a prominent conceptual basis (Day, 2008; Day, 2016; Curwen, 2018; Lacey et al., 2016; \& Itoh et al., 2017) and expands more systematically on the ideas proposed in these studies in the methodology chapter. The results of this research also point to a strong conceptual basis among participants.

In a different thematic axis, Ward et al. (2006) discuss synesthesia in relation to music notation, at the time the only empirical study on how music impacts notation. The authors address the relationship of color associations between letters of the alphabet and musical notes in the English language (Ward et al., 2006). Cross-modal interactions of this sort are also discussed elsewhere in the literature (Afra et al., 2009). While this study proposes a tangential question to that of those in this dissertation, its focus on notation is only relevant to the present inquiry in that it investigates the mechanism of perception and processing of music notation, thus referencing their potentially conceptual basis.

In yet another thematic axis, Van Leeuwen (2013) and Hubbard et al. (2005) make a differentiation between "projector" and "associator" synesthetes in the context of grapheme-to-color synesthesia. This distinction is based on the nature of the synesthetic sensation associated with a grapheme. Projector synesthetes "see" the color on the page, or where the grapheme is represented. Associators "see" the color in their "mind's eye". 
This distinction is paramount for the present research in that it speaks to how participants of the research experience their color sensations in response to music notation.

\section{Visual-to-visual Synesthesia: Grapheme-to-color}

Synesthesia

Scholarly publications on other modes of synesthesia have also been selected for this review, as they suggest applicability to the present topic and its mechanisms. This section of the review discusses the literature on instances of synesthetic perception that involve a visually perceived inducing stimulus and a visually defined synesthetic, concurrent sensation. This section is subdivided into (1) grapheme-to-color synesthesia and (2) the role of attention in synesthetic perception.

Grapheme-to-color synesthesia is likely the most discussed mode of the condition, accounting for the majority of scholarly articles addressing synesthetic perception. It denotes the synesthetic perception of graphemes, entailing the graphic representation of a letter, usually associated with its semantic meaning and a concurrent color. The impact of semantic meaning and the recognition of graphemes in terms of their symbolic content is discussed in some detail in Dixon et al. (2006). The research shows that the concurrent synesthetic sensation can vary in function of the semantic meaning attributed to the inducing stimulus (Dixon et al., 2006). In other words, it is not the visual attributes alone that would determine the nature of the concurrent sensation (such as its shape, font, or format, to name a few attributes). Rather, the concurrent sensation appears to be tied to the semantic content associated with the inducing grapheme. Conversely, Ramachandran and Seckel (2011) argue for a non-conceptual eliciting of synesthetic color. The authors propose that an inducer may elicit a synesthetic sensation before it is recognized by its 
meaning (Ramachandran \& Seckel, 2011). This proposition aligns with De Thornley Head's (2006) suggestion that synesthesia is not conceptual, which idea has been discussed above.

It is important to note at this juncture that synesthesia does not necessarily go both ways; that is, the literature usually does not account for color $>$ grapheme synesthesia, but rather the unidirectional grapheme $>$ color mode of the condition. However, Paffen et al. (2015) suggest the idea of bidirectional priming in grapheme-color synesthesia (Paffen et al., 2015). Although the literature on grapheme-color synesthesia is vast and some of the methodologies used to describe this mode of synesthesia can contribute to an understanding of music notation-to-color synesthesia, the presence of bidirectional association is not primarily explored in the present research.

Since concurrent synesthetic colors of music notation are often imported from the letters that give their name, the present study accounts for scholarship that explores transference of synesthetic color between languages based on similarities in sound and or graphic representation. It considers music as a learned language —one that is often learned secondarily, especially if the students who are undertaking music are already literate by the time they start having lessons. Asano and Yokoswa (2012) discuss transference of synesthetic color between alphabets, focusing on late-acquired Japanese graphemes. Asano and Yokosawa (2013) also propose a model of grapheme-color association, which offers some insight on the mechanisms of synesthetic color eliciting (although perceptual models are considered a hermetic and rigid approach to experience). Since synesthesia is phenomenologically defined (Sagiv \& Frith, 2013, p. 1), perceptual models are reductionist in approaching the condition and many only account for the 
experiences of some individuals while leaving others out. This points once more to the need for qualitative inquiry in synesthesia research. Although a general grounded theory is advanced in the present dissertation, no phenomenological models for perception are proposed. In any case, the transference of synesthetic color proposed by the authors (Asano \& Yokozawa, 2012; Asano \& Yokosawa, 2013) is elucidating in this study in what touches the learning of music as a language.

The same relationship between late-acquired graphemes in an alternative alphabet other than a native alphabet is discussed by Blair and Berryhill (2013). The research suggests that, while there is growing consistency in synesthetic color over time in a newly learned alphabet and language, the transference of color is not grounded in the phonetic similarities between two graphemes in different alphabets (Blair \& Berryhill, 2013). This is to say that, while there is transference of concurrent synesthetic color between graphic representations of sound they may not be heavily dependent on auditory similarities. To be sure, tracing parallels between phonetics and musical sound (such as frequency, for instance) is at least a stretch, yet it is relevant to consider the significance of an auditory percept as a potential inducing stimulus in the context of auditory-based music synesthesia; even if auditory-visual modes of music synesthesia may not be the primary focus of this dissertation.

Transferability of synesthetic color shows the potential for importation, fixation, and gradual solidification in the newly acquired language based on visual similarities between graphemes rather than phonetics (Brang et al., 2013; Brang \& Ramachandran, 2010; Brang et al., 2011). It follows that, although Dixon et al. (2006) suggest that it is the semantic content associated with a given grapheme that will elicits a concurrent 
sensation in the mind of a synesthete rather than the visual attributes of a grapheme, it appears that the latter plays a prominent role in the transference of concurrent sensation from one language to another. The results of this dissertation research show that music notation often has a conceptual basis, thus subscribing to Dixon et al.'s (2006) proposition.

As for the neural basis of grapheme-color synesthesia, unlike most previous research, Hupé et al. (2011) challenge the "reality" of synesthetic color, arguing that such concurrent sensations might not lie in the color system for some synesthetes, in that areas of the brain responsible for color processing are not cross-activated (Hupé et al., 2011). The authors make use of functional magnetic resonance imaging to detect crossactivation of bran regions and consider structural differences in synesthetes' brains. The neural basis of synesthetic experiences of music notation is not accounted for in the present study due to the priority for the phenomenological quality of the synesthetic experience, rather than the physiological process involved.

\section{Synesthetic Memory}

This section of the literature review explores overarching idiosyncrasies of synesthetic memory as a perceptual phenomenon involving recollections of the past. While later portions of this review address advantages in synesthetic memory observed in literature more specifically, this section involves generalities collected from different studies on the topic.

Although researchers have alluded to a potential advantage on the part of synesthetes in recalling memorized information, recent studies have pointed to generalities in how the condition manifests that indicate a rather more complex 
understanding of synesthetic memory. In conclusion to their study on associative memory in synesthetes from different age groups, Pfeifer et al. (2014) suggest that, as a perceptual-mnemonic continuum, synesthesia could be understood as a type-specific phenomenon (p. 11). In other words, synesthetes may manifest greater ease in memorizing events on information connect to specific modes of synesthesia.

Witthoft and Winawer (2013) recognize the potential for synesthetic pairings (comprised of inducer and concurrent sensation) to facilitate the retrieval of information. The authors indicate that the mnemonic associations enable synesthetes to access highly specific information due to the automaticity, consistency, and, therefore, reliability of synesthesia. While Withoft and Winawer (2013) approach grapheme-color synesthetes only in their study, the applicability of the aforementioned realization is far-reaching in encompassing other modes of the condition involving specific concepts (p. 7), such as numbers or musical notes - the focus of this study.

Van Campen (2009) concurs with this wide range of applicabilities in talking generally about synesthesia as a mnemonic device. In focusing on recollections of the past, however, Van Campen (2009) suggests that synesthetes and non-synesthetes retrieve memories in the same manner. In other words, the phenomenological process of memory retrieval remains virtually intact. Yet, the uniqueness of synesthesia as a perceptual phenomenon allows for a highly specialized form of retrieval that is inherent to individuals who process the condition. The most compelling discussion in Van Campen's (2009) argument is the suggestion that one constructs meaning and, therefore, retrieves memories using whatever abilities one has (p. 5), identifying synesthesia as a one-of -a-kind for of recollection. The author's emphasis on emotional attachment to 
synesthetic recollection of memories speaks to a specific quality in synesthetic remembering past events.

\section{Synesthetic color and memory}

Given the centrality of grapheme-color as a prominently addressed mode of the condition - which is probably due to its prevalence among the population of synesthetes in comparison to other forms of synesthesia - this section includes two articles that show an approach that is restricted to color. Prichard et al. (2013), in elaborating on the continuum-based model of perception and memory addressed in other discussed studies (Pfeifer et al., 2014), suggests that memory can be enhanced in regards to synesthetic color if employed in "specific ways" (p. 230). As the next section will discuss in more detail, the literature suggests that awareness and intentionality in using individual manifestations of the condition are fundamental to the resulting degree of memory. Differently from other recent studies, Baron-Cohen et al. (2007) offer a fresh perspective in connection to Savant memory in Asperger Syndrome. In a case study involving a synesthetic individual, the authors propose a correlation between the three conditions in terms of co-occurrence. This research is also unique in that it approaches number-color synesthesia, as opposed to the usual grapheme-based inquiry. Although this study has a more restricted applicability, in that it entails the co-occurrence of three conditions affecting a minority of the population, the approach to numbers suggests a greater variety of alternative synesthetic memories in relation to the commonly approached graphemescolor binary. 


\section{Advantages of synesthetic memory}

Several articles suggest that synesthetes are at an advantage in comparison to controls in retaining information and events. In approaching enhanced recognition memory in grapheme-color synesthetes, Ward et al. (2013) indicate an advantage on the part of synesthetes in memorizing "abstract visual images (fractals) and scenes for which color can be used to discriminate old/new status" (p. 1). Pfeifer et al. (2014) concur with this perspective in discussing advantages in associative memory. In pointing that out, the authors indicate that, because advantages in synesthetic memory are type-based, there is no neural basis for synesthetes simply having a better memory than non-synesthetes. In a previous group study involving grapheme-color synesthetes, Rothen and Meier (2009) suggest a similar perspective, proposing that synesthetes do not have an innately more acute memory, but can benefit from conscious associations as a mnemonic device in having a general advantage in visual search and episodic memory. This is illuminating in indicating that synesthesia can be used as a learning tool if employed consciously. Pfeifer et al.'s (2016) study on synesthetes from different age groups and controls proposes a growing advantage of the former in relation to the latter in memory. The authors provide correlational evidence that synesthetic memory improves with aging by testing individuals' ability to learn through associative processes. In a previous study involving different age groups, Pfeifer et al. (2014) suggest that there is a correlation between age and memory in older adult synesthetes, pointing out that age might be a factor in enhancing synesthetic memory.

Contradictorily, Rothen and Meier (2010) propose that synesthetes do not have an advantage in memorization. The study indicates that synesthetes have a better episodic 
memory but do not score better than non-synesthetes in short-memory tests. Even though this piece from the literature is in stark contrast with the other items discussed in this section of the review, this study is still significant in that it is a group-based study in comparison to previous case studies that have suggested otherwise (Rothen \& Meier, p. 258). Yet, the prevalence in literature in approaching intentionality in associative memory as a mnemonic device debunks this study in terms of its generalization that synesthetes do not perform better. Rather, as others have indicated, they may perform better if synesthesia is employed consciously (Pfeifer et al., 2014; Rothen \& Meier, 2009). A later study involving the same researchers indicates that while not all information or percepts that trigger synesthesia may be better remembered — and consequently not all events that do not trigger synesthesia are less likely to be well remembered - there is still an advantage on the part of synesthetes in displaying an enhanced memory in particular cases (Rothen et al., 2012), such as the aforementioned conscious employment.

\section{Synesthetic Incongruence}

This section briefly discusses synesthetic congruence/incongruence and its impact on the perception of music (in its various modes), given its potential impact on the learning of music and music-related concepts. Using the Stroop task text, Kadosh and Henik (2006) propose that, in grapheme- or number-color synesthesia, incongruity (incongruence) between the "real" color of an inducing stimulus and the concurrent sensation it elicits may delay behavioral response. Conversely, congruence between the two accelerates synesthetes' cognitive processing of percepts (Kadosh \& Henik, 2006). In this research, the subject tested responds slower when encountering incongruences. 
Although there are no substantial scholarly discussions on the impact of synesthetic incongruence on music education, this dissertation argues that this potential lack of congruence is a central reason why synesthesia deserves attention when it comes to music education.

\section{Further Thoughts}

Although the literature on synesthesia has grown to accommodate a thorough overview of the condition, several gaps in scholarly output can be easily identified in mainly three areas. Firstly, while literature accounts for different modes of the condition, publications on music-related forms of synesthesia are relatively rare-let alone studies on synesthetic perceptions of music notation. Compounded with the lack of research in this direction, the issue of terminological inconsistencies in addressing music-related forms of synesthesia adds an extra layer of difficulty in conceptualizing the term "music synesthesia", in that it can denote a variety of forms of synesthesia that are sometimes not specified in detail. Secondly, the lack of autobiographical, narrative-based, and, essentially, qualitative studies on how music synesthesia is experienced exacerbates the unilateral, mainstream, and rigorous quantitative approach to synesthesia, which, much to the disadvantage of research on this condition, fails to account for nuances that only a qualitative study can provide (Sagiv \& Frith, 2013). Thirdly and finally, there is much need for research to address the impact of synesthesia on education consistently, especially music education.

To be sure, qualitative approaches are not inexistent and some of the items discussed above do feature qualitative designs or overarching aspects of qualitative inquiry. Yet, there is still much ground to cover in terms of research and scholarly output. 
While mindful of these three broader areas of literature scarcity, the present study proposes a qualitative approach that sheds light on each of these three aspects alike. In looking systematically and qualitatively at the synesthetic experience of music notation within the field music education, this research offers an alternative and novel approach, entailing: (1) an alternative conceptualization of music synesthesia evidenced in the notation-to-color focus; (2) an autobiographical and narrative perspective; and (3) a consistent approach to synesthesia within the realm of pedagogy, with attention to music education. This study begins to satisfy the need for a systematic and organized study of synesthesia as it relates to music and music education.

\section{Chapter 3 Summary}

This chapter reviews literature immediately relevant for this research, even though a review is sometimes not present in grounded theory studies (Glaser \& Strauss, 1967). The endeavor to conduct the review was grounded in the nature of the field and the significance of the study in light of current research. Literature was organized thematically according to six correlated and relevant areas that impact this study prominently. The next chapter outlines the methodological procedures designed for this research. 


\section{CHAPTER 4}

\section{METHODOLOGY}

\section{Overview}

Qualitative inquiry, by nature, is a customized, inductive, emergent process that permits more of the researcher's personal signature in study design, implementation, and write-up.

-Johnny Saldaña (2015)

With the intent of understanding the impact of music notation-to-color synesthesia on early stages of music education, this study proposes to collect a substantial number of narratives from synesthetes with symbol-based, music-related synesthesia in a crosscultural approach and analyze how they interact with one another in terms of conceptualizing synesthetic experiences pertaining to this topic. This chapter addresses the methodology in connection to population sampling, the obtaining of data through specific instruments and protocols, the storing and organization of data, and the analytical procedures involved in the research. Appendix F shows these steps within the broad research cycle.

The methodology presented in this chapter directly addresses the research questions advanced in the first chapter of this dissertation, namely: (1) How are music notation-to-color associations experienced by synesthetes? (2) What possible roles might 
music notation-to-color synesthetic experiences play in early stages of music education?

(3) What are alternative ways in which music can be taught to synesthetes? The two proposed sub-questions were also taken into account: (1) Is there some indication of consistency in narratives collected cross-culturally? (2) What are the resonating points and similarities in these collected experiences?

The qualitative approach proposed for this research was designed to answer these questions systematically in terms of traditional qualitative methodology. As discussed in the literature review of this study, quantitative methodologies have permeated most research efforts related to the present topic. Given the phenomenological nature of synesthesia as a condition, an evaluation of personal narratives of synesthetic experience is fundamental for a more thorough understanding of this condition, its perceptual/experiential mechanisms, and, most relevantly, how and to which extent it affects behavioral response in comparison to non-synesthetes. Although quantitative methodology such as functional magnetic resonance imaging, for instance, only accounts for the presence of the condition and whether or not it affects perception, it fails to acknowledge the extent to which it does so and what the implications are for different individuals at a practical level.

The chosen approach featured in this study, a qualitative grounded theory perspective with a phenomenology component, proposes to collect and analyze narratives from individuals who have notation-to-color synesthesia cross-culturally. In analyzing these narratives, the study looked for commonalities and emerging themes that surface upon their intersection. In discussing these commonalities, this study aims at arriving at a grounded theory. 


\section{Research Sample}

The sample targeted in this study comprises individuals who are synesthetes and met three criteria: (1) manifest music notation-to-color developmental synesthesia, (2) are over 18 years of age, and (3) have had training in music. Since synesthetes comprise an estimated $4 \%$ of the population, it is challenging to locate and access these individuals within a set geographical locus or loci. Fortunately, online-based networking facilities, connect synesthetes, researchers, and artists nowadays, thus counting on a myriad of subscribing synesthetes around the world who are willing to collaborate and interact for the advancement of research on synesthesia. Figure 6 shows a visual representation of this sampling.

Synesthetes

\section{Music training}

Adults

Music

notation-to-

color

synesthetes

Figure 6. Population sample. 
Synesthetes participating in the Synesthesia List online-based group, as well as curated synesthesia communities on Facebook, were contacted and assessed as to the meeting of these three criteria. The latter are closed communities to which members have to be accepted. These communities often have rules about the nature of contribution from participants in terms of maintaining the thematic focus of the group and cooperating with members at large. Members of both these online-based group categories-Synesthesia List and Facebook curated communities - are often involved and collaborate with one another in research.

As for the requirements for participation, while the first and third criteria are selfexplanatory in that they reflect the focus of this research, only adults were chosen for this research in that they would be able to recall early stages of their music education from a reflexive perspective. The consistency of their condition and the intact way in which participants experience music notation in comparison to the time in which they were undertaking music education also attests to the feasibility of this criterial approach.

Moreover, due to the rapid development of synesthesia research within the last 20 to 30 years, these individuals were likely to have had their music-educational experience at a time in which the condition was not widely known. In recalling this lack of awareness about their experiences, participants were able to reflect on what they wish had been done differently in their early years learning music and their struggle to understand their experience from a purely individual perspective. These recollected narratives stand in stark contrast to the growing awareness they feel their experience has gained today. In struggling to understand their own condition from this individual perspective, their 
narrative is often vivid and fresh in terms of describing the elements involved in their experience.

The nature of this criteria-based sampling strategy is mainly twofold, in that it entails an amalgamation between (1) "chain" and (2) "criterion" sampling. These strategies are described in Creswell (2019, p. 385) and denote, respectively, (1) a group of people who possess the same characteristics and (2) participants within this group that meet certain criteria established by the researcher. In this research, this intersection is created from the combination of participants who (1) have synesthesia and (2) who have gone through formal music education.

There is also a "theory-based" (Creswell, 2018, p. 385) aspect to this sampling. As a grounded theory study, this sampling seeks to verify the hypothesis that synesthetic congruence and incongruence are influential in the learning and performance of music notation. Likewise, the research will count on an aspect of "intensity" sampling (Creswell, 2018, p. 385), in that it seeks intense information on the circumstance studied in order to check the validity of the hypothesis raised as well as the implications of the surveyed aspects for synesthetes. As discussed in other portions of this study, synesthesia is a multimodal condition and manifests differently in every individual, but the aspects surveyed in this study may have broader applicability.

\section{Research Population}

The online basis of this interaction with the proposed sample grants a crosscultural perspective to this research, which is desirable in the context of what the study aims to achieve. Music notation, as a linguistic construction of Western society, works as a common language between different cultures and backgrounds inserted in this social 
milieu. Given the volunteer nature of the collaboration in the Synesthesia List and other communities as well as the willingness of these participants to advance research on the topic, this study counted on a minimal budgetary expenditure. Amazon.com gift cards in the amount of USD $\$ 25.00$ were sent to participants who engaged in the complete interview process.

\section{Research Design and Structure}

This research is modeled after a traditional grounded theory study. It entails the interviewing and collection of narratives from individuals through a semi-structured protocol. In analyzing these collected narratives, a theory is derived that explains the

idiosyncrasies of the synesthetic experience of music notation on the part of participants, all while prioritizing the topic of this research: their significance for music education.

This study is structured as a cyclical system (Saldaña, 2016) that revisits the essential research questions at every step of the process-especially at the end of the research process. It is comprised of twelve procedural steps, as outlined in the research cycle graph in Appendix F. The paragraphs that follow explain these twelve steps in prose. In light of the purpose of this study and the gaps identified in the literature review chapter, a brief preliminary survey and narrative-based semi-structured interview were elaborated and designed so as to assess the contacted individuals in terms of their synesthetic experience of music notation during early stages of music education.

The first step in this research process involved the crafting of the research problem and questions. A literature review was carried out, as outlined in chapter 3 of this dissertation. The problem, purpose, and significance of the research, along with the essential questions it poses, were refined as the relevant literature was reviewed. A full 
research proposal—including methods, analytical procedure, and data collection instruments - was then developed. When the research proposal was finished and the researcher became certified by the National Institutes Health (NIH) training program (September 23, 2019), the proposal went through approval by the Institutional Review Board (IRB) at Andrews University, reproduced in Appendix G (December 13, 2019).

After obtaining IRB approval, several synesthetes were contacted through the Synesthesia List and curated Facebook groups targeting synesthetes. 22 individuals reported meeting the three established criteria for participation and responded by filling out the preliminary survey. Participants were then interviewed. After interviews were conducted, only 12 individuals qualified to be included in the research, having met the three criteria after questions and testing. Other participants were excluded from this research when the researcher observed they did not have music training, were under 18 years of age, or did not have synesthetic sensations related to any music-notational percepts (anything that can be written on a page of music). Data collection methods are elaborated on in further detail in the following section of this chapter.

The collected narratives from interviews were transcribed (scripted) verbatim and the collected data was analyzed through a process of coding. As themes and commonalities were identified, they were organized into categories and further explored in terms of what they mean contextually as well as what their implications are for the present study. The researcher was also actively invested in memo-ing and note-taking throughout the research process, keeping a research journal log at all times. The cyclical approach suggested above was followed strictly so as to secure alignment between all stages of the study. There were recurrent revisits to the raw and transcribed narratives in 
order to avoid the researcher's own interpretation of narrative-based details shared so as to maintain the maximum level of accuracy in the meaning intended by participants. One of the following sections of this chapter describes data analysis in more detail.

Analyzed data was then reported and discussed in relation to the research questions and the literature reviewed for this study. The results are reported in detail in chapters 5 through 9 and the discussion is featured in chapter 10. In reiterating the cyclical approach of this research process, there was a recurring return to foundational steps in this grounded study research design throughout the process of sampling, data collection, analysis, and synthesis, such as the direct assessment of the proposed research questions and the immediate relationship of the findings to the literature. In so doing, this study maintained a priority for true significance in juxtaposition to extant research.

The results of this research were not only discussed but used purposefully to develop a grounded theory that reflects the significance of these synesthetic perceptions of music notation to early stages of music education, thus addressing the research questions proposed at the outset of this endeavor as well as the hypothesis furthered in this study.

Finally, as the research process graphic shows in Appendix F, each stage was recurrently revisited in terms of its intentionality to reflect a cycle rather than a linear procedure. Alignment between each stage in relation to other stages of the cycle was taken into account throughout this process.

\section{Data Collection Methods}

Following IRB approval, prospects participants were reached by email (if on the online database Synesthesia List) or by invitation (if members of curated Facebook 
synesthesia groups). The recruitment letter, shown in Appendix A, outlines the call for participation sent to participants of this group. The letter targeted those who belong to the criteria-based intersectional sample discussed above, namely, adult individuals who have notation-to-color synesthesia and have undergone Western modern music-notational instruction. Participants were sent an access link to the preliminary form outlined in Appendix C, asking for basic information such as demographics. The form was developed through the Google Forms online application. An Informed Consent Disclaimer/Form, shown in Appendix B, was included in the preliminary form as its first page. Participants were only able to proceed to the questions in the preliminary form if they did not sign the Informed Consent Disclaimer/Form with their email address.

Participants who completed and submitted the form were sent a link to a Zoom (computer software) video-conference call via email, which was scheduled on an availability basis involving both the researcher and the participant. There were no time limitations or restrictions for the duration of interviews, so as to allow for a maximum of narrative flexibility under the circumstances involved. The interviews were semistructured but were carried out in a conversation style to ensure naturalness of flow via Zoom or in person, for some of the participants based in Canada, Europe, and South America. The structure of interviews followed the flowchart depicted in Appendix D. The course of the interview varied slightly according to participants' answers to some of the interview questions, while still maintaining the overall structure of the interview and addressing the principal points. Participants were provided with examples by the interviewer or a sample sheet music whenever required. 
The semi-structured interview asked participants about generalities pertaining to early stages of their music education. Next, they were asked to describe in detail the idiosyncrasies of their music notation perception, including the ability to project or associate synesthetic sensations. The intersection with other modes of synesthesia was also taken into account (both music-related non-music-related forms). Participants were also asked to recall the impact of their synesthetic perceptions of music notation on their learning, accounting for the positivity and negativity of the condition. This part of the interview also inquired about potential congruences and incongruences in synesthetic perception. Next, participants were asked to elaborate on teaching methodologies that they would think would have worked with them or with other synesthetes with notationto-color synesthesia. Lastly, participants were asked for their thoughts and comments about this research. Appendix D provides further detail on the conceptual flow of the interview.

In verification and confirmation of participants' synesthesia in terms of its automaticity and consistency, the interview protocol included two questions on synesthetes' exact perception of notation. They were asked for their unique colors at the beginning and then asked again at the end of the interview. The researcher performed multiple other checks for the consistency of their sensations throughout the interview. Even those who did not have exact colors for each individual pitch concept were tested as to the automaticity and consistency of their synesthesia for other notational elements. All 12 participants fared remarkably well in these questions and tests. Therefore, they were confirmed in this research as synesthetes. All of the participants were also very descriptive and detailed about their experience. 
All interviews were recorded and stored on a password-protected computer device. Files were saved in both video and audio-only format and organized in different folders. Materials and original files were organized by participant. As a means of encouragement and token of appreciation, all participants who participated in the complete interview cycle - entailing the preliminary form survey and interview were automatically sent an Amazon.com \$25 gift card. These tokens of appreciation were sent by email to each participant.

All personal information and personal details shared in the preliminary survey, as well as the interview, were not included in the analysis and results of this research in order to ensure a maximum level of honesty while preserving sensitive information. Although participants described details of their personal experience, sensitive information such as name, address, or any other identifying details will not be asked or divulged in any portion of this survey or the research at large.

\section{Data Analysis and Synthesis}

Interviews consisted of about 6 hours of narrative, which were first transcribed verbatim with the help of the Otter.ai application. Since this program offers a digital, automatic generation of literal transcription from audio and video files, several inconsistencies and mistakes in transcription were observed. Then, the researcher revisited the entirety of the narratives, making corrections and amendments in order to render the raw transcribed data a high level of accuracy in terms of a scripted representation of verbal expression. Expressive nuances such as tone of voice, word emphases, pauses, sighing, laughter, etc., were taken into account and included in the narrative in brackets. Relevant gestural expressions such as visual indication of location 
of experiences (hand motions and pointing, for instance) were also included in brackets in the final transcripts. These qualities are discussed in the analysis portion of this dissertation.

This study used the coding methodologies described by Creswell (2018) and Creswell and Potts (2018), who suggest the identification of codes (themes) according to recurrence and relevance. The 12 narratives were coded independently as well as in juxtaposition to one another. Although the researcher had developed an early coding map in the aforementioned research journal log, the final codes (themes) were extracted purely from the narratives in terms of recurrence, emphasis, and relationship to the focus of the study. In this sense, the qualitative approach entailed a mixture of deductive and inductive approaches. The identified codes were grouped, organized, and categorized with the help of the NVivo software for qualitative research. Although NVivo was used for coding organization and categorization of codes, analysis was done manually. The researcher extracted codes (emerging themes) manually in order to ensure involvement with the data for validity purposes and avoid the generation of unwanted codes.

Appendix E shows a coding categorization/hierarchy divided by color. Yin (2009) recommends organization by topic (category) in reporting of grounded theory study findings. Five categories were identified from the data, involving (1) generalities of synesthetic perception of music notation; (2) mechanisms of synesthetic perception of music notation; (3) location of synesthetic perception of music notation; (4) implications [of synesthetic perception of music notation] for music education; and (5) other significant themes. The codes involved in each of these broad categories are reported in separate chapters in this dissertation (chapters 5 to 9) so as to ensure ample exploratory 
room for each of the emerging overarching themes, as well as to afford a more refined organization for this dissertation. In spite of this segregation, nonetheless, these codes are marked by intersections and intercommunication throughout, as the discussion of the reported results points out in chapter 10 .

In the analytical portions of this dissertation, direct quotes transcribed verbatim from the collected narratives were made available in support of each discussed category and code (theme). Direct quotes in the participants' words, including non-verbal expressions in brackets, were sometimes supported by visual examples provided by the participants.

Some of the participants voluntarily shared visual representations of their synesthetic perception of music notation that demonstrates the quality of their color sensations. These documents were also organized and sorted in conjunction with the narratives to which they are connected with the assistance of the NVivo software. These representations were made available in context through the analysis portions of this dissertation. In this manual analytical process, the three stages of coding mentioned by Creswell (2018) were used: open coding (creating of categories), axial coding (considering their conceptual intersections), and selective coding (building a story with selected codes). The first two stages were procedural on the part of the researcher and took place prior to the writing of the chapters of dissertation entailing the results of this study, whereas the five chapters reporting the findings of this research entail the third stage. In these chapters, a "story" or "continuum" (Creswell, 2018) was told for each of the five identified categories (Appendix E) through selective coding. These thematically- 
defined stories contain examples and direct quotes from narratives, which were made available to the reader in support of the essence of each category.

The analytical and synthetic procedures adopted in the present study also count on a multifaceted approach that goes beyond the sheer identification and analysis of codes. This approach involves (1) memo-ing and annotation strategies throughout the data collection process; (2) abundant note-taking with attention to connections and intersections with extant literature; (3) a thorough organization and mapping of the identified emerging themes and cross-overs between narratives as well as a structure/hierarchy themes, and (4) a comprehensive conceptualization of the identified themes. In this sense, the similarities between these categories, as identified through a thorough note-taking-based approach, are as important as the differences used to separate them in this study.

\section{Ethical Considerations}

Since synesthesia and its associative patterns, as manifested in music perception, are part of the innermost, inward essence of one's synesthetic experience of music, some individuals may feel uncomfortable sharing their narrative. The findings of this research have identified instances of disbelief, bullying, and lack of validation when it comes to their voicing of experiencing the world synesthetically. Heightened sensitivity to this issue was paramount in conducting interviews with these participants.

Participants may also prefer not to disclose their identity, which can cause concern during the interview process. However, the preliminary survey protocol outlined in APPENDIX C excluded the field for such personal information entirely, whereas generalities such as gender, age, and cultural/linguistic background were still kept as 
information that was helpful in analyzing narratives in light of the data available in previous scholarship and extant literature. Participants were assured that none of these details were disclosed.

Some still may feel uncomfortable about having an interview-type conversation recorded and analyzed. All participants were informed prior to participation in the study, however, about the nature of this data collection methodology, as the recruitment letter (Appendix A) and signed informed consent disclaimer/form (Appendix B) indicate. All participants interviewed for this study signed the informed consent form prior to scheduling a video interview time with the researcher. Moreover, participants were informed as to the nature of the research and of the recording process at the beginning of every interview. All participants interviewed also provided verbal consent about the recording of the video interview session.

\section{Trustworthiness and Validation}

\section{Triangulation}

Creswell (2018) proposes several strategies for validation. Triangulation is discussed as an effective form of validation, although different authors have disagreed about the necessity for others to read and analyze the researcher's work for credibility. One of the strategies mentioned by Creswell (2018) and adopted in this study was to use multiple sources of data.

Firstly, the data collection took into account both verbal communication as well as visual expressions. The narratives were analyzed in comparison to the video recordings featuring participants' gestures, facial expressions, and other visual indications within the communication. Moreover, documents other than the narratives 
collected in interview format were collected. Participants offered visual depictions of their synesthesia created by themselves or by their students, which are reproduced in this study as further evidence of the truthfulness and accuracy of their narrative and the researcher's interpretation.

\section{Role of the Researcher}

In recapitulating the issue of researcher bias in this context, especially in that I am a synesthete, Lincoln and Guba (1985) propose that the researcher keep the procedures of the data collection, analysis, and interpretation at all times in reporting the findings in written format, which have been alluded to extensively in this chapter and will be further elaborated on in subsequent portions of the study. In particular, the following five chapters expand on these experiences in detail and provide quotes verbatim from these sources.

Analysis of data and creation of codes were done manually by the researcher, thus ensuring closer contact with the data and avoiding inconsistencies emerging from computer-generated analysis available on the NVivo software. It was especially due of the avoidance of research bias that researcher familiarity with the data was prioritized in this study over the interpretation of computer-generated results.

Furthermore, this research approaches an experiential process on the part of synesthetes, taking the role of the researcher and his own reflexivity into account throughout the research proper. The study relies on valid sources of data analysis, such as coding and memo-ing. Diagramming and graphic demonstrations are also proposed in this study for clarity of comprehension and future directions in research are accounted for throughout the analysis and discussion chapters. 


\section{Recapitulation of Research Significance}

This research helps to raise awareness about synesthesia as a neurological condition and to further validate the commonalities hypothesized throughout through the development of two grounded theories. The more synesthetes voice this concern, the more the argument consequently strengthened in favor of what this research sets out to do and advances as a topic for qualitative inquiry. The thematic patterns and recurring, emerging themes observed during data analysis processes render the present study validity in confirming the gap in literature alluded to in the literature review section. They also promote a significant step towards an adequate acknowledgment of such a pressing matter within the scope of music education for the specific synesthesia population.

\section{Chapter 4 Summary}

In this chapter, research questions were recapitulated in support of the chosen research design, structure, data collection methodology, data analysis and reporting, and discussion. Trustworthiness in regards to the interpretation and reporting of research findings, as well as ethical considerations, were also taken into account in determining the validity of this study. The next five chapters report the findings of this research, followed by a discussion of the results. 


\title{
CHAPTER 5
}

\section{GENERALITIES OF PERCEPTION OF MUSIC NOTATION}

\section{Overview}

\begin{abstract}
And then I explained it, and she was like... she didn't know what it was. She thought it was crazy.

-Debbra (participant)
\end{abstract}

The following five chapters contain the analysis and reporting of data conducted in this study. It entails the third and selective stage of coding proposed by Creswell (2018). In being selected for analysis, codes have been organized into five overarching categories, each of which is addressed separately in a respective chapter. Narratives were quoted verbatim from the interviews in support of these five categories, often in full, so as to thoroughly portray the thought process of the interviewees. Some of these participants were thinking about several of the questions asked for the first time and needed room to articulate their thoughts verbally. The development of their narrative is often as important as the point they are trying to bring across in trying to choose appropriate terminology, imagery, and analogies. These quotes still represent a small portion of the collected interviews, which ultimately yielded about 300 pages in total. These represent the "golden nuggets", as it were, extracted from the original narratives. In other words, although I have constructed them sequentially as a story, I have let them speak for themselves. 
The first and present chapter begins by stating the demographics collected from participants involved in the study through the preliminary survey (Appendix C). It ensues by analyzing portions of the narrative that point to the generalities of participants' synesthetic perception of music notation. As Creswell (2018) proposes in discussing qualitative methodology, the objective is to "understand" rather than "explain" the phenomenon through the narratives.

This chapter goes on to explore details pertaining to the quality of their perception, awareness about their own synesthesia, other modes of synesthesia possessed by participants, and potential interactions with perfect pitch. The core of this portion of the dissertation reports on the surfaced issue of a conceptual basis for synesthetic perceptions of music notation raised by participants at different points in the interview process. In close relation with the conceptual basis of notation-to-color synesthesia, participants brought up examples of perceptual dependence on focal attention and interaction with yet other concepts deriving from music notation such as intervals.

The chapter closes by reporting participants' perspectives on occasional "romanticizing" and idealization of their condition, a mild difficulty in recalling childhood experiences, and various thoughts on the difference between sheer multisensorial perceptions that are common to people in general as opposed to what they understand as synesthesia and its unique, automatic, and consistent associations.

\section{Demographics}

In this section, each of the 12 participants is given a pseudonym that will be used hereafter to target specific experiences described in this analysis. The quantitative data reported in this section was collected through an online-based preliminary survey form 
that participants filled out prior to scheduling a live interview with the researcher. Table 1 summarizes participants' pseudonyms, identified gender, reported age, nationality, and native language. The order of participants reported on the table was based on the order in which they were interviewed and organized by researcher. That being said, this order has no correlation whatsoever with the data collected, analyzed, reported, or interpreted.

Table 1

Preliminary Survey Partial Results by Participant (pseudonyms)

\begin{tabular}{llllll}
\hline Participant & \multicolumn{2}{l}{ GenderAge } & Nationality & Native Lang. & Other Languages \\
& & & & & \\
\hline Iria & F & 29 & Brazil & Portuguese & English, French \\
Samantha & F & 26 & Canada & English & --- \\
Esther & F & 36 & Canada & English & --- \\
Daisy & F & 26 & Canada & English & --- \\
Kailey & F & 41 & United States & English & --- \\
Amanda & F & 31 & United States & English & --- \\
Zoe & F & 31 & United Kingdom & English & French, Spanish \\
Debbra & F & 36 & Canada/Italy & English & French \\
Alba & F & 21 & Canada & English & French \\
James & M & 20 & Canada & English & Czech, French, Gaelic, ASL \\
Heidi & F & 29 & United States & English & --- \\
Keira & F & 22 & Austria/Croatia & German & English, Croatian, Spanish
\end{tabular}

Although participants were not given a gender binary or any other pre-defined gender identifier in the prompt—but were rather openly asked about their gender identity — all participants identified as either female (F) or male (M). As the table shows, only one of the participants was male while the remainder identified as female. No specific nationality options were given to participants; The reported nationalities were stated by participants. 
The age of participants varied between 20 and 41, attesting to a rather narrow variance. Since the study was conducted cross-culturally, participants identified as belonging to 8 different nationalities, with the majority being Canadian or American. Since language transference between alphabets and music notation was verified in the literature review, participants were asked to report on their native language as well as other languages spoken, even if not proficiently. The preliminary survey form asked about participants' proficiency in other languages, but participants stated non-proficient languages as well. Some of the interviewed participants reported synesthetic color transference between languages, including music.

Table 2 accounts for the completed level of education and level of music education of participants. Levels of education across participants varied between high school diplomas and one doctoral degree. Participants also accounted for their level of music education, which ranged from amateur to professionals and doctoral students in the field of music. Participants also referred to their experience as music educators and music professionals in their narrative, which cases will be explored in more detail in the analyses below.

Table 2

Level of Education and Level of Music Education by Participant (pseudonyms)

\begin{tabular}{lll}
\hline Participant & Level of Education & Level of Music Education \\
\hline Iria & College or University & Conservatory (7 years) \\
Samantha & Master's Degree & Doctor in Musical Arts, Composition (cand.) \\
Esther & College or University & Bachelor of Music (incomplete) \\
Daisy & College or University & Professional \\
Kailey & Master's Degree & Ph.D. in Music Education (cand.) \\
Amanda & College or University & High school, college band, private lessons \\
Zoe & Doctoral Degree & Grade 5 and Theory Exam (or equivalent)
\end{tabular}




$\begin{array}{lll}\text { Debbra } & \text { College or University } & \text { Bachelor of Music Education } \\ \text { Alba } & \text { High school } & \text { University student, conservatory } \\ \text { James } & \text { High School } & \text { University student, professional } \\ \text { Heidi } & \text { College or University } & \text { Bachelor of Music } \\ \text { Keira } & \text { College or University } & \text { Music Pedagogy, violin performance }\end{array}$

As Table 2 shows, 9 out of the 12 participants involved have gone through higher levels of music education, although some higher than others. This certainly speaks to their awareness and ability to reflect consciously on their music notation-to-color synesthesia. Unlike gender and nationality, ethnicity was asked in compliance to the currently recognized ethnicities in the United States, involving: Hispanic or Latino or Spanish origin of any race, American Indian or Alaskan Native, Asian, Native Hawaiian or Other Pacific Islander, Black or African American, White, two or more races, or race and ethnicity unknown. The distribution of ethnicity among participants is shown in Figure 7. All participants identified as white, with the exception of one individual, who identified as Hispanic or Latino or Spanish origin of any race. 


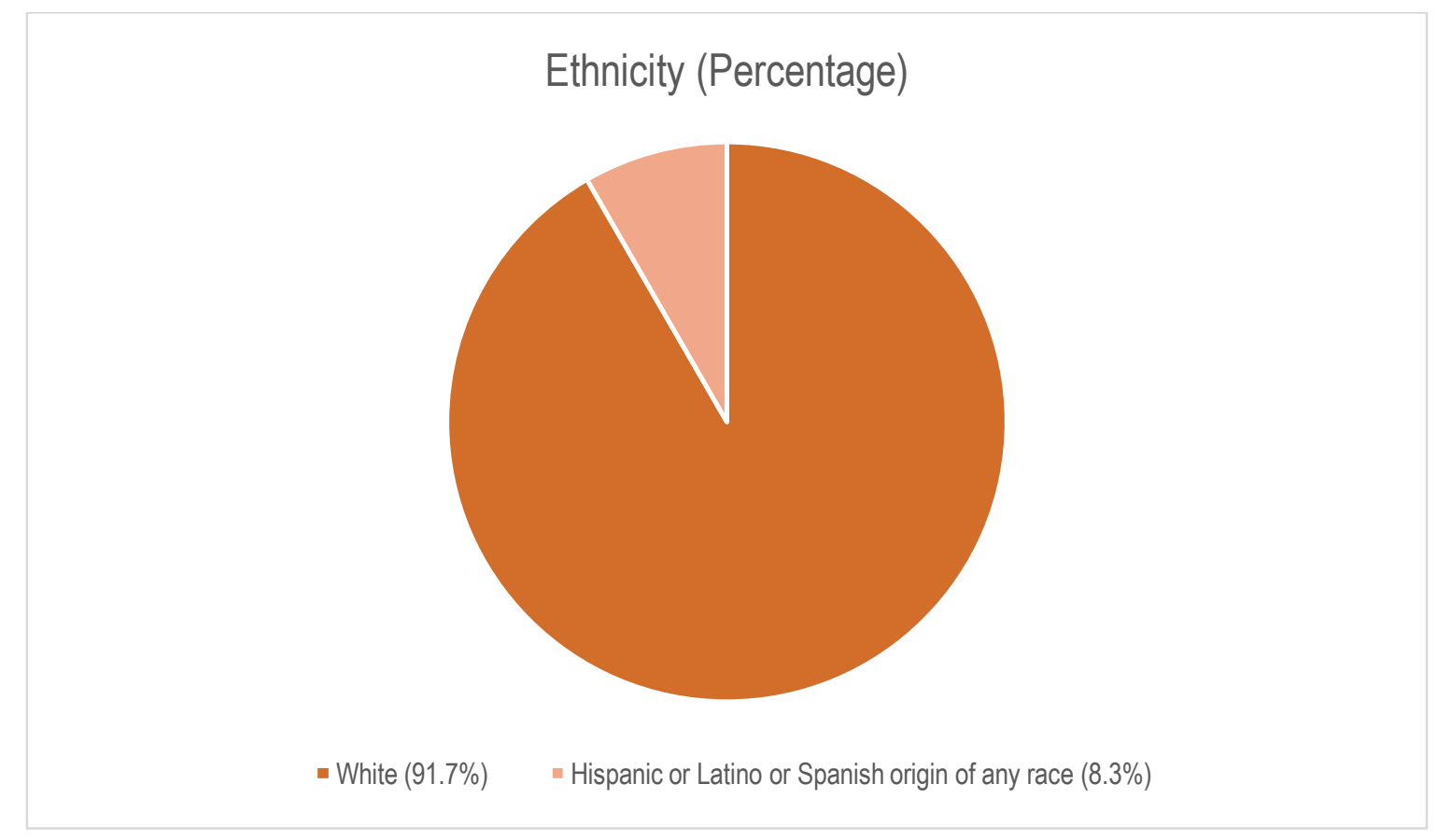

Figure 7. Ethnic distribution of participants.

\section{Quality of Perception}

When asked to elaborate on their synesthetic perception of music notation, participants described in detail their color sensations and how they relate to the different symbols on a page of music. Sheet music was made available to participants throughout the interview when necessary. Some descriptions were more vivid and detailed than others. Nevertheless, they generally expressed at length the perception of participants and several commonalities between the narratives were observed throughout.

When exposed to music notation, the participants reported having immediate synesthetic sensations of color. This is, to be sure, the main commonality between all the interviewed participants and a criterion for taking part in this study. Yet, the way in which color manifests and the concepts that trigger it are different for different 
individuals. For the synesthetes that associate specific notated pitches to a color, there seems to be consistency as to the resulting concurrent color. Daisy, for instance, says:

If so, for instance... if I see the note A within the staff, I immediately associated [it] with the color yellow, but it's only when I hear it with other notes that I can actually form a different color depending on exactly, like, what the key is... what the chord is...

James, on the other hand, sees colors for specific notes as well as for other elements on

the page. Synesthetes report seeing colors for symbols other than notated pitches, such as

the signifiers alluded to in the conceptualization of music notation in chapter 2 of this

dissertation (Figure 4). He states:

Yeah, there's definitely... there is a color for each note. And I'm starting to explore microtonal music which is kind of driving me crazy. So yeah, every pitch has a different color... But then, like, 32nd notes have a different texture tone to them than half notes do. And the same thing if it's like triplets, especially if it's a ... if it's a really strong... it's like three against two or another polyrhythm that changes the... it doesn't change the color itself, but it does change the other characters associated with the color. For example, like the way it's moving, the way it's moving in the lens, or the way it is... like geometrically if it has a crystalline structure or more of a milky structure. That's an affecting concept, I guess.

When I asked James if these sensations were consistent, he replied:

Yes, yeah, it's fairly, it's fairly consistent. The strongest one is E and that's always green. Basically, it doesn't matter what else is going on around it, even if it's within another ... another key center... It is green.

Elements on the page of music other than notated pitches also have a color for Alba and

Zoe, respectively:

Just seeing the shape of each note as a color or like the collapsed symbols, for example, or various performance instructions that would be written ... now, that would be letters [and] not so much musical notation. Not every element has a color per se. Like, I don't really think about the lines, having colors or like repeat symbols or anything like that, but anything that might, for example, have some connection to a letter, whatever color... so, like I said, the treble clef would be green because it reminds me of an S. The bass clef is kind of blue because it looks like a C, but it's also kind of black for a reason I don't understand. But the two dots are black because dots are always black. And then, of course, I would... when I look at a page 
of music, I would project the color of the letter I would see it as, but I would also kind of associate at the same time, like, weirdly. So I would more experience like a cloud of color in my head as well as projecting the color onto the note.

So the clef, the clef would because it looks like a C so it looks yellow. Oh, okay. That's only because it... like a C... Sorry. I mean, what would you call it? Bass clef? That looks like... Yeah. Not the treble clef. The other one that looks like a C... Yeah, the bass clef. Whereas a treble clef, I think, yeah, so a treble clef... does it? So I don't... I don't have a strong association, but I think it comes under the category of... of, like, I... I don't know how to describe this, but for... It can be black or red. A treble clef is the same. Like if you told me treble clef is black or red. I'd be like, "Okay", if you told me the treble clef was blue. I'd be like, "no, you're an idiot." (Laughs). But it... it could also be brown because the word treble is like a smoky brown. Okay, so yes, but I don't have it in the same way that [I have] for letters. Yeah, there are more options that feel right. And I don't know, I'm not... I'm not projecting in the same way of, like... I'm definitely seeing a thing.

Debbra sees colors for generic but highly specialized symbols such as "downbow" and "upbow" indications on the score, used to suggest the direction of bow strokes to string players, especially in an orchestra setting. Orchestra scores are usually filled with such markings above the notated pitches. Debbra says:

Yeah. So I haven't really adjusted to that very much. The downbow sign to me is black. I don't know why. The up... Oh, I don't know. I think it's like a lighter... I want to say gray. But it's... I don't know why I say that... But it's definitely not black like downbow. Those are definitely like a strong black, for me. And upbows are not.

Yeah, mine is like a faint green as well. Like it's not a strong color. Which is interesting psychologically because an upbow is like part of the note. So I don't know to answer your question like in music I think I do project the colors onto the page more than I do when I'm reading. But even when I'm reading, I still... there's some, there's some colors on the page, but it's more in my mind when I'm reading a book.

Another commonality found in narratives was the differing shades of color

depending on accidentals (flats or sharps). Daisy's experience is as follows:

I tend to have the same color... There's... the shade of it changes. So for B-flat major, for instance, if B is blue, I think I mentioned, B-flat would be like a haze of the blue, like, maybe a lighter or darker. Definitely with A-flat Major, I noticed that my A is yellow and then A-flat is like a mustard yellow, so it changes to a darker kind of yellow. 
Heidi sees another color component depending on the presence of accidentals:

But I'm always... I'm always... I'm very interested in how people conceptualize... If a note is sharp or flat... Like, for me, if... if theoretically in a key if a note is flattened, I imagine sort of a ... it's sort of a light blue haze over it. And for sharps, for me, it's also kind of a haze. But it's really strange because it's like, um, you know how when you look through $3 D$ glasses, there's that kind of like red and blue blur with that, but it's not red and blue. It's like a rusty color and chartreuse.

While the shades do not change for Amanda, she experiences a different intensity to the tone depending on the rhythmic value of the notes.

Sometimes, so, for like a half note or a whole note. Those will be light brighter because the inside of a note is white, and for some reason that picks up more color for me. So I've noticed I don't see any on that page. But like, for example, some of the most colorful things on this sheet are the treble clef and the time signature. Because they have more white in them. And so, I think it just brightens the color.

Keira shades also intensify according not only to note value, but quality and color of the paper.

And moreover, it depends on the note values. The whole and the half notes are more colorful than the black notes. So the blacker the note value, the less colorful it is. If it is more black and the color is not that present. Another aspect that influences my synesthesia is the paper quality and type of edition. The closer [together] the lines and the more musical instructions there are at once the less colorful the notes are, so it's more black or gray. And the other way around is the opposite... (indistinct)... the more colors there are. It's the same with the paper quality. So the grayer the paper, [as in] copies [copied music], for instance, the grayer the colors get. So it also depends on the quality of copy for instance. And the colors more or less disappear. But, still, I have them in mind. Yes, in my mind.

Keira's shades may change depending to the range in which a note is situated as well.

And the higher the position of the note the lighter the color gets. On the other hand, the lower its position, the darker it gets.

When asked about potentially importing colors from the letters of the alphabet, participants reported different perspectives. Alba says she did not import them from letters of the alphabet: 
But I'm not saying that I learned my specific colors from any sort of letters. I think that's just how I view them. Yeah, yeah, because the names have always adopted the color of the letter, the graphemes have always been the strongest.

Amanda, on the other hand, has the same colors for her alphabet letters as well as musical notes:

Yeah, so I'm going... I look at a page of music. And each note has, it's kind of like in between projected and associated, you know, though it has color. But and it's basically, I think it's pretty much the color of the letter. So D, the note D would be purple, because the letter D is purple. And then when I play it, it kind of just fills the room with that kind of color.

Debbra's letters of the alphabet, in turn, are the same as the musical notes that they name, with the exception of E. Because she cannot identify the source for the single deviation from the norm, she states that as an odd instance for her:

But I think because I started music so young... because I knew what the letters were in the music... I just automatically connected those letters with the letters of the alphabet. So when I see those notes in music, even though it's not an E, but it's like a whole note E, a color comes to mind. Now it's really interesting that we're talking about $E$ because most of my colors are the same. So like $A$ is blue for me, $B$ is orange, $C$ is yellow. But then in... in the treble clef, like those spaces and lines, are those colors in my mind... But, I mean, like, not in real life, but in my mind, I see those colors on the staff but then $E$ is the only one that's different in music for some reason. It's green in music, but it's blue when I read, like from words. So I don't know why that happened. But it's an odd one, but mostly, I think that the letters of the alphabet that I had in my mind are the same as what's... what they are on the staff in treble clef. And then, same for bass clef as well.

Contrarily, Keira says she might have learned to read notes before reading the letters of the alphabet.

I think I could read notes... maybe even before I could read letters. (Chuckles). Because she learned music at home at a very early age and from her parents, who were also musicians, her graphemes might have been learned after she already knew musical note-names. 
Interestingly, two out of all twelve study participants did not see colors for specific pitches. Kailey and Esther reported seeing colors in other ways. Kailey only sees colors for written graphemes on the page, such as dynamic markings like piano $(p)$, forte $(f)$, mezzo forte $(m f)$, etc., for instance:

I mean, I know that $\mathrm{p}$ is always pink. So, at like $\mathrm{f}, \mathrm{p} . . \mathrm{f}$ is always... well, it's funny to me... [it] is actually purple... but on a page, it's black. Mp, kind of I recognize that they are pink, but I don't think I ever even think about it. I don't know, I've never really thought about it, because I guess when I'm looking at music... I don't, actually... it doesn't trigger anything.

Esther does see color in relation to specific notes of the scale, but not in the way described by most participants. Rather, she sees colors in relation to the range in which they are notated on the page of music. When shown sheet music with notation, Esther reported:

Not the specific notes. It's more of ranges, I would say. Yeah. (Laughs). Yeah, I mean, most of this would be kind of lower, earthy. It's not the lowest but it's like... I'm trying to think the right words... up to like, the high $C$ and above, I start to see like an atmosphere almost and get kind of more of, I don't know (laughs)... Like things floating around. And lighter colors, maybe. Not always, but different textures, whereas there's like a denseness and a darker kind of feeling, almost a sensation to, like, the lower notes...

Esther accounts for her perception between chuckles and laughter.

These general qualities of perception already suggest the prominence of a conceptual basis, as later sections of this chapter will point out in more detail. Yet, there are cases in which specific notes do not generate a color, but other elements such as range, do. Dynamics, clefs, time signature, etc., have also yielded a color association to some of the participants. 


\section{Awareness (About One's Synesthesia)}

Some of the interviewees have reported a rather early discovery of their

synesthesia and some degree of awareness about its effect on their daily activities,

especially in the context of music and their music education. Debbra and James both find

it a little difficult to articulate, but state they learned about their synesthesia at a fairly

early age. Debbra reports some support on the part of her mother, upon finding out about

synesthesia:

I didn't, like... I knew it was in my brain. But I didn't know that. Like, I didn't know other people didn't have it. So I thought... I thought I was normal. And I thought everybody was, like... had it until one day on the way home from a like a violin lesson or something, my mom and I were in the car, and I think I was around... Like it had to be like 12 or 13 years old. Where I just like asked her a question about B being the color blue, because for me, it's blue. And she was like, "What are you talking about?" (Laughs) And then I explained it, and she was like, what I... she didn't know what it was. She thought it was crazy. So anyway, we... she researched into it and found out that, like photo-synesthesia is a thing. And then I could like... then that's... I guess, when I was 12, or 13 is when I first realized like that I had synesthesia. And then ever since then she, like, tried to give me articles on it and, like, whenever there was information published about it, she would, like, give it to me and stuff. So, um... I guess I knew, like, as a teenager, that... what it was, but up until then I, like, I just... I knew that different letters were different colors, but I didn't know that other... that didn't happen to other people.

Admittedly, synesthesia may be difficult to articulate or understand if the concept is not coined by others. This is apparent in Iria's perspective:

I'm not sure what came first: if I really had synesthesia [color associations] just by myself [naturally] or if I learned something after [that] in school. So maybe my brain just related those, so I'm not a hundred percent sure.

Both Alba's and James' discoveries of synesthesia were connected to personal reading that they conducted on their own. Alba's discovery of synesthesia was spontaneous and took place before her going to university - therefore relatively early in comparison to some of the other interviewees: 
I don't think I realized I had it until I was in more high school age. So, no, because I only really, well, I didn't really realize I had synesthesia until probably first or second year university. Um, I remember when I was in high school, I think I told you about this. I read this book about a girl who had synesthesia. The name of the book, it's a manga... it's called Ultraviolet, and I can't remember who it's by. But it's a really interesting book. I think you'd find that cool. And I was reading and she was talking about all these colors and I remember thinking, "well I know $A$ is pink, $B$ is purple and $C$ is this..." but I never really thought about what the rest of the letters were and I'm like, you know what... sometime I should just sit down and I should just, like, write down all what these colors are and just, like, draw them out in the color they are, but I never really did it at that point.

James's personal reading on synesthesia seems to have been related to more technical

literature on this neurological condition:

Yeah, I guess yeah, I, I don't necessarily remember... I remember linking this ... some of the music memories I do have color very strongly associated with them ... even when I was like 2, 3, 4. But I didn't know it was a thing. I guess I probably found out about it when I was... Well, yeah, somewhere around 12. I was reading, reading memory... about the memory competitions, about synesthesia, in that sense, especially associated with numbers at that point. And I realized and I found out about it in music as well... I kind of realized that that's... that's a thing and then became conscious of it and I don't know whether I developed it further or just sort of discovered what was already there.

The causal condition for Heidi's discovery of synesthesia is rather rare among participants and is, in fact, one of the issues targeted in this dissertation, namely the broaching of synesthesia stemming from a teacher's prior awareness about it:

And it was around that time that in another one of my classes, I think it was a teacher. We were just having a sort of fun day. And our teacher did an activity with us. It was one of those things where color words are written in other colors, and you have to pronounce the color that the word is and not what is written. She sort of went off on a tangent about synesthesia, and about... "oh, some people see letters and different colors or experience letters and different colors", and was talking about it. And I'm like, "oh, yes, I do that." And then I didn't really think too much about it more at the time. I thought it was, you know, it's kind of like your nose... you see it... your nose, all the time, but you kind of forget that it's there. 
While this is a desirable condition, however, it unfortunately falls outside the norm in the lives of synesthetes. As the next section explores, some of the participants report having heard about synesthesia only well into their adult lives.

\section{Late Discovery}

Both Amanda and Iria attested to this delay in learning about their condition and trying to make sense of that experience in relation to others. Especially non-synesthetes:

And I didn't know I had synesthesia until I was 22. So even though all this was happening, all growing up, I had no... I didn't know... you know, I didn't know anyone else who experiences that. So it just went under the radar. But once I realized it was something that was happening, I couldn't believe not everyone-like, with the tuning note-wasn't saying, like, the room filled up with gold!

Actually, I didn't know at the time that this was, like, special or [a] different condition. I found that it was just the way my mind works. So, when I really realized that it is not for everyone, I was surprised. Because for me, everyone had this color thing for music and for letters, for example, as in my case, and for numbers and stuff in general (chuckles).

Late discovery is naturally observed among some of the participants due to one of the criteria for engagement in this study. Since they are all adults with a rather little variance in age, they were likely to still experience an educational system that is vastly unaware of their condition at the time when they were introduced to music. In Iria's specific case, coming from Brazil — my own country of origin — the poor condition of education and instruction still pervading the nation at large is certainly an aggravating factor to consider when it comes to awareness on the part of instructors. Teachers are often unequipped to assess and address conditions that impact cognition much more significantly, such as ADHD (Bédard et al., 2010) and autism spectrum disorders (Mottron et al., 2006), let alone less document neurological phenomena such as synesthesia-especially during the 1990s and early 2000s. 


\section{Other Modes of Synesthesia}

Seven participants remarked on other forms of synesthesia they possess.

Grapheme-to-color and number-to-color were common among the interviewees, although

some did not manifest these modes. Daisy, for instance, only has synesthesia that is

strictly related to music. In this sense, there was considerable variety as to the extent of

multimodal synesthetic experiences observed among participants. Yet, some of the

interviewees clearly reported being multimodal synesthetes.

Amanda's and Zoe's synesthesias were the largest-spanning in terms of the

number of modes. Both reported having tickertape as well as multiple other forms of

synesthesia. They stated, respectively:

So, I have the grapheme-color and so that's anything that, you know... symbol wise. So, music, letters, symbols, numbers, and I have ordinal, linguistic personification, so, and then also object personifications. So symbols, letters, numbers, and then anything really who's going to have, like, a personality... It often has to do with kind of the combination of shapes that it's made out of, because circles are certain, you know, girl, they're yellow and... So, and I have that and then spatial sequence so, time, shoe sizes, numbers, the alphabet, literally anything will have, you know, that kind of a map. Yeah, year goes around me like a colorful ribbon. Um, what else? So, the sound... so pretty much any sound is going to have kind of like a... a mark or a shape. Sometimes listening to music, it's not like some people with their synesthesia... where they're like, "yeah, this is the colors are so trippy and amazing"... And mine's more just kind of a boring, like, some color and kind of some, like, hash marks and some, you know, dots and it moves along to the time. And then the tickertape synesthesia, it's kind of related to that. So, you know, I see all the sounds that are made if they happen to be or, you know, words, then they're... they're spelled out.

Yep. So letters, numbers, days of the week, months... but I also have quite a few other types in terms of... I have some degree of... was it ordinary personification...? Or whatever it's called, you know, where you have gender and characters attributed to numbers. Definitely. And letters do have gender... ticker tape. So when you're speaking... when I'm speaking to you, I see all the words in my head, you know, have a very vivid "mind's eye". Calendar... that's a very specific kind of shape.

Occasionally, I do get some with music. So, if there's, you know, a particular phrase or repeating riff or something that will... that will appear colored in the shaping, I see it as a cone shape. But that doesn't happen very often. It's... Yeah, it's so new. It's 
very infrequent and nothing seems to be... no, I can't tell you why certain things that have that have a kind of runoff, but yeah, otherwise, I don't have any other kind of musical synesthesia.

Although only Amanda's and Zoe's synesthesias were reported here, several other participants brought up grapheme-to-color and number-to-color modes of synesthesia.

\section{Perfect Pitch}

Only two of the participants of the study-Iria and Keira-reported confidently on the relationship of perfect (absolute) pitch and a synesthetic color-based sensation to music notation. Absolute pitch is defined as the ability to recognize a frequency promptly, automatically, and accurately upon hearing it. All other participants did not have perfect pitch, although some reported having a good relative pitch. Since 9 out of the 12 participants are engaged with higher levels of music education, it is expected that they reported having an average-to-good relative pitch, as that is often a requirement through different courses in a music degree, such as Music Theory, Musicianship, and various performance courses. Relative pitch is also an important skill to have as professional a musician and is, therefore, encouraged and nurtured in music studies.

Although the presence of absolute pitch is tangential to this research, some of the participants alluded to it in talking about their notation-to-color synesthesia. Perfect pitch may also interact with notation-to-color synesthesia in the perceptual process. In pondering about the relationship of her absolute pitch with notation-to-color synesthesia, Iria recalls:

This pitch thing [absolute pitch] is natural as well as the color process for me, so, I don't know how... I just really know that a note [is or] is not the note, I don't need the color for this case, I think. 
In Iria's case, there seems to be an interaction between recognized pitches and notation. They have the same color for Iria, suggesting both consistency and their conceptual basis in her experience. The interchangeability between these two conditions, in any case, is apparent in her statement.

Samantha, like the other participants who referenced absolute pitch even if they did not report to have it, remarks on her relative pitch:

So, like, on the page, of course, I see them, like... because I'm a pianist, like I said... so I have kind of, like, on the piano, I associate like, you know, the way the keys are laid out, I associate them with like, the colors, but also, like I don't have, like, perfect pitch, but I have, like, a really, really good relative pitch. And I think that's mostly because, like, when I hear a note, you know, my whole life growing up when I hear a note on the piano and have that color, and then if I hear it on the piano without, like, actually seeing what note it is or knowing, but I'll get that color and then it's like okay, like that's a... that's a G because I know that color is $G$...

The intriguing aspect of this statement is that Samantha seems to be able to recognize a heard pitch based on the color sensation she has. The color sensations are the same for both the heard pitch as well as the notated pitch, suggesting a conceptual basis once again. Yet, if Samantha is able to recognize the color of a heard pitch, in knowing what color a frequency is, she would be able to tell what note that pitch is. In other words, her colors also seem to work as a form of absolute pitch for heard notes, while remaining consistent with notated pitches. In her narrative, however, she seems not to be aware of this realization —at least not to a conscious level.

James' relationship with the concept of absolute pitch is similar. He states that he can recognize heard pitches sometimes based on the color they yield when he hears them, but he does not seem quite sure about it:

I don't know, because I did have it. I developed it and had it for about two years. And then I stopped practicing. I stopped thinking about it, and I haven't, I haven't really 
used it. So I don't think I have it accessible to me right now, but it may be somewhere in there.

He also says he does not use his absolute pitch consciously:

I don't think to utilize maybe in that in that sense, but it is absolutely. And I can, especially when I hear a song. Maybe that I don't know, but within an idiom, which I do know very well, for example, with the fiddle music that's involved in... there is an emotion. I don't have to look at their fingers. I don't have to look at what they're doing to know what key... The song is in... It just is that key. And that's, that's what I have the strongest color sensations is when the song just it just is, in a sense.

It is difficult to determine Samantha's and James's absolute pitch without further testing, but their ability to recognize a note from the color a pitch yields is certainly a noteworthy feature of their synesthetic perception.

Heidi and I elaborated on the topic further during our conversation and discussed the recurrence of this mediated indication of perfect pitch, allegedly done by a synesthetic sensation:

And as time went on, I, you know, I kind of realized that those concepts applied to other things... as I know your study specifies music notation ... but to me, I don't have... I don't have perfect pitch. Seems like, if I, if it triggered a specific response when I heard that, it would seem like I would know... Like if I had... if I... If it triggered, like, the burst of bright teal ever every time somebody played an $F$, which might not break people, but just you know? Like, it seems like that would be so constant that you couldn't ignore it. It seems like even if you knew nothing about music, you would be able to, you know, you would be able to easily put [the two together] "Okay, every time this bright teal thing is there. It's like, well, somebody could just come up and tell me" We'll just instead of say bright teal thing say that's an $F$, right or... Yeah...

After she concluded this thought, I remarked on the fact that this would indicate absolute pitch, to which she agreed. In this sense, it is possible that both James and Samantha also have perfect pitch, yet they do not use it without the mediation of their synesthetic colors and possibly not at a conscious level. 


\section{Conceptual Basis}

Issues pertaining to a conceptual basis for synesthesia surfaced in response to different prompts in the semi-structured interview. Several instances were, however, not at all prompted by the interviewer's questions, yet participants mentioned them in detail. In response to one of the first questions of the interview, to do with the quality of her color impressions of notated elements, Zoe offered the following perspective:

So, they... they definitely did at the time, because for me, it's sort of conceptual. So, $A$ is yellow. So anything that means $A$ will appear yellow on the page. So, and it's the same kind of the concept of five is blue, and therefore doesn't matter if it's a dice pattern or Roman numeral, or even you holding your hand up like that (shows hand indicating number 5), if I kind of, if I interpret it as five, that will be... that will be blue. So, it's the same four notes in that, you know... I knew then... I now can't remember which one is which, because it's so long ago... But, you know, if I'd saw in a note it would the actual, you know, physical thing on the page would appear yellow.

She also speaks of the essence of notes as the trigger of her color associations:

So if you had, like, a B coming through a cloud where I couldn't see the B properly, it would only be a B once I could see... it was a big like... Oh, it's a big... so it looks blue. So it's exactly the same... it's... it's the B-ness of it that makes it blue... you know, me seeing it, interpreting B makes it blue. So again, you know if, if there were if there were notes, musical notes all jangled over the page and I couldn't be sure what was supposed to be... they wouldn't have colors, it would only have a color once I knew that was a note. So it looks yellow.

Zoe alludes to "meaning", a term that is difficult to define, suggesting that only upon recognizing a concept she would have a color-based synesthetic sensation. She uses an example from language transference between English and Greek (which she learned for a bit) to demonstrate the conceptual basis of her synesthesia:

It's... it's the meaning... if it means that, you know... if I had to learn a new language where triangle was an A. I think the triangle would start looking yellow... because I would... yeah, exactly like the ancient Greek. Yeah. Yeah. Because I remember thinking when I first saw it, I thought it was, you know, like a Y, watery gray because my $Y$ is that color and it looks the most like that. Yeah. So, when I learned it was gamma, then it became orange. 
The notational concepts that trigger colors have never changed for Daisy, demonstrating not only automaticity in relation to these concepts but also consistencyboth of which are synesthetic features.

Yes. So, it would automatically come and it would tend to stay, like, I think I developed the foundational colors. In middle school when I first started music, I don't think that they've changed drastically since... since it started...

The most illuminating quote in regards to this recurring conceptual basis of notation-tocolor synesthesia among the participants of this study was delivered by Debbra, who, in recognizing her lack of absolute pitch, described her process of conceptualization of notational elements before they finally adopt a specific concurrent color sensation in her perception. Her account shows similarities to what Zoe shared. Debbra states:

So, like, if I don't know the key, it's just like... you know what, for me... actually, it's the color of the instruments. So, like, if I hear like warm luscious, like string music, well actually like as a string player, like I can usually tell like if I hear certain notes when either and because I can tell what string they're on, or if I hear an open string, I can. So then usually, I do figure out the key but if, let's say, like it, let's say if it was like, choral music, or let's say, if it was like symphony music, and let's say there was this really bombastic, like, brass part in the music. Then I would think yellow because, like, brass instruments are kind of, like, shiny yellow, and then, if I heard like a cello solo, I would see brown because the cello was brown. But then, or if I heard a clarinet solo, I would think black because the clarinets black, but then, if I knew the key, though, it would be different because then I would know, like, tonic, dominant, subdominant, and I would start analyzing the harmony using the colors of the letters of the notes. And I'm not saying I could figure out exactly every, like, inversion of what chord or anything like... I'm not that, like, detailed with my ear training... but, um ... but just knowing like, we're in this key, and then it goes to the dominant and then I feel like, "okay, well", if we were in D major in our, like, in a major harmonic section, "I feel more blue"... because.. it's like in that key center, I guess. Yeah, if I know the key. But if I don't, if I don't, then I just think how the music makes me feel or like I think of the instruments that are playing.

The concept of a note goes beyond the page- - beyond the notational symbol. The concept of a note seems to trigger the color, whether it is on the paper or identified as a sound. Keira concurs, in explaining her notation-to-color: 
... as long as the note is definable at first sight. So, if it's too high or too low from... from the "positions" point of view, it doesn't have any color. But when it's definable at first sight, so it automatically has its color. But if I define the "undefinable" note afterwards (chuckles), it automatically gets its color.

Once more, it is her recognition of the notated pitch as a concept that elicits her colors.

Heidi's description of her notation-to-color synesthesia surfaces some similarities to the

experience shared by Debbra and Keira:

And as time went on, I, you know, I kind of realized that those concepts applied to other things... as I know your study specifies music notation, but, to me, I don't have... I don't have perfect pitch. (...) So, pitch to color is not really a thing for me. It's more like the individual concept of a note of a color and even things like the theoretical concept of it being sharp or flat affect I get, I guess. But yeah, it's more of it as a concept whether, you know, regardless of the placement on the staff, whether it's no treble clef or bass clef, or any kind of movable clef. It's just the concept of that note.

When asked to elaborate on her perception, Heidi offered a well-structured definition of

the conceptual basis of her notation-to-color synesthesia. She said:

Um, I don't know if I, when people say do you see the colors on the page? Like I'm looking at the page. I can logically tell you this is a black and white page of music... if you know if somebody's holding a piece of sheet music over here, and I'm just like, you know, I like look at it and then I look back. No, but if I'm sitting here... and I sit down... and I'm going to sight read the piece. And I'm going, you know, just through each, yes, each... each note. And each, you know, if there's accidentals there. Yes. This is just one point to be, like, little microburst as I read across the page. (...) It's nothing in my eyes... It's all up here (Points at her head.) When I, you know... I look at the notes flowing across the page and... you know, even if it's a fast passage, I still have to, I still have to internalize the note and, you know, it comes and it goes to here. (...). Um, when I got into college and like before, I had never really had any need to read another clef unless I was just, like, looking at a friend's music in class or something. It was always treble clef, but I understand it. I understood the concept of bass clef and movable clef from, you know, talking to people who played other instruments and looking at piano sheet music and I understood those concepts, but I didn't really face that until I got into college and I, you know, I did have to sit there and, you know, actually be able to fluently read and, like, bass clef to get my class piano assignment done or, you know, if I had a theory teacher who was... he was kind of mean, he would want us to, he would, like, time us to analyze a piece of music and, you know, then my brain would get a little scrambled but once I, once I kind of got a little bit more used to it, it's like, okay, yes, these... the concept of this note does 
retain the original color of it... (...) When it gets down to it, it's not so much the placement of the note on the staff. It's the concept.

She suggests that she would primarily see the colors black and white, which are normally the colors featured in a page of music, especially if looking at it at a glance. The color is not in the perception of the ink, or in her eyes, as she puts it, but rather in her mind, as she processes the graphemes.

Conversely, Esther's and Kailey's experience of musical notes notated on the page is not related to color, as I have indicated in the analysis of qualities of participants' perceptions above. This raises questions as to the extent of the conceptual basis of these experiences. Esther and Kailey still see other elements on the page, however, that do trigger sensation conceptually, such as numbers and letters. The conceptual-basis of their synesthesia may be selective depending on the circumstances involved. A definite conceptual basis seems to be present for letters and numbers on the page for both Esther and Kailey, but not for specific notated pitches.

\footnotetext{
Attention

Along with the recurrence of a potentially pervading conceptual basis of notationto-color synesthetic perception among the participants in this study, several mentioned the role of attention in experiencing music notation. Their synesthetic perceptions seemed to come to the forefront of their awareness in function of the elements that are enjoying primary attention at a given moment. Their colors seemed to shift often, depending on the primary focus of their attention. I asked participants to expand on how they would perceive different notes belonging to one chord (harmony) or to one sequence (melody).
} 
The responses differed widely in quality, but the overarching principle of focal attention was resonant across the different narratives.

In support of the conceptual basis she identified in her own synesthesia, Debbra proposes that the concept of the root of the chord (the most important note of the chord, or the note that gives it its name) plays a fundamental role in terms of color prominence for her:

I think I would... I would think of all the colors but the first... the bottom note would have the most, like, priority... so, if it was in root position ... for me $C$ is yellow... like, yellow would be the biggest color and then since it's $C$ major, like, this bright green because it's the major third, because E-flat is a different color because flat for me... This is weird. I don't know why but flats are orange. Oh, so... E-flat is like an orange and green mixed together. So, that would make it minor. So, if I'm playing a $C$ major chord, it would be like a bright green. But still the yellow of the $C$ is like more important and then the $G$-the red of the $G$-is, like, less because that's the order of the arpeggio. But, like, let's say it was, like, a double stop and like the root was... or the triple stop... and the root was not the lowest note... I think I would think the lowest note would be the main priority. But that's... but I always had trouble with double stops as a violinist. (Laughs). Because, they're so hard (laughs) and also because like, I would probably prioritize the lower notes color and not so much to the higher note, even though I should have, like, because my mind needed to, like... what I needed to do was more... And I probably did this near the end of like my university days, but like, in the beginning, when I was learning double stops. I think I didn't prioritize the tuning of the top note as much as the bottom note. So they would be like out of tune, it would bother me and it's like, it's my, like, higher note that's out of tune. Like why can't I just get that in tune? Because in my brain, I'm thinking more the lower note because the color is like more priority, because that's like the root of the chord or something. So, what I would really need to do like get those higher notes in tune is like practice the double stop separately, obviously, and then like equalize the priority that the colors take in my mind.

James and Samantha propose the role of attention in their perception of notation:

[In an E minor chord], the E is automatically more prominent as the root... Now if I were to change that and say do $G, B, E$. Then I'm thinking More of the emotion of like a $G$ with a six. And then, we sort of at that point we come a little more to the brighter blue. And E definitely fades a little bit more. But... interesting... it interacts very strongly with the other notes still.

No, I like... kind of like, see it as the sum of all the colors in C major, like the root probably would be the dominant thing I associate with that. Yeah, there usually is 
one that stands out is more prominent. It always depends on, you know, whatever I'm looking at or whatever the context it's in... But yeah, I usually do have a prominent color when there's like more than one thing going on.

Heidi emphasized the role of her attention in explaining where she "focuses her ear", so

to speak:

Yes, the root does sort of take over... the root does take over the color of the chord... especially... but I've been focused for so many years on a melodic instrument, the flute. And I'm, you know... I was in college, I had to take things like piano proficiency and whatnot, but I didn't really want to think about what I was doing. I just wanted to get the exercise done and... but I'm now with guitar that I'm actually kind of more interested in learning a harmony instrument, and I'm getting into things like playing chord melody. And understanding that things are very... everything I hear right now is very root. Like the whole chord is like in this haze of whatever the root color is. But some time when I sit down, and I examine that chord and I examine each degree within it. It's like yes, the, the original colors are still there. It's kind of, like, there's this... if there's this sort of little cluster of all these... all these notes like they normally are, but there's this sort of haze of either the root... or sometimes if it's an inverted chord, you know, whatever's in the bass or whatever, yeah... It just kind of depends on, like, what part of the voice-leading my ear is focusing on and on kind of what's there, but usually... usually it's the root of the chord. Especially at the stage where I am now where I'm, you know... you know, playing bar chords all over the thing and just trying to... trying to figure out how to move my hands around.

When I asked Alba about the prominence of the color of different pitches on the page

when belonging to the same harmony. She answered:

Depending on how I understand it theoretically. Or, like, if I understand as a C chord, I will see the C. But, in my Ravel [a piano piece by that composer] I did recently, there was a lot of big rolled chords and I always visualize it as the root of the chord, but sometimes... sorry, the bass note... which sometimes was the root. Yeah, it was just kind of the starting note of the chord that stood out to me the most. But if I'm thinking in theory, and I'm like analyzing each chord, then I will see the color of the root usually. And sometimes I'll also see, like, all the colors of the notes within that chord. And I'll also always visualize that on the piano, and that's probably a normal thing.

When I asked her to expand a little more on her experience, she offered further insight:

Um... I probably, while, like, depending on if I was paying attention to the colors, I would probably more see, like, the outer voices and such, the colors of the outer voices, rather, just because that's the easiest for me to, you know, locate on the 
piano... just go to the outer voices. But I don't always, you know, just think immediately... "Oh, that's an E chord". And just, like, "that's E. Play that".

Keira concurs with Alba's experience by stating:

And my sheet music to color synesthesia also depends on the complexity in harmony. For instance, if a piece of the classical era is in D major, the whole sheet music is orange colored, but the notes themselves still have their own colors. So, the background would be orange in D major because D is orange. But the more complex the harmony is, the more importance every single color gets. That's also the reason why I love music of the late romanticism the most, because music is so colorful.

All participants described the prominence of color as manifesting in much the same way. The root of their chord was more prominent since the chord is called by its name in tonal harmony. However, they saw individual note's colors depending on which of the other notes of the chord they were focusing attention. Although the explanations varied and may have had different contexts, the importance of focal attention on a specific concept (or note, in this case) is clearly recurrent.

\section{Intervals}

One participant mentioned colored intervals in detail. Debbra says that until she recognizes the note as a given concept by looking at it on the page, she will have overall impressions of the colors of her intervals, which are the same as the colors of her numbers. Debbra says:

I just thought of like another question ... because I've been teaching my students intervals right now, like, this past couple of weeks in terms of like ear-training and how to hear intervals within the octave in grade nine. And so, like, for some of them, they've done this before, but for some of them, it's their first time learning this. And so how do you like... in your mind, "how do you know like, if it's a perfect fifth or whatever? "So, I've taught them many different ways, because there's like so many kids, like... how do you know which way works for each kid? ... but like, one way is, like, the do, re, mi, fa, sol. Another way would be like, in what I used to do, is 12345 of the major scale. So I use numbers, which is weird, but it's probably because I didn't know what the pitches were. And, so, when I hear about Perfect Fifth, I hear green because five is green. 
Now, for like minor [interval] and like augmented and things like that. It's a bit different... but just for, like, the main intervals it's just the colors of the numbers...

... When I'm hearing music, okay, like, I don't really know what the key center is. So like, I just hear music and I hear, like, the colors of the instruments. But then if like an interval pops out, I'll hear that interval is, like, that color. Or, like, if I know... if I figure out, like, what the chord is of one note, they'll be like, "okay, now I know we're in D major, it's pink", or something.

Once again, the conceptual basis of Debbra's synesthesia is confirmed by her dependence on identified concepts, in that she needs to find the meaning of the notational or heard symbol before she experiences a specific color. Moreover, colors will change in her perception as she is able to identify new elements, thus substituting the first impression she had experienced.

\section{Romanticizing (of Synesthesia)}

Three additional, yet mildly recurring themes with significance for this study are discussed in the remaining portions of this chapter. The first is participants' mentioning of a romanticizing and over-idealization of synesthesia on the part of some artists and the media. Samantha demonstrated certain displeasure in her tone of voice when I asked her if she uses her synesthesia creatively as a composer.

Yeah, I like, whenever I tell someone I have synesthesia, that's the first thing they ask me. And it's like I do, but I don't think I do it in the way people would expect. Like, I'm not trying to paint a pretty picture in my brain with it.

Heidi mentions certain annoyance in passing, while referring to her sister's attitude toward synesthesia:

Yeah, I try not to be "woo" about it because I, I have a sister who is a synesthete as well. And she's very "woo" about it.

Amanda elaborates a little further on it: 
I think it's totally romanticized and I think that maybe when synesthesia was first kind of hitting the world as like, more talked about thing and these books came out, children's books, and it was very romanticized. And it's like, oh, so we just can identify these children and they'll and they'll find out and they'll just be so much more understood and it isn't so great that they see the world this way. And you know, it doesn't look that cool, like... (Both laugh). The music like I see... Yeah, I see it but it's like it could look a lot cooler in my opinion. And yeah, I don't think that ... Yeah, the... Yeah, I think you said it perfectly. An orange is orange. It's cool but [indistinct].

She seems to indicate that synesthesia brings about just one more layer of meaning to percepts; and that does not necessarily overwhelm a synesthete. Neither is it a necessarily remarkable aspect of her experience. From her statement, it seems that the reason for that is rooted in synesthesia's consistency throughout one's life experience. In other words, synesthesia is, to the synesthete, ordinary.

\section{Difficulty in Recalling Experience}

A certain difficulty in recalling educational experiences from the past accurately was voiced by three participants. The difficulty was not connected to the synesthetic experience per se, but with the recollection of the music instruction scenario. While they recognized that their synesthetic colors for notational symbols had always been the same, it was difficult for them to remember examples that elapsed in their early stages of music education. Iria, a cello player in her childhood and teenage years, states:

The problem is that I don't play music anymore a long time ago. So, I'm not sure now. If I was still playing cello, I don't know - I [sold] my cello a couple of months ago-so I'm not playing anymore recent.

Esther, who changed her career path to an area other than music during university, said:

Um... I haven't even looked at a piece of music and so long... (Laughs) It's mostly like I know vividly sound like listening to music and sound has been the biggest thing. There's like, no question. So that's that would overtake like everything. But I don't remember. If I have notes in my head when I would read music, it would 
probably have some effect. Yeah. I guess. I don't know. I'm really out of touch now. But (Chuckles), yeah, I guess.

And Kailey, in spite of her extensive background and experience as a music educator, found it difficult to remember exact examples for the purpose of the interview.

Maybe later, once I knew more of what I was as a musician, but as a kid, I don't remember any instance of that. That's a good question. I just don't remember.

Their recollection seems to be based mostly on the notion that their music notation-tocolor synesthesia has remained consistent throughout their lives.

\section{Multisensory Experiences vs. Synesthesia}

The fundamental difference between multi-sensorial associations understood by people at large and actual synesthesia was evident in some instances among the narratives. Some of these associations might come up so frequently that we barely notice them, as they are part of our culture, society, and collection of linguistic expressions. Examples of that could be "that girl is so sweet" or "this is such a sour smell". Although someone may not be literally sweet or a smell literally sour, those are generally understood by synesthetes and non-synesthetes alike. Ward (2008) mentioned that difference in a general book on synesthesia. This issue bears significance to understanding the perceptual manifestation of synesthesia and may impact the perception of notated musical sound. In exploring her notation-to-color synesthesia, Heidi puts this issue in her own words.

... that's one of those things that I've been trying to figure out for a long time. Actually, what actually sort of led me to... to join that page and eventually join your research is... I was sitting in a recording session. And it was a four-day long recording session. I was, you know... they needed some archival help with video and so I was there helping doing that. (...) We had to record a whole catalog for a publisher. And, you know, sitting there listening to all the different pieces and I was sitting there trying to figure out okay... now is this me having a vivid imagination 
with all of these associations that this is creating in my mind or does this has something to do with my synesthesia? Because it I could be wrong but it should make logical sense to me that if I... with anything... if it were with timbre of a certain instrument or even different timbres within the same instrument, like a flute, playing with a with a darker, more focused tone or a brighter tone. Seems like, if I, if it triggered a specific response when I heard that, it would seem like I would know... Like if I had... if I... If it triggered like the burst of bright teal ever every time somebody played an F, which might not break people, but just you know? Like, it seems like that would be so constant that you couldn't ignore it. It seems like even if you knew nothing about music, you would be able to, you know, you would be able to easily put two "Okay, every time this bright teal thing is there. It's like, well, somebody could just come up and tell me, "We'll just instead of say bright teal thing say that's an F, right or Yeah,

Heidi demonstrates heightened self-awareness in regards to her synesthesia and stated several times throughout her interview that she likes to remain "objective" and "critical" about her perceptions before labeling something as intrinsically synesthetic.

So, I try to be critical of that. Um... as far as, like, tone and timbre and things like that. It's not like there are no visual associations there, and textural associations, and even sort of tactile associations, but I'm not 100\% sure if, once again, is that synesthesia, or is that just, you know, in my imagination?... Yeah, [I] keep things objective, especially for the purpose of your research.

She also points out how music instructors make non-sonic and non-auditory references and allusions to exemplify their point or to try to make the student produce sound differently. These references are widely understood and help improving sound quality even though the students and instructors involved in that pedagogical moment may not be synesthetes.

Oh yeah, but that makes definite sense. I'll never... I'll never forget... once in one of my college studio classes, a flutist from the Air Force band came to work with our studio. And one of our... one of my colleagues got up and played and she critiqued her tone and said something along. She had a wonderful tone and she said something along the lines of why don't you vary your tone color a bit more and you know, play with some... some yellow instead of just everything black... such a dark tone all the time. And that makes perfect sense to me and it was dead on the needle as far as I perceived her tone to be, but once again... I grew up with, you know, I was in band and you hear every band director say, "Oh, we want a nice dark sound." So, is that 
synesthesia talking? Or is that just you know, or is that more of a cultural thing among musicians?

Although tangential to this dissertation, the realization of the difference between multissensorial associations and synesthesia is an important notion.

\section{Chapter 5 Summary}

Chapter 5 has reported the findings of this research in regards to the first of the five proposed coding categories, namely the generalities of color-based synesthetic perceptions of music notation told by participants. The chapter has made the narratives of these participants available in their own words and often in full. The quotes were taken verbatim from the original transcripts. The next chapter in this sequence discusses the second of these five proposed categories. 


\section{CHAPTER 6}

\section{MECHANISMS OF PERCEPTION OF MUSIC NOTATION}

\section{Overview}

And the synesthesia is just another aspect of that. Energy, emotion, vibration, that's... that's being communicated.

-James (participant)

This chapter addresses some of the mechanisms involved in color-based synesthetic perceptions of music notation, such as positive and negative factors voiced by participants of the study. Since the aim of this study is to devise the implications of this perception for education, this chapter considers these in light of their potential improvement of pedagogical processes. Among the positive factors, benefits related to memory and improvisation stood out as particularly salient among the collected narratives. Among the negative factors, the most prominent emerging theme was incongruence and the different ways in which incongruence manifests. While memory, improvisation, and incongruence are approached in independent sections, the findings related to generally positive and negative mechanisms are reported within the same subsections. 


\section{Positive Aspects of Synesthesia}

When asked if their music notation-to-color synesthesia was overall more positive or negative, participants remarked on the aspects of their perception that support the positivity of their condition when it comes to music notation. Samantha promptly answered:

Yeah, I definitely would say it is a positive thing to have.

Kailey was asked if her synesthesia affects her negatively in any way. She recognizes the addition of her synesthesia but also voices her desire that she could have a better idea of what it was:

No, I think... I think it added a lot to it. I think it made me... again, I wish as a kid, I knew what it was and it would have made a lot more sense because, of course, when I'm trying to describe things, I don't know... I wasn't much of a vocal kid, so it's not like I would have explained to my clarinet teacher, "but this song is purple and yellow”. Like, I just never would have said that. Because I kind of knew it didn't make sense to anybody...

Several times throughout her interview, Zoe remarked on the benefit of synesthesia in adding one more layer of information to which the brain can refer in assessing knowledge. She summed up her perspective in saying:

Exactly. And I think that is why synesthesia exists... because it does confer advantage. It's just a way of conceptualizing information that makes it easier to process.

Debbra mentions both positive and negative aspects of her notation-to-color synesthesia. The latter will be discussed at the end of this chapter. The former was evidenced in her ability to work on intonation as a violin and viola player when reproducing the notated pitches.

Um, I think playing in tune is like the main one. Um, it really bothers me when people are out of tune and, like, as a teacher, I just like.... listen to out of tune playing all day... [it] is, like, horrible. So, as you know (Laughs). But I guess, like, 
that could bother of person without synesthesia as well. (Laughs). But I think that that's the first thing it helped me with learning was in playing in tune, because the note is not that color until it's, like, that note. And or if you're playing a different note, you're playing a different color. So it, it quickly aligned my intonation. And then I also think like having two parents who are musicians really helped my intonation.

James, in turn, goes beyond and talks about synesthesia as a potential to connect

to oneself and others at an entirely new level. He goes on a tangent and talks about

synesthesia in more general terms and not only in connection with his perception of

music notation.

I would say it's all positive. I don't feel it affects me negatively whatsoever. It's all positive. And it's but for me, it's almost like... it's like another form of hearing, or, or sensing feeling. It doesn't change the way I do things. It maybe changes the way I latch on to things. And if I'd been exposed to it earlier, if I'd talked if I had someone, tell me about it, talk about it. I still know that it would have changed the way I do things. Maybe I would have been able to recognize it and in that sense, develop it earlier and innocence allow, allow it to become stronger. But for me, it's almost like it's another form of enjoying music. Just having it there and feeling it. I think of music as essence, the purest form of emotion, just like if you want to get an emotion across music is so much easier than language. And synesthesia is just another aspect of that. Energy, emotion, vibration, that's... that's being communicated. And so it's interesting, especially to talk to someone else who has it and see how they take the same message in a sense and how that emotion affects them. But I don't think... it's just a... it's a part of me. I would enjoy it becoming stronger. So I'm able to, in a sense, be in that world more. Because it's totally different. But no, it's all... it's all positive. And I don't think it's ever really changed the way... changed the way I've learned except for running into other people who have tha...t who have it, who are generally... on some of the people in front of you who have a really strong... they're on like a different wavelength... There are so extremely good and then just being able to talk to them about that give us insights about the way music is.

\section{Memory}

Upon being asked about the benefits and positive aspects of notation-to-color synesthesia, 11 out of 12 participants voiced the role of this phenomenon in helping them to commit information to memory. Many compared synesthesia to a mnemonic device.

While mnemonic devices need to be learned and fixated besides the information to which 
they are linked, synesthesia poses automatic and involuntary associations that are natural to the individual synesthete. Synesthetes may be at an advantage in that this mnemonic apparatus, much like a color-coding strategy in the case of notation-to-color synesthesia, is available to their perception completely free of charge and without effort.

Like any other discourse in any language, music is comprised of sections, phrases, sentences, periods, units, and wholes. Having colors automatically associated with its intra-musical elements may make memorization easier on the part of synesthetes.

Samantha attests to the prominence of synesthesia in her musical memory for repertoire ("rep") she commits to memory.

Um, well, I think the biggest way is that I think it helps me memorize. I think it helps me memorize, especially as a classical pianist. I... It helps me memorize my rep a lot easier. Because, I don't know, I have kind of areas where it's like, "oh, this color is happening". And then it would, like, kind of trigger, like, "oh, this is, like”. Does that make any sense? (...) It's kind of memories, like the color regions, and then I could figure out the rest by having that. So, yeah, and even like in other sort of, like I said-because I have it with the letters and numbers too-if I'm like writing a test, and can't remember the answer, I'll be like, "oh, I remember this had... this had the color yellow associated with it. Oh, it must be this". (...) So that's, that's one way... and I told you about the composition, how, you know, you kind of associate patterns and music theory and, um... trying to think of any other ways... I think probably memorization actually, might be the ... the biggest thing.

Daisy attests to the way synesthesia played a role in her choice of repertoire ("rep") and

how it helped her remember particular keys and scales. Daisy would eventually be able to play repertoire without the music sheet sue to her memorization of their colors.

So, my choice in rep, you know, my choice in rep also definitely was affected by my synesthesia. I just recall, the pieces that I would choose for recitals or for juries would be similar keys... not necessarily because they were easier [or] because my fingers knew them... but just associating with certain colors like I... I tend to go towards more, like, $F$ 's and more B-flat keys than any other keys... and sometimes $D$ major. And then any other keys like C or... a key I don't like... (Chuckles). A! I, like, I wouldn't pick C or A just based on that idea alone, you know? (...) Definitely, when doing keyboard skills... it would... it would click in my brain, the color as I was playing the scale and kind of just, like... I would think of the color and immediately 
think of a form that the scale was creating in my mind and then my fingers would sort of play that form, just like by like a little blob that just appeared and immediately thinking of the color of the, the key there that the scale would take shape. And then it helped my brain go, "Oh, this is now the key that we're playing in". So it's more than just looking at the key signature and going "you're now going to play an E major." It's... my processes [is]... "E Major! Oh, it's it's green." "Oh, this is the form it takes." "Oh, this is how my fingers work".

Some may learn quicker than others due to an exceptional synesthetic memory,

like Amanda, who could remember concepts associated with her colors easily. Amanda's notated pitches have a specific color.

And so I think it also helped memorize music and when we had to commit to memory it's really easy to remember the color combinations as well as the sounds. (...) Since at the time, I wasn't aware that I had synesthesia, I can't say that I consciously used it as a new kind of device to help me learn or remember. That being said, I know that it definitely did help me learn to read and learn to read music. And let's see... when I was learning, I mean, when you're that young, it's just so easy to pick up another language, you know, so music was easy to learn at that age and happened really quickly. But I do know that when we were going to do, you know... learning it.... committing it to memory... I absolutely would hold as I played just the whole stuff in my mind, colors and everything, and just play that... play the note like I was reading music. And color would come out with the note and so I would imagine that if I didn't have that... that would be a bummer. (Laughs).

Amanda says that remembering the colors for notated pitches would be like "reading music" in her mind. Similarly, Debbra used her synesthesia to remember sequences of notes played in different positions according to their color. She traces a parallel between notated pitches and the colors of the notes on her violin's fingerboard.

Yeah! That helps me, actually, I think when I shift into higher positions, because then I, like... especially on violin, like, you're going really high on the E string. Like, for me, like, yeah, finding the harmonic E helps me, you know, to know where I am. But I also know that that's green. And so like I aim for the green or aim for the D is like a lighter pink. So if I'm in third position, fourth finger, oh, I'm just, like, I think of that color for my finger to get there.

She also benefitted from her synesthesia specifically in remembering sequences of notes in difficult, rapid passages of music notation in violin repertoire. 
And I also think it really helped in terms of memorization. So, like, when I was in university or RCM, or whatever... you have to memorize a concerto and it's like, all these pages of sixteenth notes. It really helped to know the colors of the notes. (...) I think it was mostly melodic sequences, like it was mostly note by note. Oh, and I would memorize the colors. I mean, like, yeah, if it was, I guess if it was, like... it was in a scale or something... I would just memorize the color of the first note of the scale. And I would know, "okay, this is like, you know, Mozart or something”... you can turn on D major... it is like, "okay, this is, like, another D major scale". And I would think, "pink", because of D. But, um, but I think mostly it was based on melodic sequences and, like, individual notes.

Iria, who identified having both notation-to-color synesthesia and absolute pitch,

describes her synesthetic memory of music. Her colors seem to have helped her how to

play a note on the keyboard. They seem to have worked as a mnemonic mediator between

the notated music and the keyboard.

So, when I try to play piano, I look to a note or a chord and I had to remember how to do it and I think this is when the colors come to my mind. This is the process for me. I had piano lessons, but I don't remember. (Chuckles). So I don't know which finger to use [for which] note. It [the colors] made me... it makes me remember exactly what I have to do there. And if I have, actually, when I have to play the song, for example, if I will play a song that I already have listened to and remember how it is, colors come to my mind. [Playing by ear]. The main colors of the song. I never knew... I think it always helped when I needed to remember, for example, how to play a song. The benefit is really like an association in my mind to remember [things] or to be 100\% sure about something. Sometimes I feel: "no, I know this is the [right] note!", for example, [about a] song, because the color comes to my mind so strong and I'm sure this is right, for example. (Chuckles). Or wrong. It really tells me. (...) I have no examples, but as far as I can remember, I think, as I said, it's always helped me to remember things or, like, to feel, you know... If my former teacher said a given song was in D major, my brain, like, in this moment would see the color green and it would help me to remember what the [key signature would have been for that key]. Yeah, so I think that the color, like, brings the song's key and helps me to remember while I'm playing.

James does not engage his synesthesia consciously as a mnemonic device, especially depending on the circumstances surrounding the memorization of a given piece of music. He says:

Yes, but not on a conscious level. To be working on something with a deadline, with a recital coming soon, I'm automatically going to go straight to, like, route learning: 
practice and practice... (...) Pieces that I enjoy, and I've played long term and especially that I perform with on a regular basis... so it's not... maybe I don't even know what I'm going to play next. But it... almost... it comes into my periphery. And then it's just there.

Heidi also attests to the mnemonic characteristic of synesthetic associations of notation and color.

Um, I wish back then that I... I knew how I do now in some ways to kind of use it to my advantage more, I think I think I did in certain ways. Like I've always I've always made up silly little, I guess mnemonic devices to help clean information. I've got fun one that I would like to share. Recently that has come to me this year with teaching myself guitar. But I think I've always kind of done little things like that, and they don't make any sense to other people. And it may be this very silly thing, but I think that is something I've used to help myself retain, you know, like, when I was in high school, you know, sitting there drilling scales, and as I would, as I would go through each scale, it would be, you know, all the, all the colors jumping out at me. And those, those patterns would kind of help internalize what I was trying to learn. (...) A lot of a lot of mnemonic type things. (...) Yes, um, every once in a while if I have if I have an alternate fingering that I have to use on something, I'll mark it, but uh, the fingerings, I don't know, I... there's probably a little bit of a different association... like on flute a big thing is with all of our B flats. We have different B flats we have the standard one that everyone learns in beginning band, we have the lever $B$ flat. We have the thumb $B$ flat and they all sound a little... a little bit different. And I think there is maybe a slight... a slight synesthetic implication there as far as... may want, you know... one being a little lighter than another... the other being a little hazier than another. Depending on, you know how it sounds on the instrument and whether it's a look like the thumb, the flats a little flat, the lever is, you know, about right where it should be.

Keira's synesthetic memory of music interacts with her absolute pitch.

I think I have very many memory benefits by this type of synesthetes. Because it has a big influence on my memory, because I easily remember the colors. And in addition, I have perfect pitch so it's easier, it's much easier as well, so... I don't have problems remembering music.

Lastly, Kailey, although she did not have colors for notated pitches, could remember color patterns elicited by sound. Her experience is tangential to notation-tocolor synesthesia, but still worth reproducing in full due to its rich content.

But the one that I remember as a kid, piano pieces, clarinet pieces, whatever, I could memorize them almost immediately, and a lot of it was based on I can tell you every 
song that ever played exactly what colors they were I kind of remember because I had such a connection to them. So I feel like there has to be something there where the color was kind of dictating what I memorized. So I could memorize it going, Oh, well, it goes from green to blue to yellow, you know, so it wasn't just me, you know, I wasn't that big on kinetics or anything. It was more that I was literally just memorizing the color patterns. And so I could memorize things quickly, if that makes sense. (...) Yeah, for me. I mean, I could memorize things. It's not as good. You know, now that I'm older, but yeah, as a kid, I can memorize things very, very quickly. And a lot of that, again, was the numbers and letters but musically, I remember just being able to memorize things way faster than anybody else I knew that was playing, so, I feel like maybe there was synesthesia there, but of course, I was too young to even know that was a thing. Yeah. So it's hard for me to put it in words, you know... (...) um, but I think, personally, it did help me, because every song like I said, for me, it was easy to memorize it because I saw the picture. I was living in the picture of the music, so I knew what the song was, you know...

And Esther, who also does not have colored-pitches, would remember general images or landscape-like patters. She is the synesthete who sees colors for ranges notated on the page, rather than specific pitches.

Um... from memorizing music. I remember bits and pieces. I, I don't remember exactly how. But sometimes, like, just like images in my head would kind of help me remember what to do next. If that make sense?

Chapter 10 discusses these rich narrative findings in light of the extensive literature on synesthetic memory reviewed in the final portion of chapter 3.

\section{Improvisation}

If synesthesia is regarded as a potential mnemonic device, it may carry implications for music-related activities that require memorization. Improvisation is one of them. Improvisation entails some degree of emancipation from music notation, in that it requires musicians to extemporize and exercise their creativity in creating phrases and harmonies. The need to memorize sections, structural portions of the discourse, harmonies, and melodic sequences, may well benefit from synesthesia because it is often 
firstly notated on the music page. I asked Debbra about the role of her colors and casually

mentioned how I use my synesthesia for improvisation. Her reaction was thus:

Oh my gosh. You're so right! I'm just saying this because... okay, so, like, I was a classically trained musician and I, like... that's all I did until like after university. But then after university I started playing in rock bands. And it was like exactly what you're describing like so I would just follow the guitar player's shape of his hand. No, okay, like he's playing like, this shape is like G major. So it's like dark red. So I can play a $G$ major and like the colors of G major arpeggio would come to me. So I would know what notes I could use in that improvisation because at first I didn't know how to improvise. And so the harmony of that chords like the chord structure would be like so important to me because the color of that cord would give me so much information. But I didn't... But I didn't start improvising until like after I had like my degree in music. So, it's interesting how, like, a melodic player might think differently than, like, a harmonic instrument, like, the piano or guitar or something.

Alba also has had some experience improvising on the piano throughout her ongoing music degree:

Like, when I improvise on the piano... like, when I improvise, I'm thinking always about like, you know, what am I playing... I, IV, V and so on [functional harmony degrees]. So I not only see the color of what that would be, according to our system, our system of numbers, not the Roman numeral system, because I'd have different colors [for them]. And I would also see, I got also visualize the chord number. So if I was playing IV7, I will literally see a red four with the [indistinct] seven, okay, you know, in my field vision, and, you know, six, three, blue, pink and so on. And when I think about, like, scale degrees... Anything like that, I will always see that color for that. And if it's not visually present before me, I will often visualize it as my tickertape.

In Alba's case, she visualizes the music notation in a "tickertape" style if there is no music notation in front of her. James is involved with folk fiddle music and jazz, both of which are highly improvisational styles and draw upon developed skills in extemporization (“improv"). In speaking of these two genres, he says:

Improv color is huge. All right, color is huge. I have done projects... I've done recordings and stuff. And both on the like dispensing end of these and on the receiving end, the charts... is the song title of the front in a color and shapes. There is no... there is nothing other than that. Generally, I'm happy to have a key center to work out... just to let we're on the same page, but it's yet colors. And it's very interesting for me, I'm pursuing a jazz degree right now. So it's, I'm coming at it from 
it, like very structures. I'm working, I'm running 147 different scales right now. Practice. So that's... that's a different side. But for me, when I come into a solo, if I'm not pressuring myself to work specifically with what I'm learning right now, if I'm just trying to make music, it's just all about color. I don't care if the notes are right... I don't care if the notes are wrong... Does it feel something? And where can I go from that feeling which is a color...? Feeling is a color... which I guess is something to, like, hurt is generally red, darker, warm tones... warm tones is wrong. No it's not warm tones it's... often possesses some of what we would call warm tones. But comfort is also warm tones and they're different. Burning yourself. Yeah that has a color to it. Putting salve on it that's that is actually it. That's a cooler color. But like a blanket around you on a couch is that's a warm color as well.

James's colors not only go beyond the music notation page but beyond note concepts altogether. He seems to rely on his colors for feelings more prominently. Since this form of his synesthesia is not notation-based and we were discussing improvisation, I did not explore the interaction of his emotion-to-color synesthesia's interaction with his notationto-color mode.

In any case, these narratives portray some aspects of the role and implications of synesthetic perceptions of music notation in connection to improvisation. Participants have attested to the role of synesthetic color in their recalling of notes, harmonies, and sequences for both improvisation as well as memory.

\section{Negative Aspects of Synesthesia}

Only three of the participants remarked on the negative mechanisms of synesthesia when it comes to their processing of notation. In responding to this prompt, however, they departed from the central topic of music notation and expanded on general aspects of their music concept-to-color synesthesia. Amanda, the same woman who remarked on the romanticizing of synesthesia, complains that it may entail too much information to be processed at the same time. In the following quotes from her narrative, 
she departs slightly from music notation and talks about how the concepts' colors can be

bothersome to her depending on the context.

Hmm. Too overwhelming. I don't know. Um, kinda... Oh, yeah, so I think the most common tuning note that we use is B-flat and that's brown... and it's kind of, like, not the most exciting (Laughs) looking note and so when we started on C, I just was, like, "that so much better". And then, you know, some of us will raise to D and then we'd have that purple mixed in there. So I just... I guess part of me never understood why we had to use ugly old B-flat as our, you know, tuning note so much and I guess I now realize no one else felt that way. (Laughs).

And so... similarly, certain passages, maybe, that had a lot of dark colors like that, or brown or... and you know what, so also there's... there's the ordinal linguistic personification aspect too, so, sometimes the personality I just didn't quite like, right? And so... so, that would be just kind of a distasteful to me, but I wouldn't, um, it wasn't challenging. I don't think to get over as far as playing music. It was just my own tastes.

Zoe recalls an event from her childhood:

I remember a friend of mine, age seven, had one of those pianos where they have, like, colored dots on them. Well, the keys are colored to help you learn. I don't know if you've ever seen those kids have them. I remember thinking, well, that's confusing, because the colors are wrong. I mean, like, why... why, you know, why would you mess with your head? Because obviously, I was too young to realize that no one does that. So, I guess in that sense, it was negative that I wouldn't be able to use a learning process like that.

Finally, Debbra introduces an idea that needed to be expanded into a completely new coding category - the idea of synesthetic incongruence:

I would play the wrong note. (Both laugh). Like, I mean, I think I would have... it just took me twice. I had to think twice about the notes that I was playing at first because it was, like, "this should be so easy", but it's not... because this other part of my brain is telling me this is not what it is, but I know it should be this. So it just made me have to practice more and after many years, like, after a long time of practicing and playing and, you know... eventually now like that $A$ is blue... but it took like over 10 years to kind of... and there are still some notes like ledger lines... don't even get me started. (Chuckles). I was like, "Okay, now the alto clef staff is the right color for all the notes". But if I go, like, ledger lines below the alto clef or above, sometimes they're the same as treble clef. Like I haven't completely gotten rid of that yet. Because I guess because I started piano and then violin at such a young age and flute that it was like treble clef was just engraved in my mind. 
Debbra is talking about changing clefs, from instrument to instrument, or in playing the same instrument. She is referring to her transition from the violin to the viola- - both are bowed-string instruments, but the notation for each is done in different clefs. When the clef changes, the concept of each notated pitch changes, since the clef determines the pitch concept (Figure 8). The following and last section of this chapter explores such examples of incongruence in more detail.

\section{Incongruence}

Incongruence, in this context, refers to two or more conflating percepts that may cause a mistake in interpretation or a delay in behavioral response. Much like in Debbra's example above, in which she would play the wrong note completely, incongruence can pose a challenge for synesthetes. The paragraphs that follow draw upon the points raised by the participants of the study in relation to different music notational elements.

Incongruence stood out as one of the most prominent emerging themes in this study. All 12 participants referred to it throughout their narrative statements, some of which are reproduced below.

\section{As a Source of Annoyance}

Some of the research participants only reported feeling bothered by incongruence. Iria, Samantha, Esther, Daisy, and Amanda describe analogous circumstances, reproduced in that order. They were juxtaposed in this manner so that their resonating points and differing qualities became more evident.

But when I see, like, for example, if you show me the note A in, like... for example, it is yellow... I'll have like a little "no it's not", you know, moment. (Chuckles). "No, it's just red for me." (Chuckles.) 
Yeah, I definitely have had that. I'm struggling to think of a specific example. It, like, honestly could even be like, if there's like a tempo marking and I see the word and it's like a different color, then, I don't know, maybe a chord that's going on at the same time. Like, this is like the second of like discomfort with that. Even once I'd seen it was like an installation that someone or composer had made and they had colored the piano and like, it colored the $C$ blue and I remember looking at that and being like, no, it was a little uncomfortable about it. Trying to think of like other specifically within like education. Yeah, I think maybe just like words sometimes would kind of interfere with that maybe even like, Um... Yeah, I don't know. I can't think of anything else.

Yeah. I've definitely had those experiences a lot. Overall I know... I'm not sure if specifically, if I can remember an example with music education, but over the course of my life, yeah, lots of like in class coloring, like alphabet letters or anything like that. Um... I mean, the same would have gone for any music class where we had to associate any colors, I'm sure. Or... Um... I seem to remember a color-coded keyboard, um, that my one teacher had at one point that really irritated me. (Laughs). I don't know if that was because of that, though, it was so long ago.

Okay, um, sometimes I would say... so, I think, like I mentioned before, like any composer that decided to write a piece of music in the key of D major, and then all of a sudden the entire pieces and A-flat major, it... (Chuckles)... It would just lose me and then I'd be, like... I'd be really confused and be, like," this is not what I expected". Or, you know, actually... to probably answer your previous question... because I remember just playing a few nights ago, a piece of music where I would read the title and that alone would make a color appear and I was like, "Oh, well, this color is now going to be green or lavender". And then the piece turns out to be either right or wrong. (Chuckles). And so what happens is after I've, after I've played the piece completely, I would then associate that color with the title and then my brain would change. It's like, " okay, so you thought this piece would be lavender now it's red". (Laughs) that's really funny. So yeah, then you're kind of trying to rely on do I rely on the color... Because the color is kind of the thing that comes first when I glance at the page. And so do I rely on that or no? I have to pay attention and see what it is I'm looking at! That's funny.

Heidi offers a practical experience involving band rehearsals and sharing a stand with

another musician (having a stand partner) who is a non-synesthete:

I remember. I did this, not from a teacher, but I do remember them. One of my friends who also played the flute. When we were in, we were in beginning band, we were baby baby learners, and she would color each different... Like, you would highlight all the As pink, or all the B-flat yellow... and I'm like, "why's your B-flat yellow? It's the most blue thing ever. It's blue with a haze of blue on it. It's supposed to be blue. Why are you coloring it yellow?" But I mean ... I mean, I understood on the inside... that like, that's just... that's just a silly "me" thing... I don't know if she 
was synesthetic or not, but it helped her at the time. We didn't get into any argument about it, but yeah...

Well, actually, yeah, for a while we were actually sharing a stand and that was kind of... Yeah, that was kind of annoying, especially since I was a... I was the pencil purist, you know, pencil kid and she had all these little markers that she was writing all over everything [with]. And I'm like, "Why do you do all that?" But um, yeah, I remember sharing a stand with her. And that being a little annoying. (Laughs)

\section{Between Clefs}

Debbra's experience is illuminating as it touches the transference of notated

pitches between clefs. In her conceptual synesthesia, she found herself transferring from treble clef to alto clef at a high level of performance and repertoire difficulty, yet her colors seemed to be wrong, as she pointed out in a quote mentioned earlier in this section.

She goes on to explain this incongruence between clefs in more detail.

So, um, in university and third year, they wanted me to play viola. And I said, "Yes", because, you know, I just thought, why not? Yeah. And so I had to really quickly learn a different clef at the university level. So it wasn't like I was learning from scratch and as a violinist I kind of just thought, okay, in third position, the notes... if you think like you're playing in third position, it'll be, like, faster. So the notes of alto clef, for me are kind of a jumble... the colors, I mean ... because, um ... it took me... so now that like, I've been out of university for a long time, but I've been playing viola ever since university... I still play violin as well, but a lot... I get a lot more gigs on viola, as you know. (Both laugh). And so, um, so I've had, I guess, like, I graduated in 06. So, I've had like more than 10 years to kind of really come to terms with the alto clef... and I'm slowly working out the colors to what they should be. But when I first learned alto clef, it was kind of like treble clef. The colors were, like... I was... I was mixing up the colors at first.

Figure 8 exemplifies a musical pitch notated on the same line on the staff, yet signifying completely different notes in the context of the clef in which it is written. The colors in Figure 8 were randomly generated to illustrate Debbra's perception of different pitches. In her synesthetic perception of music notation, the colors of pitches notated on one and 
the same line/space on the staff, ultimately depend on the clef. Otherwise, the notes have the "wrong" color.
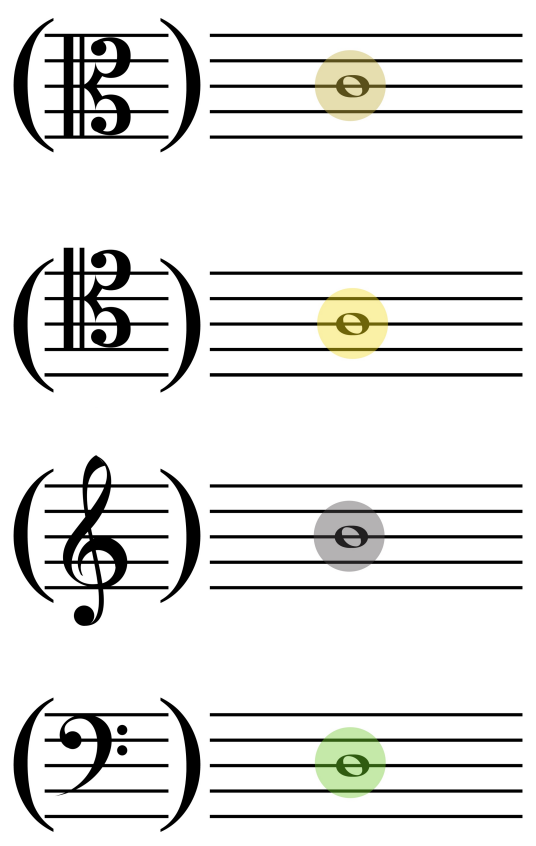

Figure 8. An example of Debbra's perception of different pitches (random colors).

Alba, a piano major who also plays violin, brings up the incongruence between notes perceived in different clefs as well:

Like, if I just start reading in the wrong clef, and usually this happens on violin, for some reason, I think it's because the left hand is doing the fingering... so, I automatically... I think, bass clef. And then I have started reading in that clef, and then I'll see the color. I read the color before I really read the note for the letter. I often find that like, in Greek... like anytime I learned a language with another alphabet... I... I start once I.... so "let's make the association between these sounds like this", or "this looks like this". Then I'll start reading the color first. So I do that with music. I do that with English... French... Yeah.

Alba's colors are immediately associated with the default pathway the notational element has adopted in her experience. She goes on to say: 
Yeah. Well, like, if I just misread it, it will appear the color that I think it is, until I realized that I'm in the wrong clef, like on orchestra tour... I don't know... Or on the practice before... I don't know how many times I started... at least three... I started playing like a third [an interval between two notes] away from where I should be because I was reading in the wrong clef and, like, "wow, this is strange".

Heidi has a theoretical experience to recount:

Um, when I got into college and, like.... before, I had never really had any need to read another clef unless I was just, like, looking at a friend's music in class or something. It was always treble clef, but I understand it. I understood the concept of bass clef and movable clef from, you know, talking to people who played other instruments and looking at piano sheet music... and I understood those concepts but it didn't... I didn't really face that until I got into college... and I, you know, I did have to sit there and, you know, actually be able to fluently read in, like, bass clef to get my class piano assignment done or, you know, if I had a theory teacher who was... he was kind of mean. He would want us to... he would, like, time us to analyze a piece of music and, you know, then my brain would get a little scrambled but once I... once I kind of got a little bit more used to it... it's like, "okay, yes, these... the concept of this note does retain the original color of it..." It did, you know...

Because if I were in ... because it's not really so much... When it gets down to it... it's not so much the placement of the note on the staff. It's the concept.

Between Fingerings and Pitches

The author or editor of a piece often suggests finger numbers (numbered 1 to 5)

for the player to use while performing a specific passage. Fingerings are notated above the pitches in a musical sheet and their raison d'être is to facilitate the effective or clear performance of a difficult musical passage (shown in Figure 5). For a music notation-tocolor synesthete, they may pose incongruences, however. Debbra goes on to explore the overlap of her musical notes with fingering indications.

Yeah, and that bothered me so much because I knew I was supposed to be playing, like, first finger $A$ on the G string or something. And I knew in my mind that should be blue. But on the page it was the color of $G$ which is like a darker red for me. So that bothered me a lot but I eventually got used to it. (...) I think what happened was I would see the A but it would be the color of the G. So, I knew... I knew that I was supposed to play an A... I knew. like... like. in alto clef, the second line. I knew it was first finger A on the G string. I knew it was... I knew it was pitch A, but I, it was... instead of being blue, it was red. And I was like, "This doesn't make sense". So, I 
knew, like... I knew what I was supposed to do on my instrument. I... my brain was just having a hard time with the colors.

Her experience with synesthetic incongruence between the colors triggered by different percepts extends to conflating concurrent sensations involving finger numbers. Alba's

challenge is somewhat analogous to Debbra's but different in essence:

No, no. All of the musical notes are very, and... the numbers that would be used... are very distinct. They just have, like, their own little character, not as in personification character, but it's like five-green is so much different than ninegreen, or two-green. Or G-green... it just... I would say no... they have no relation to each other aside from the fact that they're all green.

But on the topic of fingering, the only time that's really a problem for me is switching violin to piano just because the colors get mixed up between the fingers. Because like in piano, white, green, pink, red, green, but then this this becomes green, this is white, pink, and red (indicates her fingers on the left hand).

Her difficulty is grounded on transferring finger numbers from one instrument to another, rather than struggling with notational aspects. The reason for that is due to finger numbers being different for playing the piano and playing the violin. On the piano, fingers are numbered from thumb to pinky, 1 through 5 . On the violin, in turn, they are number from index to pinky, 1 through 4 , on the left hand, since the thumb is not used to press the string on the fingerboard. Therefore, Alba's finger colors would change depending on the instrument she is playing, which causes her occasional confusion. Keira's experience also yields similarities and a perceived challenge when incongruence between fingerings and pitches arises. She is a violinist and states:

Nevertheless, there are situations where I mix up the notes color with the color of a written fingering. For instance, once I... Once I played the Prokofiev Violin Concerto No. 2, and there was a passage where I mixed up the note with the fingering and I was wondering why I, I played the right note but with the wrong fingering. They wrote with the "wrong" finger because it would be the second finger, but I played the third finger because the number three is yellow and the E-flat is also something yellowish. It has to be the second finger... and the second finger is green, 
as the number two is green for me, so I played it with the wrong finger. But then I... Okay, synesthesia... synesthesia can also mix up the mechanical (Laughs).

Heidi, from a different standpoint, alludes to alternative fingerings as a flutist:

Yes, um, every once in a while if I have if I have an alternate fingering that I have to use on something, I'll mark it, but uh, the fingerings, I don't know, I... there's probably a little bit of a different association... like, on flute a big thing is with all of our B-flats. We have different B-flats we have the standard one that everyone learns in beginning band, we have the lever B-flat. We have the thumb B-flat and they all sound a little ... a little bit different. And I think there is maybe a slight... a slight synesthetic implication there as far as... may want, you know... one being a little lighter than another... the other being a little hazier than another. Depending on, you know how it sounds on the instrument and whether it's a look like the thumb, the flats a little flat, the lever is, you know, about right where it should be.

Although fingering markings are not as recurrent for woodwind instruments as they are for strings and keyboard instruments such as the piano or organ, they do occasionally appear on the score. Some of these challenges might be instrument-specific and become exacerbated depending on the medium used for performance.

\section{Further Insights}

Debbra also broaches two tangential topics that are still worth mentioning in this context, namely transposition in relation to perfect pitch and the different left-hand positions on the violin. They are not notational aspects, but may interact with the colors perceived for notational elements.

I think it's similar to... and I don't have perfect pitch... but I think it's similar to someone who... who has perfect pitch who plays a transposing instrument. Like, they're playing what on the page is a C but in what they're hearing is a B flat or something. And so to them, it bothers them and eventually you just get used to that, like so that's... that's what happened in university I just was like survival mode because it was like "third year and you're playing viola at a third year level" like "Oh, can you switch to viola" "Sure." "Okay, here you're in all these quartets". And you're like... in of my fourth year I was principal viola. And it was like, I had to, I just had to survive. (Both laugh). So I didn't really convert the colors. I didn't do that work. I was just like, okay, like, just play the notes and like practice this, and I think I relied more on my ear as well. And then but I did have that thing in my mind 
being like, this isn't the right color. And sometimes I would make mistakes because of that. And I mean, probably also for many other factors too, but um... (Chuckles). but then eventually now like, I find myself really like my sight reading is a lot better now because I... the colors have kind of somewhat aligned in the alto clef...

I do, actually. So, it's, it's like... so I do have different colors for the numbers. So like, for me, one is white. So if it was on the D string. So D is like, a kind of, like darker pink for me, and then E in music is green, and then $F$ is purple. And so the $F$ sharp... and for me, sharps are black. I don't know why. And then like, so like one is white, and then two is brown for me. So, I guess, I do think of all those colors... I don't think of when I'm playing like difficult music where the music is going by so fast, you don't really have a chance to really think of all of that. But if I if it comes down to it, I'm thinking of the color of the note more than the color of the number. But then sometimes, like, if there's like, let's say I have to shift and like... one, like let's say I'm going to third position on the G like of the D string. So where I would put the finger, but now I'm putting first finger I'll think "white" Because I'll be like, "Well, no, I have to play that with first finger". So, and then sometimes, so like... the number three for me is light blue. So if I'm in third position, I'll also think all of those notes in third position are like in a cloud of blue, because even though they all have their own, like individual colors... but within that, like they're all kind of in this blue section, right, because I'm in third position.

This is to say that incongruence is a very significant mechanism in her perception of notated music. Debbra points out that this is something a synesthete musician, especially if a professional musician, music come to terms with and learn how to manage. I can attest to a very similar experience as a violin and viola player myself. Debbra keeps a positive and lighthearted attitude in admitting that it does pose a challenge, though. And one other thing that really I hate the most about viola, which I love playing viola, and all violists hate the treble clef. But I especially hate reading treble clef when I'm playing viola, because I took 10 or so years for my mind to reach, train itself to the colors of the alto clef, and then you throw in treble clef, and the strings are different and so many levels are like, I don't want to play this right now. I hate that. I know you understand.

She says this in a playful way. James is much more optimistic. A violin and viola player himself, he seems not to be affected in an overly negative way:

So that's not a problem whatsoever, right? It just, it happens. I deal with it. It's the same. Same thing for me as just knowing where the note is in the clef. It's, that's not a problem. For the last week, I've been practicing my Viola on my violin, that is a 
problem. (Both laugh). For other... Well, not even for other reasons. It's just knowing. Just from a transitioning perspective, it's like it's hard to transition back to reading the weird note on the weird instrument because it's getting a different note, but then it is the wrong color, in a sense, from what I should be hearing.

Those with a strong conceptual basis for synesthesia may experience a struggle with incongruence. Kailey, on the other hand, said that incongruence does play a role in her experience but not in the case of music education. As the previous chapter pointed out, Kailey also did not experience specific colors for each note concept, which likely explains the absence of incongruence in her music notation experience. Her notation-tocolor synesthesia arose from other percepts on the page instead.

\section{Chapter 6 Summary}

This chapter has drawn upon quotes from the narratives that inquire into some of the positive and negative mechanisms potentially involved in the color-based perception of music notation. Two positive and one negative mechanisms is particular have been analyzed in richer detail, as emerging themes among the narratives: memory, improvisation, and incongruence. Chapter 7 contemplates further details involving the reality of notation-to-color synesthesia - the location of color perception. 


\title{
CHAPTER 7
}

\section{LOCATION OF PERCEPTION OF MUSIC NOTATION}

\author{
Overview \\ Yeah, is it's like a lens that I can bring into focus... \\ -James (participant)
}

Van Leeuwen (2013) makes a distinction between projector synesthetes and associator synesthetes in connection to grapheme-to-color synesthesia. She argues that the former "see" a color sensation "where" or "around the place where" the stimulus is coming from (on the page of sheet music, for instance). The latter, in turn, would "see" the color sensation in their "mind's eye". This distinction is important for this research in that participants reported to have their colors either projected on the page or in their mind's eye. There were some, however, who seemed to experience a combination of both; and others still who "saw" the colors "in the middle", as a sort of lens between themselves and the music.

This chapter accounts for these experiences and draws upon the descriptions provided by participants, some of which are reproduced in full through the following subsections. This research did not assign participants to a given category ("associator" or "projector"), in that some aspects of their narrative indicated one or another at different times throughout the interview. Although there are subdivisions in this chapter, the subsections that follow are in no way conclusory. They merely allow for these narratives 
to speak for themselves. Some of the broached elements fit, indeed, into these categories, yet others do not fit into either.

\begin{abstract}
Associators
Only two participants reported associating their colors strictly with music notation in their "mind's eye". Some had a certain difficulty in explaining the location of their perception, however. Iria states:

Yeah, I see just in my mind, I don't like see it on the page. It's more when I need to recall information or to remember how to start a music for example, and then I remember the page [of music] and I remember to color for example, in my mind. I don't have, like, this feeling of really seeing anything.

Esther is quite sure her colors do not project. It is important to reiterate that she does not have specific colors for each note either. Her colors are range-based and experienced in her mind alone.
\end{abstract}

It's in my mind's eye. It's like in the back of my brain almost. (Laughs). Um, yeah, it's inside my head. (Laughs). Yeah. It's more like, if I close my eyes, it would just get... become stronger. If it continues... thinking about it, I would see it somewhere back in here (points to the space close to her head and chuckles). I'm assuming... yeah.

Heidi agrees, in saying:

It's more in my mind's eye, but... yes, more in my mind's eye.

I mean, I could, if I sat there and imagined it... I could. But once again, that's one of those things where I try not to, like... like, am I just projecting that because of what these triggers in my mind? Or am I actually seeing that? Which I think it's... I think it's the first one... I really do...

Although Heidi attests to association, her perception also seems to be projective if she deliberately thinks about it. I have made another portion of her narrative available in the following section that illustrates this. Heidi remains objective about the nature of 
synesthesia; she questions whether the reality of either projection or association is a matter of will when one is aware of synesthesia.

\section{Projectors}

Although projector synesthetes see the color of their perception quite literally "projected" onto the page of music, they can still see the black ink with which it is notated. Their synesthetic reality and the impression of their color is so strong, nonetheless, that they feel they actually see the color on the page. I can attest to that form of the condition in my own experience, but have included here the narratives of the interviewees in response to my question about the nature and reality of their synesthesia.

Heidi sums up her experience in the following response:

Um, I don't know if I... when people say, "do you see the colors on the page?"... Like, I'm looking at the page. I can logically tell you this is a black and white page of music... if... you know, if somebody's holding a piece of sheet music over here, and I'm just like, you know... I, like, look at it and then I look back. No. But if I'm sitting here and I sit down and I'm going to sight read the piece... and I'm going, you know, just through each, yes, each, each note... and each, you know, if there's accidentals there... Yes. This is just one point to be like a little microburst as I read across the page.

Moreover, Heidi is again attesting to the conceptual basis of her synesthesia (discussed in chapter 6) in saying that, in seeing music notation in passing and quickly, it does not trigger colors for her. Yet, if she recognizes specific symbols and what they mean, they trigger a color. Kailey resonates with Heidi in recognizing the black and white colors on the page. Kailey's colors manifest only for notational elements other than specific pitches, however. She also does not seem entirely sure about the associative or projective nature of synesthetic reality.

In my mind, the way I've always kind of tried to describe it to people... of course, I see it on the page... and I'll get to people and I'm trying to explain it is like, "I'm not 
crazy”. I know this is black ink on white paper, like... I... I'm, you know, I'm recognizing what I'm actually looking at. But when I think of the number four, it's purple. And I don't know how to think of it in any other way I just know. And so, yeah, I think it would have to be in my brain, in my mind.

Although there are elements of projection discussed in her statement, Kailey's experience indicates that she might be an associator.

Even though Samantha uses the term "associate", she reports seeing her synesthetic color on the page as well as on the keyboard.

So, like, on the page, of course, I see them, like, because I'm a pianist, like I said, so I have kind of, like, on the piano, I associate like, you know, the way the keys are laid out, I associate them with like, the colors.

Samantha's statement departs from notation, yet it attests to the conceptual basis of her synesthesia. Both her notes on the page as well as on the keyboard have the same color, since they carry the same meaning. Amanda's experience is similar. When asked about the nature of her synesthetic colors for music notation, she used the projection of letters and numbers on her computer's keyboard to exemplify her experience during our video interview.

I mean, yeah, well, I guess it's projector. It's just not. When I've seen the documentaries, some people experience... it's like very much just like... we look at the number three and it's, it's pink. And it is, I'm looking at my keyboard and it is pinker than all the other you know, so I guess I do project it. Yeah, it's just [indistinct] Yeah, interesting. Yeah, I just I guess I am a definite projector. (Both laugh).

Zoe distinguishes her synesthetic projection from the actual colors of the percepts.

Yeah, so I'm very much a projector like it's, it looks as though you've printed the note in that color. Even though I know that it's black-I can see that it's black at the same time-it looks yellow to me and...

Debbra seems to concur with Zoe. She also compares her music notation-to-color synesthesia to her grapheme-to-color mode. 
So, I don't know... to answer your question, like, in music I think I do project the colors onto the page more than I do when I'm reading. But even when I'm reading, I still... there's some, there's some colors on the page, but it's more in my mind when I'm reading a book.

Further down her narrative, Debbra also points out to the colors being in her mind's eye, however. The next subsection starts by accounting for that portion of her statement and introduces the idea of a middle-ground between projective and associative synesthetic reality of colors among these participants.

\section{Middle-Ground}

Four out of the twelve participants gave clear indications that their synesthesia cannot be classified purely as projective or associative. Some have said it is "in the middle" or described having color sensations both in their mind's eye and on the page. The following statement, for instance, is quite lengthy, but it entails several interesting points for discussion on this aspect of synesthetic reality. She also traces comparisons with her grapheme-to-color and number-to-color synesthesias to explain what she experiences in relation to music notation. As she strives to describe the location of her synesthetic colors, Debbra touches upon issues such as reading from different media (a book versus an iPad screen, for instance), conceptual basis, and, ultimately the problematic issue of classifying synesthetes as belonging to "either/or" categories.

Um, I think... Okay, I think it's both for me, because I don't actually... like, when people ask me about it... like, when I tell people about it, they're like, "what is that?" And like, "do you actually see the colors"? My answer is "no, I don't actually, really, obviously... I don't really see those colors on the page, but then they're triggered in my 'mind's eye'”. But then if it's, like, a piece... So... at the same time, I think it's different for reading words... because in words, like, in English, there are so many different combinations of letters that you can have the... like... so like, how do you know what color that word is? Well, it's a bunch of different colors, but the word usually takes on the color of like... most, for the most part... it takes on the color of the first letter. Like that's like the strongest letter for me. So, like, the... 
it's interesting... or, like, the number 4 for me is like a dark blue... the number is... but then like the word "four" is more purple because F is purple. Anyway, so when I'm reading on the page, like, I usually... those colors go in my mind and usually mostly based on the first letter, but I do see the colors of all the other letters. I just kind of don't pay attention to them as much. But then, when I'm reading, like, I'm not actually, like... I don't think the colors are on the page as much for me, especially for some reason, when I'm looking at a screen. This is weird, but when I'm looking at a book, I definitely tend to see like the colors more on the letters in a real book than if I'm reading an online article... I don't know why. I still get the colors in my mind. But on the page, it's like completely white and black because I guess screens are just... I don't know. Yes, more bright, brighter, like more imposing... Yeah, so the book is, I guess not as imposing. So, I can, like... my mind can, like, really put colors together, I guess.

Debbra goes back to applying this explanation to her music notation-to-color synesthesia.

But then, in terms of, like, when I'm reading music, I definitely... I have the trigger in my "mind's eye". But I also definitely, I don't actually see the colors on the page, but they're just... they're in such a much stronger presence. Because it's always in the same place. So like on the staff, $C$ is always a $C$... it's always going to be yellow in that space for me. And because I've been growing up with music all my life, I had like my whole life to establish... those areas of the staff are these colors... So, I feel like that happens more in music than it does when I'm reading, because words are always like different combinations of different letters. Whereas, like, I know in music, like, obviously different pieces of music or different combinations... I have noticed this, but the staff is always there. So, for some reason that's stronger to me in terms of actually, like, the color being projected onto the page because it's just always there. But like, I've recently started using my iPad for like for gigs and stuff. So, talking about, like, that screen-to-book connection... So, like old... old school, like, music on paper that I've grown up with my whole life, like, that's all colorful and stuff in my brain because it's just... that's how it is. But in my iPad, I... I haven't used it enough to really, like, make that determination of reading it and not seeing the colors as much but what does bother me is when you, you know, like the pencil, like for the iPad... And so, like what I'm writing in fingerings, or something, or bowings with the pencil... it comes out in one color, like red, so I would mark... I would mark it in red. And then it's like all of my bowings and fingerings are in red because that's just the color that the "Pro" [version of] Forscore assigns the pencil and so that bothers me because on a regular piece of paper, it would just be in pencil and for me, like, the pencil is such a lighter presence, then like this red-like downbow... (Laughs).

Debbra's statement surfaces different topics that pertain to other analytical codes and other portions of this dissertation, but the potentially changing quality of her color 
realities depending on the medium from which she is reading music notation or text is certainly worth noting as a unique aspect mentioned in this study.

Alba seemed to be a projector at first when I asked her about the reality of her synesthetic experience of colors in relation to music notation, but it also appears that her colors are present on the page as well as in her mind.

Kinda, but I'm not sure if it's an actual projecting kind of way that I would physically see it as such. But I would kind of visualize those colors as I play them.

And then, of course, I would... when I look at a page of music... I would project the color of the letter, I would see it as... but I would also kind of associate at the same time, like, weirdly. So I would more experience like a cloud of color in my head as well as projecting the color onto the note.

James's perception of color tends "toward the music", but its location can vary depending on a number of other factors in his perception, which he describes quite vividly.

Yeah, so for me, the notation to color since these... Yeah, is it's like a lens that I can bring into focus... instance between me and the music and I would say it's never... it's something that affects when I'm looking at the music it affects my entire awareness I guess. (...) But it's not always is not ever distracting and I would say I can bring it I can bring it to the forefront or being bring it more to the background depending on how I feel. (...) My level of tiredness, emotion, stress, whatever it all affects that and in a sense as a filter, and generally it's between me and the music, but also all encompassing, I guess. (...) I would say it's definitely toward the music. But again, if I'm reading music, if I'm looking at a page, my focus and my attention is also that way. So it's, but it's bigger than that, too. So I don't know, it's maybe a mix of both a little bit. Because it's, it's definitely... the page definitely possesses it. But then, especially if I'm moderating it, it's everywhere and even if it's just mental ideation, if I know what the note is, if I'm thinking those notes thinking that sound it's, it's around as well as at the page.

James experience of color appears to be analogous to an interactive "lens", in his own words. James voluntarily shared a visual depiction of his synesthesia, which he created with the aid of a computer, reproduced here in Figure 9. While it may not capture the shifting character of his colored lens, it gives a glimpse into the colors he sees. James's 
experience seems to be shared by Daisy, albeit in a different way. When asked about where her colors are experienced, Daisy said:

Definitely in the middle, because if... if I have the case where I've picked up a piece of music for the first time, and I see the key signature, I already have a first impression of what it would look like in my synesthesia, and then if I start playing it, it could either be entirely correct or it could be entirely wrong, depending on how the composer used it. Especially with 20th century composers who don't necessarily follow the "rules of theory" and they can go off completely on a different path than expected you know? (Chuckles).

The difficulty in subscribing to either the projector or the associator category challenges these individual differences in terms of their conceptualization in literature (Leeuwen, 2013). Heidi is a further example of that. Her statements showed evidence of projection as well as association, yet it is not possible to pinpoint which defined category she belongs to, in judging from the phenomenology of her perception.

\section{Chapter 7 Summary}

This chapter has analyzed the narratives of participants in terms of the location of their color-based synesthetic perception of music notation. Some participants reported to be associators, some projectors, and some to belong to both groups at the same time. In special, a middle-ground alternative was created in order to allow for narratives that do not belong to only one of these categories to be just as thoroughly accounted for. Chapter 10 will discuss the implications of these statements in light of the literature. The next chapter will report the findings related to the implications of music notation-to-color synesthesia for music education. 
Viola

Symphony No. 40

VIOLA

Allegro molto
div.

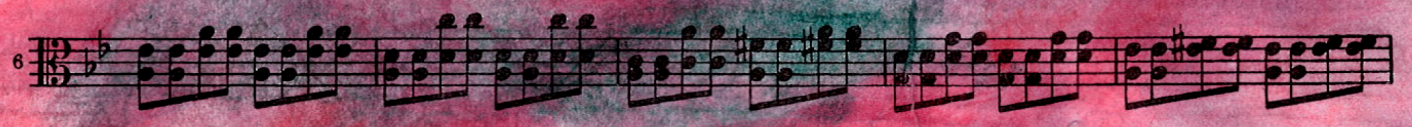

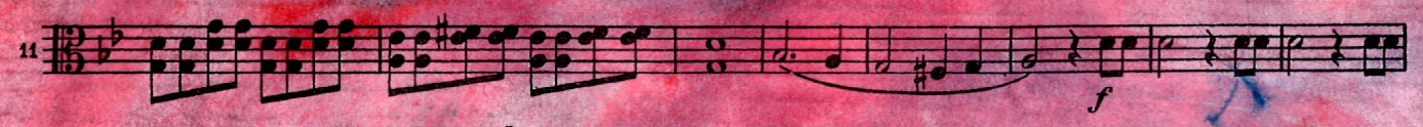

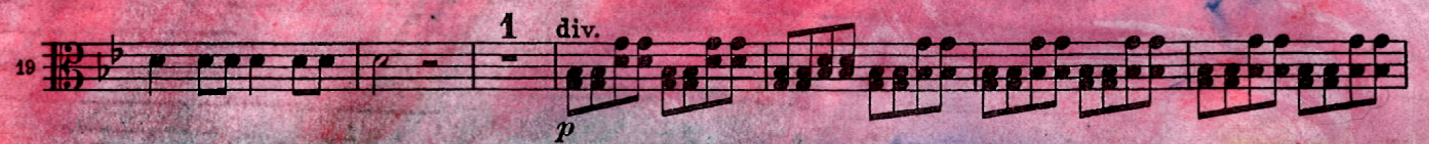

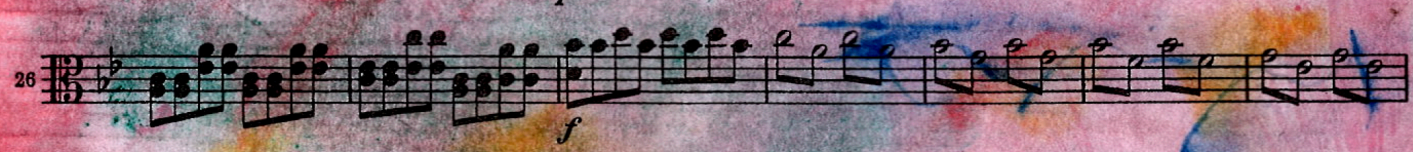

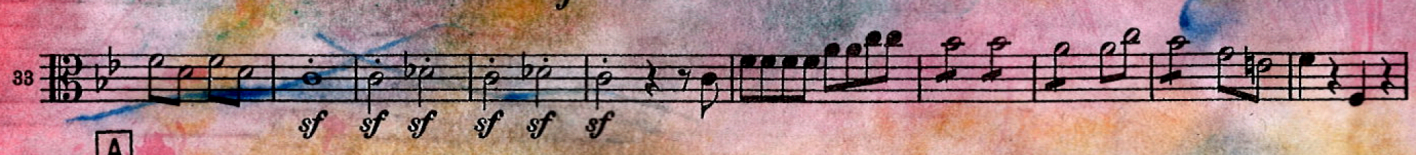

A

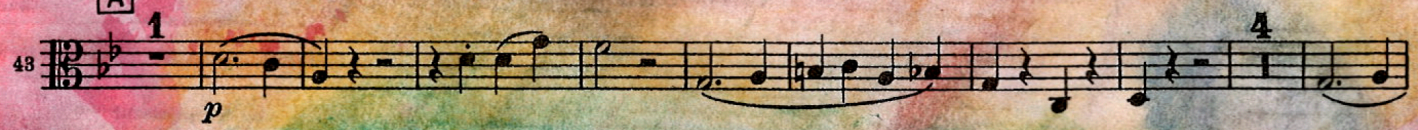

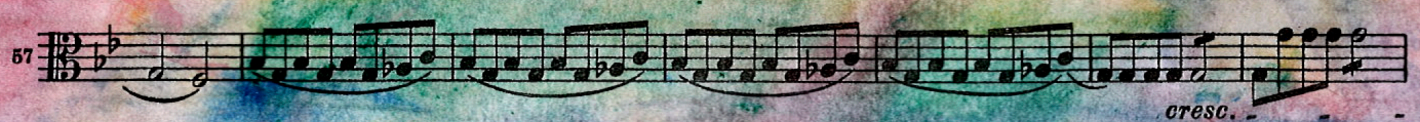

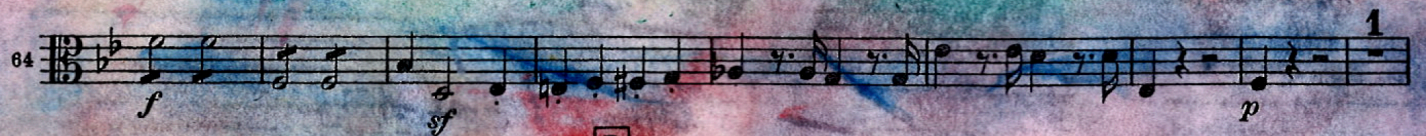

更)

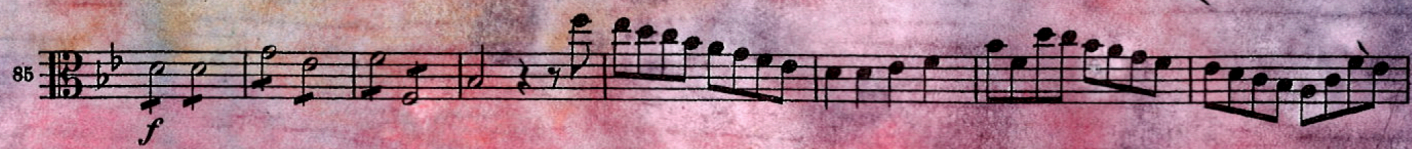

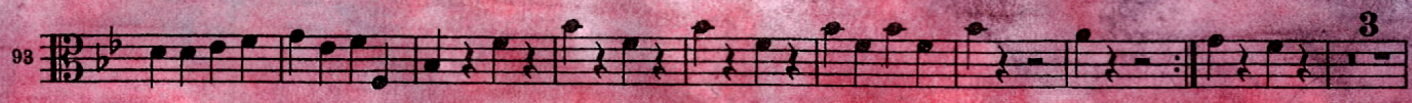

Figure 9. James' perception of music notation. 


\title{
CHAPTER 8
}

\section{IMPLICATIONS FOR EDUCATION}

\begin{abstract}
Overview
I'm going "but this is a superpower!" (Chuckles). "Like, why are you embarrassed about this?" -Kailey (participant)
\end{abstract}

Chapter 8 entails analytical codes that relate to one of the most important categories in this research-potential implications of notation-to-color synesthesia to music education. In having surveyed participants' early stages of music education throughout the interviews conducted for this study, this analysis now shares their perspectives on how music education may be improved in terms of teaching notation to synesthetes.

In the voices of these synesthetes, it was possible to hear concerns and issues pertaining to a desired awareness on the part of music educators, instructional intentionality in teaching synesthetes, and validation of students' different forms of synesthesia. Contemplating these narratives from the perspective of synesthetes creates a priority for what some of synesthetes' general needs might be like in reality. These recurring and salient themes are laid out below in conjunction with quotes from the participants. 


\section{Awareness (on the Part of Educators)}

When asked what they would have liked to have seen in their own teachers' methodologies in the past or what they think teachers should do in the future in teaching music-related notational concepts to synesthetes, several participants mentioned awareness about synesthesia.

So, first of all, like, kind of being aware of it in a student is a huge step right there. Because you might run into that.

The awareness they allude to may go beyond reading an article online upon finding out that a student has synesthesia. It may mean educators should be trained to deal with that degree of differentiation as thoroughly as they are trained to deal with other well-known perceptual differences, such as the ones caused by ADHD, for instance (Bédard et al., 2010). Esther says one might "run into that" as a teacher and should, therefore, be prepared beforehand.

Kailey shares her experience extensively from both a student's and a teacher's point of view. She draws upon other forms of synesthesia to explain her personal experience and what interactions in the real-world classroom may look like for both the student and the instructor.

Also, for me, it made sense that reading as a child was incredibly difficult and I really did not know why until I had a reason and it was like, "Okay, great. I'm not, you know, crazy." My grades were fine. I never had a problem and I love math, because number-colors make me you know, very excited. But yeah, I wish I could have explained it to my teachers and been like, I just need to slow down a little bit.

But as a five-year-old, how are you gonna know to identify that? So, to me the challenges that I had most, like... I told you, reading as a child scared me to death because it was so overwhelming. I did it! I love it! I still love reading, but I didn't... I just wish my teachers knew that it was harder for me because of what I'm seeing. But that's just for classroom stuff. That was really, really hard for me. But musically, I just wish... it's kind of like I told you with the lessons like... talk about color more, 
explain why this matters... because with kids... and I think you as a violin player, we know that the future of classical music is very much in question.

I think most teachers don't know what synesthesia is. So, why on earth would they know what it is? (Chuckles.) So, I think getting the word out there first is probably the most... But do you see, do you see it as something that is a music teachers '... I'm not gonna say "job", but I mean, I took it as my job because I was the only one that was probably a resident expert on synesthesia... but do you see a future where we can test kids early on to see if that's something they might have? Because it just doesn't exist.

Her question is rhetorical. The notion that teachers at large are still unaware about synesthesia is somewhat alarming, while it may affect about $4 \%$ of the population (Cytowic, 2018; Simner et al., 2006; Simner \& Hubbard, 2013) and research in neuroscience and psychology have approached the topic substantially in recent decades. This pervading lack of awareness about synesthesia and its role in learning processes in itself is an argument for change. She continues:

I have been thinking about that for years. Yeah, yeah. I think just having an open dialogue with kids about it. So, if they do have tendencies, they can find them and use them to their advantage, you know. But yeah, I'll continue to think on it. And I'll email you if I come up... But I thought about it for years, like how could... how could we use it more, but most people don't know what it is so...

In other words, awareness may be the starting point for change. Without awareness, there can be no change (Freire, 2013). Debbra observes that change can take place when awareness has taken place first.

And, and then the teacher could like understand, I guess how my mind would work but also, if let's say, I'm the teacher, and if I knew, like, if a student had... so, if I said like, "if you're a synesthete, hand in a piece of paper, like manuscript with all the notes and colors"... Um, then as I would teach that student-let's say, like, they weren't as in tune - I would say, "oh, like, make that note more green!"

Debbra is suggesting that awareness may be, in turn, a result of an intentional connection with individual students and a willingness to understand how she/he perceives music. 
This lack of awareness on the part of educators generates a lack of awareness among synesthetes' own perceptual differences. An individual's oblivion about her/his own synesthesia may overlook a potential, or a latent opportunity, for it to be employed consciously throughout the educational process on the part of the synesthete. Of course, synesthesia may always be there as a perceptual phenomenon, whether or not awareness takes place, but the conscious usage of this innate set of associations may be instrumental in ensuring student success. In approaching awareness from this standpoint, Amanda says:

I think that if my synesthesia had been pointed out, it could have been used in a structured way to say, "Okay, look, remember the color and like, here's the colors". And I guess I wonder if that would have, like, really helped me or sped up the process or really had some big impact.

Zoe brings back the problem of incongruence and how it can be not only avoided but intentionally and purposely dealt with on the part of educators. Zoe suggests:

I definitely think a teacher needs to be aware if they've got a synesthetic student using kind of prompts that don't fit with their colors because that's just wildly confusing.

At this point in time, with such a vast array of research-work taking place across disciplines, these participants seem to be suggesting that this awareness can be afforded. They seem to propose that it is the teacher's responsibility to keep up with a constant advancement in research on how the brain works and how inadequate certain teaching methodologies can be in dealing with learning differences. After all, learning music can be "wildly confusing" for the synesthete, in Zoe's words, and, therefore, a potential focus of attention on the part of instructors. The discussion portion of this study will point out, however, that this is a problematic assumption, given the slow yet growing accessibility and acquaintance with synesthesia literature on the part of educators. 
James does not have substantial experience as a music teacher, but vocalizes his perspective from a music student's standpoint. When asked if he would do something different when he starts teaching music more often upon completing his education, he replied:

I would, absolutely. If, like, as I begin teaching more, I would be absolutely... it's... "do you feel in color? What color is this? What do you... what emotion? What feeling? What color do you want to get across to your listener? " Because I think if you're aware... if you're aware that it's a thing, even if you don't have it then you can be aware of maybe how other people can perceive it...

James goes beyond color-based synesthetic sensations in his response. His understanding of synesthesia attests to the potentially multimodal manifestation of the condition and the myriad of connections these modes may entail. Growing awareness about synesthesia in music education may illuminate perception differentiation and allow for novel methodological approaches. These narratives start to suggest foundational ideas and methodological considerations for teaching synesthetes.

\section{Teacher Intentionality}

Intentionality on the teacher's part was broached by the narratives quoted in the section above. Kailey is a synesthete and has had over 16 years of teaching experience as a music educator, she says, departing from music notation and considering music education in a more general light:

Um, I mean, I think it's nothing but a bonus and the few students I've had over the years... because I try to talk about this very vocally with my students... because I know there's kids out there that have this... they, like me... a few students that have clued in and, you know, come to me privately like they have some secret, "I think I have this," (...) It's been fun to watch them experience music more in a joyful way.

So, I get my students to really listen to a lot of music and I say, "Okay, what colors are [hearing] you here?" "What are you seeing?" And if I allow them to open up that amount of imagination - which I don't think a lot of teachers talk about much- 
they talk about, you know, the finite, period, the eighth notes, and here are the notes and here's [indistinct], but you get more into the abstract, which really what is synesthesia, then they can experience music or on their own whether or not they have synesthesia. I just wish there was a way to talk about students more openly with it.

Her suggested methodologies are somewhat broad in scope but do include a certain degree of flexibility and exposure. Esther agrees that this flexible methodology would "keep things more interesting" for synesthetes.

In thinking about how teachers can get specifically involved with their students and learn about their individuality of perception, Iria suggests:

[Teachers could ask] kids or the person who is learning music: "let's put here all the notes, so, can you tell me what color is this note for you?" If the personal says, like, whatever or can't really associate a color to a note or song, [fine]. But, if the person does, I think that the teacher can take note, right? So, put everything there, each color with each note and then start, for example, with sheet music on paper. Yeah, for example, "this is a song in D major. Does the green color make sense for you, right?" "Oh, yes." "So, I'll put like a sticker here with green color in the front of the page." So you can, like, I don't know, it will help you.

Debbra also attests to this intentionality. As a music educator herself, she shares some of her strategies:

Yeah. Yeah. And as a teacher, I tried, like... I don't know how, like, everybody's different when they teach... But, like, for me, I tend not... I try not to write in so many numbers for the kids. Because otherwise, they don't know the pitches they're playing, right? So, I try and, like... okay, every once in a while, like, open string, whatever, or fourth finger... if you want them to play with fourth, but, like, other than that, I try and leave it blank... so that if they're going to put something in, I want them to put the letter names in. But that's just like my way of teaching beginners and, like, I know other people, you know, use numbers and, like, there's different thoughts on, like, how to teach beginners... but maybe that stems from my own experience of, like, prioritizing the letter names... because of the colors.

So, I think I... I could use it in that way... like, what the student is. But it would require me learning their colors. Which could be... like, so first of all, like, not all my students have it. Like, if I found out that one of my students did have it, I would want to learn their colors. But then, like a different student might have different colors. So, um, yeah. 
Yeah. Like I would want them to make that for me. And then I could like keep it in a binder somewhere so that when they were in my class, I could be like, "Oh, yeah, this person thinks about it like this." ... I was gonna say, I think [it] would work really well for private teaching.

In bringing up private teaching, she identifies a mode of pedagogy that could highly benefit from this approach, although there could be applicability to the classroom as well, as Kailey suggests.

For Alba, the interest of teachers in learning about students' specific forms of synesthesia is fundamental, as synesthetes will often have widely different synesthetic experiences to virtually the same stimulus.

And I think, like, if I had a student who did have that I would try to kind of learn about their type and make reference to that in a way that would help them to, you know, maybe learn or memorize or something like that, to understand a concept.

This idea of individuality and reinforcement of unique synesthetic traits through validation is analyzed in more detail below.

\section{Validation}

One of the most impacting raised themes was the desire for validation. In recalling their experiences as synesthetes during early stages of their music education, participants recognized their felt need for validation of their condition from a positive perspective. Several of them voiced feeling like "weirdos" growing up, which prevented them from sharing their condition with others at times (whether peers, teachers, or family) and hindered them from using synesthesia consciously. Encouragement of different modes of perception and expression have been welcome in reformed educational approaches and methodologies, as the second chapter of this dissertation discusses in detail. It should not be otherwise with synesthesia. 
Esther shared:

And then everything out here (motions at the space outside her head) is like, it's not like in my mind at the time, it's like, "that stuff is not supposed to make sense or not real. Right?" That's what you [think] as a kid, right? Well, I guess validating it at the time or in trying to use it would have helped us all, I guess. I don't know.

(Laughs).

Daisy also suggests that, as a teacher, encouragement is a foundational attitude toward

synesthetes. Daisy is a music educator who works with bands and her perspective is grounded in her professional expertise.

I think I would definitely want to encourage people to... not only just students, but any adults that I would ... that I would work with ... to really allow themselves to be free in their thinking when it comes to music because we're... we're visual learners, like, everyone is either kinesthetic, or visual, or auditory... like, everything is incorporated when you play music. So, if I were to tell a young student who has no idea what they're experiencing, except that they see something... they see a color, or they see a shape, or they see a thing. It's fantastic! Because it means that there's a part of that brain that's incorporated within the music and I would definitely encourage that.

Kailey admits being particularly vocal in her extensive experience as a music educator as well.

Because I try to talk about this very vocally with my students... because I know there's kids out there that have this they like me... a few students that have clued in and you know, come to me privately like they have some secret, "I think I have this". It's been fun to watch them experience music more in a joyful way because they finally understand, like, "Oh, I'm experiencing something that other people in the room aren't getting." And so, I wish, you know, I'd had as a kid... to be able to understand that ... but I just, I didn't know. So, yeah...

Well, and I think, like, the students that I taught that had autism, when they really were able to articulate what struggles they had, it was so much easier to teach them. I think it's the same with synesthesia. If a student can express something to me, I can take that and use it in a lesson that brings them into the picture a little more, you know, so that's why I'm very vocal about it. You know, a few students... I've had one in particular. She had it in a very, you know, simplistic form. She understood that... she was embarrassed and she just was like, "I hope nobody finds out". She talked to me about it. I'm going "but this a superpower!" (Chuckles). "Like, why are you embarrassed about this?" So, yeah, it's funny. It is. It's like they look at it like it is 
like an "autism", like something's wrong with your brain and I think it's the opposite. I put it out there.

The positivity and validation Kailey demonstrates to her students are remarkable.

But I always did have a wish that... I wish kids knew it's okay to have it... plus, how do you actually use it as a superpower? Not as a detriment! Because as a kid, I thought it - and I'm sure you too-that you are wrong in your brain because you're categorizing things.

I have been thinking about that for years. I think just having an open dialogue with kids about it. So if they do have tendencies, they can find them and use them to their advantage, you know. But yeah, I'll continue to think on it. And I'll email you if I come up... But I thought about it for years, like how could... how could we use it more? But most people don't know what it is, so...

It was illuminating to have interviewed so many music educators. Debbra also

speaks from her pedagogical expertise as a music educator.

Yeah. And then also, like, for the student to know that the teacher understands what they're thinking. I think that'd be so cool. Because, like, I definitely did not have that when I was a kid. I just thought I was weird. Like, my mom told me like, "nobody else has this. You're weird." Like, not in a bad way. But just like, "your brain is different than everyone else". So, I thought nobody else really got it, except that I started meeting other musicians that had it every, like, once in a while in my life. So, I think you're like the fourth person that I know that has synesthesia, who's a musician... Um, but even just, like, as a teacher... to have that chart would be so good. But I think even just giving the student the knowledge that your teacher gets you is such a huge tool that you can reach the student much faster. Like, they would just trust you more, then.

Children, in particular, can be quick to judge their peers and make fun of other students' differences. Teacher validation could also signify affirmation in regards to students' peers when it comes to their unique synesthetic perception. Alba proposes:

I think, first off, they shouldn't make the student feel like they're weird. Or it... or that they shouldn't use it. Because, I mean, one can't turn synesthesia off. And I think, like, just like showing interest in this student's synesthesia, for example, like, to show interest in mine, and it makes me feel very accepted and want to, you know, use it in a way that's constructive. 
Alba is a piano major in university and appreciates the recognition of her perception and the opportunity to use it intentionally for her advantage.

\section{Reinforcement of Individuality}

A simple strategy that can be used with synesthetes is awareness about their individual perception. This may bring implications for teachers in that they should know their students individually and be acquainted with their ways of learning. Larger classrooms might pose a disadvantage, but equipped educators usually discover ways to communicate with each student effectively. Getting to know each synesthete's manifestation of the phenomenon may be of utmost importance for teaching them effectively and, potentially, the only vehicle for finding out about their synesthesia. Iria exemplifies how a music teacher should address such situations:

Yeah, for example, "this is a song in D major. Does the green color make sense for you, right?" "Oh, yes." "So, I'll put like a sticker here with green color in the front of the page." So you can, like, I don't know, it will help you. Or maybe, I think, like, just keep associating and let the person keep associating the color that makes sense for this person.

Samantha's perspective aligns with Iria's.

I don't know, I think, maybe... maybe, I guess... like, kind of, like, talking about it first when... if you're doing, like, for a particular students and, maybe, I don't know, for me, I keep wanting to link it back to, like, memorizing or something... like, maybe when learning a scale. And it's, like, "oh, remember how this scale goes... Like, follows this pattern of colors or something like that". Or key signatures or anything like that... Yeah, when you're first learning, like, the basics of music theory.

Debbra thinks that asking a student to demonstrate her/his synesthesia could be effective.

I think what I would probably do for my student, or what I would have wanted a teacher to have done for me would just give me the staff and a bunch of pencil crayons and color in the colors of the notes. And or would like draw whole notes, but in the same color, or quarter notes in the color of what they are for you. 
Or I could say, like, oh, like you're maybe they're having trouble like shifting to third position or something on that note, like, why are they always having trouble on that note? And then maybe I would say, well maybe think like, what's your color for that note and think that color? So I think it would help in terms of, I guess, pitch and like being in tune the most. In terms of rhythm I guess it could help with numbers. Like, let's say like how many 16th notes or two quarter note there's four like color of 4 for you. So like it could be applied to that... I definitely think it can be applied to timbre, like when you're asking for a certain tone quality, although I don't know because if colors are assigned to pitches... like then how could that apply to tone quality, but if you wanted the tone quality to be like more, I don't know, resonant, it could apply because it's more in tune when its resonant. So, um, yeah, and like in terms of dynamics, like, I guess it would, you would just ask for like a more vibrant shade of color, like, like, like in, in visual art, they have like the principles of design and instead of the, like, you know, like the elements of music for musicians, but like in art, they have the principles of design in the elements of art, and one of them is value. And so, like value is just like the brightness or darkness of that color. So for a dynamic, like, let's say we're playing the note A, and A for me is blue. Well, like it's going to be a brighter version of that blue for, for like, a louder, dynamic. I guess you could say.

In speaking of this individually in a synesthete's perception and the required intentionality on the part of the teacher to reinforce unique associations, Kailey mentioned a student synesthete of hers drew out the colors for her so that she could have an idea of what his experience was like. He drew that on his iPad. Figure 10 reproduces the graph she shared with me. 

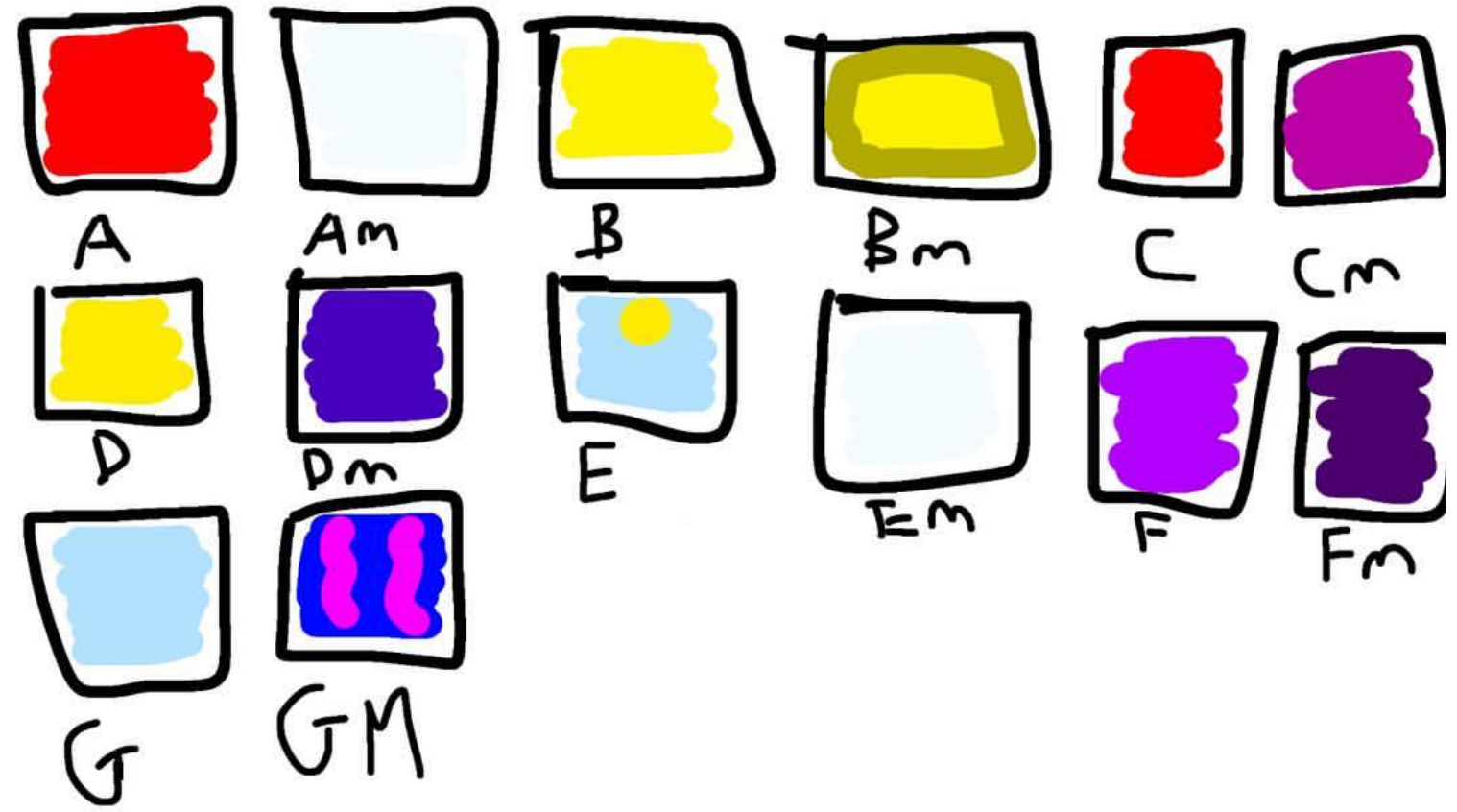

Figure 10. The color associations of Kailey's student.

This example illustrates quite evidently one of the strategies some teachers have already been using. Esther suggests that, in so doing,

... teachers could ask a student, like, to... you could come up with your own language almost in learning music this way.

In other words, learning the student's language is fundamental in making her/him succeed. Three other participants suggest much the same. Alba, Heidi, and Zoe say, respectively:

And I think, like, if I had a student who did have that, I would try to kind of learn about their type and make reference to that in a way that would help them you know, maybe learn or memorize or something like that, to understand a concept. (...) And also not giving... not trying to impose a system that would be similar to synesthesia ... and trying to make the student learn that kind of overtop... like I said about how in Greek [my professor] has his system of color coding, and it's so confusing. I can't remember half the time what his system is because I just have "genitive-bright green", "dative-blue". Alba

So, I've asked, I've asked students in the past... I've never... I've never taught synesthetic students, to my knowledge... not a private student in a way... in a 
classroom setting, I don't know... but in a private setting, I never have... but I would encourage them to come up with mnemonic devices, like I have done with their colors or whatever... Um, and even if it's something just completely silly, it doesn't matter if it doesn't make any sense to other people as long as it makes sense to you and helps you retain the information. That's what matters. So, yeah, I would... I would encourage that. Heidi

I guess me, I don't know... it would be interesting to know that if you had printed the notes in the colors that I see, would that have helped me learn faster because... again, it would have been, you know, another prompt that... "it looks like that and it feels like that and I put my mouth like that to make that..." [indistinct] or even if I tried to play the piano with two hands if I had a color, you know... in the... in my peripheral vision that my left hand in it to be making a green... might have been easier for me than trying to, you know, yeah... Zoe

These entail simple, feasible, yet potentially effective methodologies which are discussed in detail in chapter 10 .

\section{Memorizing}

This research's analysis of the significance of synesthesia for memory in chapter

5 was brought back into the picture when participants were asked about how synesthesia could be used in education. Esther states:

And then, secondly, using it, like, using it for memorization, using it to come up with kind of, like, a language or a way to read through music with your students... things like that. I think that could go a long way. Because, I know, I didn't always have the easiest time kind of learning in conventional ways. There's like a lot of clutter going on up there sometimes (motions toward her head).

To reference Zoe once more, she said that might be the very reason why synesthesia exists:

Exactly. And I think that is why synesthesia exists... because it does confer advantage. It's just a way of conceptualizing information that makes it easier to process.

Debbra expands on the way synesthesia could add to a student's ability to memorize notated music more effectively. She says enthusiastically: 
You know what? I think when I was learning, um... I just kind of thought of just the colors of the notes. I mean, I think I didn't really know what was happening in my brain, but I think when I was learning notes... and I was like, let's say, I was like, just starting violin... I guess I was learning in first position... So, the only two kinds of colors I had to worry about, I guess, were notes and numbers, but I can't remember, like, my first violin teacher. I can't remember how much... like I'd have to look at my old books, which I kept... I have to find them. Because I'm not sure how much those books use numbers. I think because of piano that I previously had that knowledge of the notes being the different colors, those took priority for me over the finger.

Debbra also believes that reinforcing associations intentionally is an important aspect of teaching synesthetes. She gives an example from teaching a violin student, who may be associating finger numbers with given notes. Even if there may be incongruence between the colors triggered by these two different concepts, the student should be able to understand them separately and overcome incongruence. In Debbra's words:

I was just thinking about how I think, for me anyway, like, the color of the pitch is like the letter name of the pitches more important, like the most important thing, because if you were to teach them shifting, like let's say, there was this kid that learned 11111 for E and then 22222, for F sharp or whatever. And then, so, like, they started, if they were synesthetes, they would have been memorizing the, like, they would have maybe been... sorry, associating.... those colors with the numbers of the fingers more with the notes than the pitches... so what happens when you shift? So like, if three is blue, but then you have to play it with one all of a sudden, it's white now and like it's not the same note anymore. So I think that's another reason why like the letters have to be more important, like the colors of the letters of the notes.

Debbra seems to be suggesting that memorization can be influenced by intentionality in associating. Heidi expands substantially on synesthesia as a mnemonic device. The first portion of the quote reproduced here was analyzed above, but now is contemplated in the specific context of memory and memorizing.

So, I've asked, I've asked students in the past... I've never... I've never taught synesthetic students, to my knowledge... not a private student in a way... in a classroom setting, I don't know... but in a private setting, I never have... but I would encourage them to come up with mnemonic devices, like I have done with their colors or whatever... Um, and even if it's something just completely silly, it doesn't matter if it doesn't make any sense to other people as long as it makes sense to you 
and helps you retain the information. That's what matters. So, yeah, I would... I would encourage that...

Yes, I have to show you this just because I think it's so fun. It's this slip (shows the interviewer a piece of paper). So, I mentioned that I'm teaching myself guitar. Oh, I needed a reference point between five and 10. So I ended up choosing eight. So eight to me is purple and 20... this is this is not exactly how I see my 20 but it's... it's a close enough mnemonic. These are the notes across the string... and how I view them. And so when I look at this fret, either... well... either 20... What's that look like? ... A hamburger.

The piece of paper she showed me during the interview is a mnemonic device of her colored notated pitches, which remind her of a hamburger in the order they have been used to memorize guitar-related patterns. Figure 11 reproduces the image she drew and shared with me. In this depiction, it is possible to see Heidi's colors for the pitches that she sees for the music notation. She uses those colors to remember the sequence of notes on the guitar strings and frets. Since her synesthesia is conceptual, the colors are transferrable between her music notation and the spatial location on the guitar. The order of note colors reminds Heidi of a hamburger, although she also provides the colors for her numbers (8 and 20). 


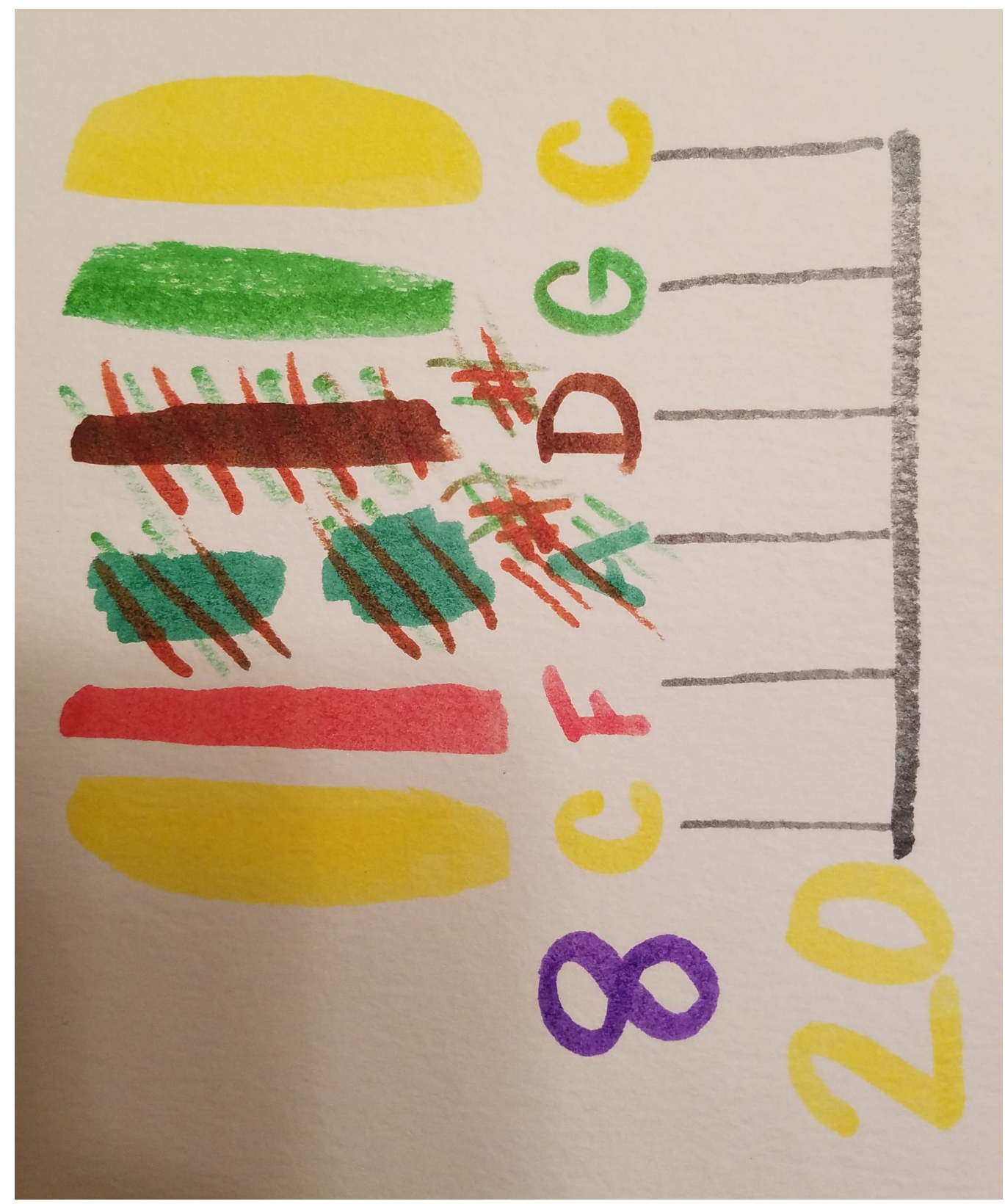

Figure 11. Heidi's color codes used to learn guitar.

Heidi continues:

It's a mnemonic device (...) with my colors. I mean, my $F$ is really a little bit more kind of reddish brown than that, but, you know, it's close enough, right? It's a hamburger! Yeah, even with the... Yeah, the two sharps in the middle. Like it's sort of that kind of brownie green, chartreuse haze. Reminds me of like, like pickles or something. (Laughs). And how I relate this to fret 8 and 20 is, I mean 20 you kind of get it... the buns with the Cs it's kind of a similar color... but 8, I'm like, "what if we put jelly on a hamburger?" And that's just like, that's the kind of silly mnemonic thing that I come up with that would not make sense to anybody else. Trying to learn 
skills or trying to remember notes on the fretboard or, you know, anything you can make up some kind of silly on it.

\section{Creativity and Imagination}

Furthermore, exposure to multisensory connections may open up avenues that spark creativity and imagination. I remember having a project like that in university myself. It involved color and sound. Kailey does something similar with her little students.

But kids, I think, it's more for me... since the abstract to me is so important... that's why I said in my classroom... I really tried to get them thinking very much on their own, visually. Because, especially with kids today, with video games and stuff, they're not, they're not allowed to think very abstractly anymore. You know, the imagination factor is not there. So, it seemed really important to me as a teacher, and something music teachers should be doing, especially for younger kids anyway, allowing them to come up with their own narrative... write their own music. And composition was something... I started composition with my kids as young as second grade, because I think it was important for them to go on and understand how to do it; and sometimes they would come up with really wacky things, but I allowed it, because they need to do that. So, I think more abstract teaching instead of "here's a box, here's what you need to do. Fill it in". So... I don't know how you make teachers do that. But I think it's more abstract, which I really try to do a lot in my classroom. So...

Yeah, I would have my kids, you know, draw a lot of pictures. We painted a lot in class, I try to bring those things in. And they would share with each other what they saw and I think it was valid for them to see that "oh, what I imagined was totally different than another kid" and, you know, sometimes that's... the best you can do is and whatever it is... it's awesome! (Laughs) Good for you. Yeah, I'll keep thinking about it, though, you know, it's been fun... I haven't been in a classroom for six months... So it's been fun to even talk about, like, what I do with the kids.

After all, participants recalled multisensory associations added something more to the concepts discussed - something extra. As Amanda put it, synesthesia "just added a little bit of color". Kailey, in turns, suggests that thinking in this direction with non-synesthetes may allow for new connections to be made. 


\section{Community}

Daisy brought up a theme that was not recurrent among other participants. Yet, it was coded independently due to its significance: that of bringing people together-both synesthetes and non-synesthetes. Again, the idea hinted by Kailey that when crosssensory or multisensory associations are regarded intentionally and consciously, they may benefit music students at large and not only synesthetes. Daisy says:

So, for me, who never knew about synesthesia until university, all of a sudden there was a new way to connect with other musicians. This musician thought of the same color as I did, something... "oh, fantastic!" We're... we're connected on the same plane and that alone is going to probably help us with playing together. So anything that would connect you more with your fellow musicians, I think it's fantastic.

As Heidi pointed out elsewhere in this analysis, there are frequent references to extramusical associations in music-making and music-teaching - many of which are crosssensory conceptually. These are understood by synesthetes and non-synesthetes alike. Perhaps, Daisy's suggestion that allowing one's associations to be known and recognized in a safe space would be instrumental in bringing people together in socially-based performance, such in chamber music-making, orchestras, and other, more intimate forms of ensemble practice.

\section{Indifference}

One of the participants brought up an instance that reflects a certain degree of indifference toward the educational role of synesthesia, which was also included here as an equally valid perspective. When asked if synesthesia affected his education significantly, James replied:

I would say I don't think so. But again, is that just me because it's always been present? It's just been part of the way I learned. It may very well be part of the way I latch on to... lyrics, even in other languages there's, they hold this emotion with 
them. It was never consciously a part of the way I learned. Up until recently it didn't even, like, come into my head for it to bother me, in a sense, but as I've... especially since we talked about it last year, it's like thinking about it and talking to other people about it. (...) It's probably affected the way I've learned, but not in any palpable way.

James' indifference was an alternative take on the matter of music notation-to-color synesthesia's potential role in music education. Yet, he clearly attests to the fact that it was part of the way he learned, albeit not consciously.

\section{Chapter 8 Summary}

Chapter 8 is filled with participant-led topics on educational perspectives and potential improvements for synesthetes when it comes to teaching them music notation and music at large. It touches on awareness about synesthesia, teacher involvement, validation and encouragement of music notation-to-color synesthesia, among other themes. Chapter 10 expands on these shared ideas and the commonalities between them, proposing an educational approach that is grounded on these narratives and experiences. The next chapter analyzes additional themes encountered throughout the coding process of this research. 


\section{CHAPTER 9}

OTHER THEMES

\section{Overview}

\section{I am enjoying our conversation... \\ -Heidi (participant)}

This chapter reports the findings that fall into the aforementioned three subcategories - (1) positive attitude toward the present study, (2) researcher-synesthete relatability, and (3) ideas for further studies - and closes with a brief survey of the use of terminology by participants throughout the interview process. This analysis was carried out in additional support of the validity and relevance of the data collected in relation to the objectives of this research and its design.

There was intentionality in this research design to foster a safe and friendly space for synesthetes to talk about personal, often inward experiences. The interviews, although semi-structured in nature, worked organically, like a conversation. All protocols of a qualitative approach suggested in the methodological procedures in this document were prioritized at all times and followed diligently, however. Participants remarked on their enjoyment of a conversation-like, "laid-back" research approach that is still founded in rigorous inquiry.

In particular, interviewees brought up two factors that impacted their participation. They displayed a generally positive attitude towards the research and also 
voiced the importance of qualitative research of this kind to be conducted by a synesthete. These two elements pose implications for synesthesia research. Additionally, some of the participants brought up interesting points that were tangential to this research but could be considered as probing ideas for further studies. I had not envisioned these themes coming up, but the organic nature of the conversation we had during the interview process allowed them to surface freely. These three broad themes are treated as separate codes in this analytical chapter.

Before exploring these coding subcategories, it is also important to note that the synesthetes in this study often asked me questions about my own synesthesia in trying to understand how the condition manifests differently for other people. Although I did not allow for my experience to interfere with what participants related during the interviews and remained faithful to the validation strategies proposed in chapter 4 , this eagerness to ask questions on the part of interviewees was intriguing. On the one hand, it points to the efficacy of an organic and dialogical interview process in approaching phenomenologically-defined data, in that they were able to explore their experience in greater depth. It also points to the need for communication to improve cross-culturally and cross-disciplinarily in raising awareness about synesthesia.

\section{Positive Attitude Towards Research}

Although the participants and I were strangers to one another when the interviews started, by the end we were often chatting like good acquaintances and being generally open about synesthetic experiences and about this research. In those moments, several individuals shared their perspectives, sometimes unprompted. Several participants shared their positivity about synesthesia research and were pleased to be part of a research 
endeavor such as this. This positivity is compounded with their eagerness to be heard as synesthetes and to change this pattern for students in the future. Iria, for instance, believes this research is particularly important for music education. She says:

So, your research is a very... a very new thing. No one has done before. So, I think it is interesting. It is important and anything in education that helps the individual, I think is valid. Like, if someone is, um... I don't know... if someone relates notes or words to animals or to, I don't know... to sensations or to... yeah, I think it can be used to, to improve the education process and to make it more natural and more interesting to everyone. I would like to congratulate you for [the] research. Very important. Another important step in education.

Samantha is willing to learn more about a condition that is ultimately part of who she is as a person and musician, and this research helped her to this about that.

I actually was interested to learn more about synesthesia, because rarely do I ever meet people who have synesthesia. You know... you don't get to talk about these things like the, you know, the patterns we all have, the registers, the dominant colors, memorizing. So that was really cool for me to hear more about it.

Esther, Daisy, and Debbra were interested in reading the results of the research they participated in.

Um... I would be interested in the results for sure, or whatever you come up with for sure. Esther

I will... I definitely like to hear more about it, like, as in what you're doing. I'm very interested in that. So, as the... as your paper moves along and gathers more momentum and you get more research done, I would love to read the final product. I'm not sure if it's close to today, or if it's a few months away or maybe years away. Who knows? (...) Yeah, definitely love to read it. I know that. A few of my friends who are also music educators, they would absolutely love to hear and read something like that as well. Daisy

I think it's really cool that you're doing this and I would just, like, love to see, like, when it's all done, like, if you have it or... anything in you know, I would love to read the results of that... Debbra

Kailey offered to keep in touch and continue conversations. She also mentioned getting into a specific project in her doctoral studies that has to do with synesthesia and wanted 
to keep in touch about it. Kailey is interested in the scholarly side of synesthesia studies as well.

Now, I'd love to keep in touch. And maybe I should try like one of those conferences sometimes, especially now that I'm starting to get into the PhD world. I'm trying to, you know, I've never done any of this stuff, even writing and stuff. I've never done much of it.

Amanda recognizes the importance of the relaxed nature of the interview process while remaining rigorous about the research methodology. She also mentions the importance of talking directly to another synesthete throughout the process of exploring her synesthetic experience. She defines this opportunity as "refreshing".

No, I think it's cool that you're doing a bit more laid-back style and just kind of getting just a feel for what people experience. And I liked your initial emails, they're very much just open, like, that you're just very curious, and that you also have synesthesia, and you just want to see what people will say, right? I thought that was a nice, refreshing approach... that was pretty approachable. And you're approaching it with a fun attitude. So I appreciate that.

The idea of relatability between the interviewee and the interviewer is discussed in more detail in the next subsection. Additionally, Amanda believes that there may be phenomena that might never surface unless there are open conversations such as these, carried out in a safe and secure space, where synesthetes feel understood and heard.

Interesting. Yeah, I'm glad you're doing this. I think that yeah, I think it's needed. And I think that there's so much more, you know, depth to the whole thing that we'll never discover, unless we just have a little one on one conversations like this.

This carries implications for synesthesia research in that certain types of survey approaches, especially those based on testing and scoring, might not provide this type of safety for participants and, therefore, compromise the validity of the research in terms of the ultimate reality of the experiences shared. 


\section{Researcher-Synesthete Relatability}

Some of the participants emphasized the importance of relatability on the part of the researcher in a study of this kind. Throughout this process of introspection, synesthetes participating in this study were brought back to moments of their lives that they may not have been able to fully share with a non-synesthete. In fact, some of the participants recounted their struggle in communicating their experience or in being understood when seeking to exemplify the qualities of their synesthesia to nonsynesthetes.

The resonances between their experience and that of the researcher were instrumental in allowing them to expand on their perspective and deepen their descriptions. Some of them felt heard and understood. Kailey was generally glad to be talking about synesthesia.

No, it's so good to talk to somebody about it, because it is not something you get to talk about much, so. Yeah, yeah, this is awesome.

Debbra mentions the inability of non-synesthetes to understand the condition more specifically, in pointing to their lack of resonance when it comes to a purely experiential perspective.

And, I'm like, so excited to meet someone who, like, understands the violin and, like, synesthesia and teaching and everything on all these levels. Like, it's so much fun talking to you. (...) it's really fun kind of talking about it in detail, because... Because you don't talk about it often. Right? So, you kind of explain it to people, like... like, the very short version and, like, you don't really go any further and so, like, to get to kind of answer these questions is really made me kind of explore it deeper and, like, discover things that I always knew but didn't really know that I knew... Yeah, so thank you for including me. And I always love talking to people who understand, because... yeah, because it's, like, fun and no one else understands. (...) Like, the other people who I know who are synesthetes were musicians. One's a singer and one's a clarinetist. So, it's like, yeah, like, we have some things in common but, like, they don't understand, like, what it feels like to play the violin or anything, like, how hard it is to switch to alto clef. 
Debbra and I shared more than one commonality other than synesthesia. We are both music educators who worked in the Toronto educational scene. We also both play violin and viola as our main instruments. Many of the examples she used throughout her narrative involved references to these areas of expertise.

Alba sums up the importance for a researcher who can truly demonstrate heightened empathy due to belonging to the researched group, in comparison to a researcher who is far removed from the researched phenomenon in terms of the raw experience involved:

Because, I'm, like, I talked to my family, a lot about synesthesia, and my brother is still convinced that I'm crazy. And none of them understands and my mom, when I first told her about synesthesia. She was like, "do I need to take you to the hospital?" So, I feel like it would have been a little bit similar with someone who didn't know they believed in the condition and everything. But believing in synesthesia is not the same as having [it] and so it's really comfortable talking to you because I can make, like, "odd" references. Like, this letter feels like sticky rice, and you'll understand even if you don't necessarily have the same perception. (...) You know, you getting a perception even if it's not your own perception. That's really cool. And yeah... (...) You understand the concept of having those perceptions. Because like, for example, would you have someone research science who wasn't a scientist?

Several aspects in Alba's narrative are worth reiterating, as they came across as essential in this context. She says: "believing in synesthesia is not the same as having it". While that could be seen as an obvious statement, she is saying that the depth of the experiential impact of music notation-to-color synesthesia may only be reported as accurately as it deserves to be reported if the researcher participates in, at least remotely, an analogous experience. In conclusion, she asks, rhetorically: "would you have someone research science who is not a scientist?" To be sure, there are many non-synesthetes conducting outstanding research on synesthesia. What Alba seems to be indicating is the ability to be fully understood in research of this kind. 
Furthermore, in her response, Alba seems to suggest that even though the modality, intensity, and overall quality of manifestation of any two synesthetes may differ widely, having synesthesia on the part of the researcher still encompasses a potential for understanding synesthetes' experiences more thoroughly. In her words, if you are a "researcher-synesthete", as it were, "you [get] a perception even if it's not your own perception."

Finally, Heidi points out that our conversation was, thankfully, not awkward:

Um, I... I find... so, talking about synesthesia with other synesthetic [people]. So, I either get one of two experiences: either it's very fun, like has been now, or it's kind of awkward. Absolutely. This has been so much fun. I... I don't get to talk about this often. My fiancé thinks I'm a weirdo.

Chapter 10 discusses these and other implications for current and further research.

\section{Further Studies}

Two possible topics for further studies are worth noting. Iria proposes a study involving two groups. She suggests an experimental interference and a comparative analysis in which two groups - synesthetes with the music notation-to-color form of the condition and controls - are juxtaposed.

Yeah. I don't know if this will work, but I think maybe... maybe it is good to try, like, to do an experiment to see if it works. And you've helped and asked these people afterwards, maybe, if it helped in the process, or maybe comparing with the other students that don't have synesthesia. So, as they use, they will not have the colors and everything to help them. Maybe it would be possible to compare the development of the two groups.

She seems to be alluding to a potential advantage (or lack thereof) on the part of synesthetes in comparison to controls. Iria is likely mentioning this in the context of the ability to memorize, which we had discussed earlier during her interview. 
Amanda poses a question that may affect the nature of synesthesia research at large. She asks if, philosophically speaking, the space and motivation for qualitative studies was afforded by a predominantly quantitative initial approach in the past.

And these earlier, you know, really trying to bring it to the masses and be accepted by scientists, I think, probably really important for them to not only share the qualitative and then but really get on that quantitative data, you know, and it may be... Do you think that's maybe part of why it's been so successfully brought in is because they've stuck to that or do you think that, you know, like, now that it's accepted as my point now that it's more okay, right? Recognize now we can get back to the qualitative and really kind of...?

This is a question that would benefit from a historical approach to synesthesia research. Both surfaced topics are relevant to the field and would benefit from further studies.

\section{Terminology Frequency}

A computer-generated query on terminology frequency was run with the collected narratives using the NVivo software in order to verify the centrality and recurrence of terms related to the topic of this study. Connecting words were excluded from the query (and, this that, etc.). This analysis serves as a validation of the themes reported in chapters 5 through 9 and attests to the overall priority for these themes in the collected narratives. Figure 12 shows a graphic representation of the salience of terminology in terms of their usage frequency. The size of the words in the graph is determined by the frequency in which they have been brought up in the interviews-larger words were more recurrent than smaller ones.

Expectedly, the terms "colors", "music", and "synesthesia" were among the most frequently recurring. Other music-related terms such as "note" "playing", "fingers", "pitch" were observed. Synesthesia-related terms such as "numbers", "letters", "associated", etc., were also prominent. Furthermore, other terminology related to the 
findings analyzed in this dissertation were "remember" (memory), "learning" and

"educators" (education), and "experiences" (phenomenology), among others.

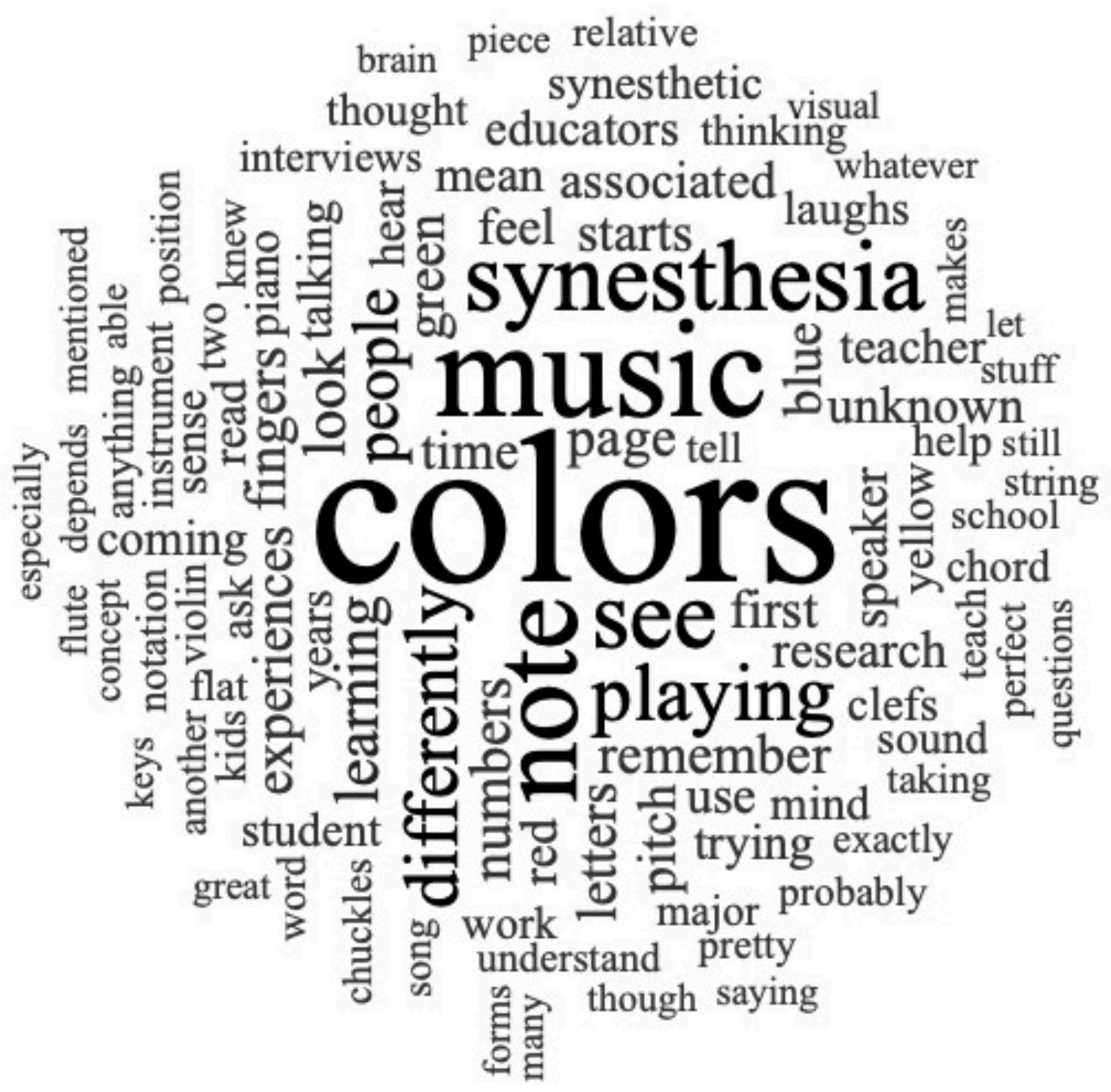

Figure 12. Terminology frequency word cloud obtained from narratives.

The themes analyzed through manual coding on the part of the researcher show close similarity with the terminology used by participants throughout the interview 
process. This points to the high relevance of the data at large and to the consequential validity of the quotes mentioned in this analysis.

\section{Chapter 9 Summary}

This chapter built on two additional supporting arguments in favor of the significance of this research: the positive attitude of interviewees and the researchersynesthete instrumental element in data collection, analysis, and discussion. It also accounts for two instances brought up during interviews that could be pursued in further studies. Finally, the chapter reports on a computer-generated query that supports the relevance of data collected for this study by analyzing the frequency of terminology used vis-à-vis the themes involved in the analysis through coding. 
CHAPTER 10

DISCUSSION

\section{Overview}

So if they do have tendencies, they can find them and use them to their advantage, you know.

-Kailey (participant)

This chapter contains discussions fomented by the collected and analyzed data. Some of these topics for discussion were alluded to throughout the analytical chapters of this dissertation and are summarized and elaborated on in the sections that follow. The core portion of this chapter has been divided into two important discussion axes. The first advances a grounded theory of the color-based synesthetic perception of music notation constructed from the findings of this study (reported in chapters 5 through 7). The second proposes another grounded theory of a potential educational approach that would benefit synesthetes with notation-to-color synesthesia constructed from the findings reported in chapter 8 .

Although the research questions posed in chapter 1 were answered along the way as the narratives were analyzed, this conclusory chapter addresses them more systematically. In promoting two grounded theories, this study provides answers on how notation-to-color synesthesia is experienced by participants, what the significance of those experiences is in relation to early stages of their music education, and what 
alternative ways might be in teaching music notation to synesthetes with this mode of the condition.

\section{Grounded Theory of Perception}

Creswell (2018), in describing the analysis and discussion of qualitative data in a grounded theory study, alludes to the creation of a "theoretical model". The creation of a model is, however, problematic when it comes to synesthesia. Although the condition might manifest similarly in a variety of ways across different individual experiences, the uniqueness of the phenomenon for each synesthete is fundamental in understanding its mechanisms. In other words, synesthesia is a highly individualized phenomenon. The findings of this research clearly point to these essential differences. In this sense, the creation of a rigid theoretical model may result in a likewise inflexible representation of the findings of this research. Rather, in constructing a grounded framework, the intention here was to create a theoretical plan rather than a theoretical model. Nonetheless, since this study was conducted cross-culturally, it may be likely that it has wide-ranging applicability and may be representative of a larger population of synesthetes with notation-to-color synesthesia in a more global sense.

\section{Theory Overview}

The flowchart reproduced in Appendix H shows the theoretical plan, constructed around the color-based synesthetic perception of music notation researched in the present doctoral project. The theory was created from the codes and thematic categories discussed in chapters 5,6 , and 7 , which report on the generalities, mechanics, and location of synesthetes' experience of color. The light-orange shapes stand for some of 
the prominent thematic elements of perception identified in this research. The blue shapes show their foundational relationships with the other identified main themes. The following paragraphs expand on these prominent thematic elements.

\section{Notation-to-color Perception Traits}

Along with awareness about the condition, one of the salient realizations in this study was participants' desire to have found out about their synesthesia earlier in their life. The desirability for a conscious engagement with their synesthesia was a recurring theme. If synesthesia awareness continues to grow, especially in the context of education, it would be interesting to carry out a similar study in about 10 or 20 years in the future. The yielded results would potentially reveal significant differences if awareness continues to grow. The lack of awareness about synesthesia on the part of educators was voiced by several participants along with occasional late discovery. From the analyzed data, it appears that synesthetes' engagement with their experienced phenomenon is closely dependent upon consciousness and awareness about their condition. Their partial awareness may also have had an effect on their ability to recall experiences accurately. Thus, awareness is, to some extent, central to synesthetic memory. Pfeifer et al. (2014) and Rothen and Meier (2009) also point to the role of consciousness in recalling synesthetic memories, suggesting that ability to commit to memory is highly dependent on awareness.

Participants did not necessarily import their notation-related colors from another linguistic basis, such as grapheme-to-color and number-to-color synesthesia. Several of the participants of the study have indicated that at least some of their pitch colors had analogous instances in their alphabet. The same was said of other notational symbols 
such as clefs, which in some instances adopted the color of a letter or concept they resembled, as in the particular cases of Alba and Zoe. The importing of synesthetic sensations across languages has been discussed by Asano and Yokoswa (2012), whose connection between primarily- and secondarily-learned languages may also be indicated in this study. If music notation is regarded as a potential secondarily-learned language, this transference could be at play when it comes to newly acquired concepts.

Moreover, this potential relationship between music notation and other languages has been observed in the participants who have multiple modes of synesthesia, such as Alba, Amanda, and Debbra, for instance. These participants have also mentioned synesthetic colors in connection with concepts other than specific pitches, such as clefs, time signatures, key signatures, fingerings, among other symbols. The multimodality of their synesthetic experience has likely a role to play in these non-pitched and nonverbal/linguistic notational symbols.

Several participants also alluded to the role of their focused attention in the triggering of their synesthetic experience of color. Most participants with specific colorbased concurrent sensations for specific pitches recognized on the page reported interchangeability of colors depending on where they focus attention. In being asked to describe the experience of a block-chord or a melodic sequence, they concurred in saying that the prominent color, which associated with a given concept, changes according to their likewise changing focal attention. In other words, focusing on the melody or harmony, or any other element will trigger different colors for the same musical event. This characteristic of their perception may also suggest a strong conceptual basis to their notation-to-color synesthesia, which is discussed in more detail below. 


\section{Location of Association}

Van Leeuwen (2013) discusses individual differences between synesthetes, thus conceptualizing two distinct categories: projectors and associators. While some of the participants in this study have subscribed to one of the two categories, several voiced experiencing both at the same time or something in-between. James, in particular, stated that his synesthesia is like a "lens" or filter between himself and the page of music notation. In his experience, while his colors may tend toward the page at times, depending on factors such as mood and level of concentration/tiredness, they are also flexible as to the exact location. Some synesthetes have also mentioned the feeling of being "enveloped" by the color sensation at the same time as projecting it onto the page - showing a potential co-occurrence of associative as well as projective features. As far as the participants of this research are concerned, subscription to either category on the basis of location may suggest a limiting approach to the reality of their synesthetic experience. This study shows that this reality might be better represented as a continuum (figure 13), rather than a finite set of categories (projector/associator). The middle-ground coding category created to describe this quality of the phenomenon accounts for rich narratives on this instance, such as James's "lens". (The associator > projector direction of the continuum line shown in figure 13 is merely illustrative.)

Associator Middle-ground ("lens") Projector

Figure 13. Location of color association continuum. 


\section{Conceptual Basis}

Different theories on the conceptual basis of synesthesia were discussed in the literature review. Researchers have proposed that the color associations are linked to a concept (Dixon et al., 2006; Paffen et al., 2015), whereas others have suggested otherwise (De Thornley Head, 2006; Ramachandran \& Seckel, 2011) proposing that they are independent of their semantic meaning. The findings of the present research point to a strong conceptual basis, however.

Most participants reported clearly on the conceptual basis of their synesthesia, often mentioning that it is the idea or notion of a particular music-notational percept that elicits a synesthetic color for them. Debbra and Heidi, for example, describe this process rather eloquently, in suggesting that they will not have a "final" color for a given concept unless they consciously recognize it as such.

The results of the analysis also suggest that perfect (absolute) pitch may play a role in the color sensation associated with a particular concept in the music notation, albeit in the same way as music notation does. In this sense, both phenomena (perfect pitch and music notation-to-color) potentially have a strong conceptual basis. Because perfect pitch and synesthesia are both automatic, involuntary, and consistent, it is challenging to point out which of the two come first perceptually. Iria and Kiera were the only participants who confidently reported absolute pitch among the interviewees for this research (Samantha and James may have absolute pitch through their synesthesia, but do not employ that skill consciously). Iria vocally attests to the automaticity and naturalness of both absolute pitch and music notation-to-color synesthesia in her perception. In any case, the concept of a note was very strong for her as well. Hence, the mere presence of 
absolute pitch in Iria's experience does not put her in a different category in comparison to the other participants in terms of her perceptual process.

\section{Positive and Negative Traits}

The dichotomy between positive and negative impacts of synesthesia in the perception of music notation has yielded two salient coding categories. In particular, themes such as musical memory and improvisational skills/proficiency were salient. Incongruence has also appeared frequently among the narratives as a significant perceptual element. The paragraphs that follow discuss memory/improvisation and incongruence, respectively.

Although Rothen and Meier (2010) have proposed that synesthetes do not necessarily have an intrinsically advantageous memory in comparison to non-synesthetes, pointing to the limitation of mnemonic devices in improving memory. In other words, mnemonic devices are only a tool for memorizing and do not entail a necessary improvement thereof. Nonetheless, this study has found memory enhancement to be the main benefit in notation-to-color synesthesia among interviewees. Several participants attested to their enhanced ability to commit music to memory and remember diverse notational concepts. Although no comparative studies have been carried out in relation to controls, interviewees displayed a strong connection between music-notational concepts and their associated colors. This idea aligns with the studies by Pfeifer et al. (2014), Rothen and Meier (2009), and Ward et al. (2013) discussed in the literature review, which were conducted with the processing of grapheme-to-color modes of the condition. There is an indication in the present research that enhanced memory may prove to be a 
generally pervading trait among synesthetes with notation-to-color synesthesia, although further testing is needed to determine the significance of this statement.

The instances of improvisation mentioned by participants in this research were almost invariably connected to memory. In remembering concepts such as notes, harmonies, among other elements, participants found it easier to recall specific portions of the musical discourse by means of remembering the colors associated with them. In moving between music notation and improvisation in music performance (two diametrically opposed concepts), synesthetic colors may be one of the strongest linking bridges between them.

\section{Grounded Theory of Educational Approach}

Theory Overview

In considering curriculum and instruction in terms of the best practices in designing the learning experience, teaching music notation to notation-to-color synesthetes would demand certain curricular as well as instructional reforms and improvements. This research proposes three phases that should take place before the curricular reform stage. These three phases were constructed from the collected narratives and entail an educational approach that could make this curricular reform possible. These phases are (1) devising a teaching philosophical foundation grounded in awareness, (2) fostering an educational framework that prioritizes individuality, and (3) envisaging methodological considerations that stem out of the previous two phases and continue to promoting individuality. These are mediated by ongoing intentionality on the part of all parties involved in this process, such as educators, administrators, and other fundamental stakeholders. The participants in this research have spoken about teachers and students, 
but awareness should pervade other hierarchical levels within education to make this desired reform possible.

Appendix I contains a graphical representation of the grounded theory involving these three preliminary phases. Since this theory does not involve individual perceptions, it will be henceforth referred to as a theoretical model. This model suggests an overarching teaching philosophy, a workable framework, and a methodological direction. The following sections elaborate on each of these phases independently. Much like the proposed grounded theory of synesthetic perception explained above, this theoretical model was based on the findings of this study as well as the literature approachedespecially chapter 8 . Short "golden" passages from the narratives were utilized in support of this model.

This educational approach is advanced in the present research as a general disposition and attitude toward teaching music to synesthetes, rather than a prescribed process for teachers, or administrators, or curriculum developers to follow. In this sense, this is the start of a conversation that this study recommends to all those who are interested in the educational success of music notation-to-color synesthetes in learning notational concepts and, just as importantly, using their synesthesia to their advantage.

\section{Phase 1: Philosophical Foundation}

\section{Awareness}

One of the salient themes observed in this research involved teacher awareness. Chapter 2 highlights the importance of awareness as the very foundation of change and curricular reform. To have "freedom of choice" is to be free (Freire, 2013). One of the research's participants, Kailey, said that “most people don’t know what it [synesthesia] 
is." Unless research on synesthesia reaches educators prior to their joining the workforce, awareness about synesthesia cannot be secured. This implies the infusion of a thorough understanding of synesthesia in teacher training.

A question for consideration at this point is: what does it take for a neurological phenomenon such as synesthesia to be considered worthy of study in teacher's college? More specifically: what does it take for synesthesia to be considered worthy of study on the part of music educators? Some might say it may be the incidence in the populationwhich we know to be quite high (see chapter 1 to 3) - while others might state that the extent of the impact on cognition may be a decisive factor- to which this study certainly attests as well. Research on synesthesia has been growing enormously over the last 30 years, but there is still much terrain for educational research to cover. Synesthesia scholarship is interdisciplinary by definition but, unless it reaches educational research and it is conducted rigorously in relation to its implications for the classroom, it is likely to remain unnoticed for yet another decade. One of the overarching aims of this dissertation is to help to raise this awareness in educational research. The following excerpts from participants' narratives speak to this respect:

I think that if my synesthesia had been pointed out, it could have been used in a structured way to say, "okay, look, remember the color" and, like, "here's the colors". Amanda

I definitely think a teacher needs to be aware if they've got synesthetic students using kind of prompts that don't fit with their colors because that's just wildly confusing. Zoe

So, first of all, like, kind of being aware of it in a student is a huge step right there. Esther

I think most teachers don't know what synesthesia is. So, why on earth would they know what it is? (Chuckles.) So, I think getting the word out there first is probably the most... Kailey 
Given the salient perceptual role of synesthesia explored in the present study as well as the relatively high incidence $(4 \%)$ in the population discussed in the literature (Cytowic, 2018; Simner et al., 2006; Simner \& Hubbard, 2013) it is essential for instructional awareness and preparation teacher training curricula to include a comprehensive study of synesthesia. This infusion bears implications not only for music education but for education in general. If $4 \%$ of schoolchildren may manifest synesthesia in some degree or form, it is certainly a perceptual deviation from the norm worth studying and understanding in preparing the next generations of instructors.

\section{Intentionality}

Another surfacing theme analyzed in this research was teacher intentionality. Participants said they wish their teachers knew about how they experience music notation individually. Their challenges and victories related to synesthesia were experienced from the standpoint of loneliness in that nobody else seemed to actually understand or relate to their condition. Some of their loved ones may have accepted it, to be sure, as some of the interviewed synesthetes discussed - perhaps a parent or a friend. Yet, their individuality of perception was uncounted for in the classroom on the part of the instructor and,

consequently, on the part of peers. Unless there is intentional involvement of educators in knowing their students and their individual needs, struggles, demands, and unique perceptions, there can be no preparation for difference and, therefore, no instructional diversification.

Intentionality is informed by positionality. Positionality, in turn, is only overcome with awareness. It follows that emancipation from positionality, through awareness, is the 
only way for intentionality to take place. In the theory graph in Appendix I, intentionality is the very transferring force between the first and second stages of this educational approach. It creates the momentum and motivation to go one step forward; to go from knowing, or being aware, to intentionally doing something about it and sparking change (Phase 2, discussed in the next section). These brief quotes from the interviewees speak of this resulting intentionality.

It's been fun to watch them experience music more in a joyful way. (...)I just wish there was a way to talk about students more openly with it. Kailey

But, if the person does, I think that the teacher can take note [of that], right? So, put everything there, each color with each note and then start, for example, with sheet music on paper. Iria

So, I think I, I could use it in in that way, like what the student is, but I... it would require me learning their colors. (...) And then I could like keep it in a binder somewhere so that when they were in my class, I could be like, "oh, yeah, this person thinks about it like this." Debbra

\section{Phase 2: Framework}

\section{Priority for Individuality}

The second phase in the process preceding a curricular reform that welcomes synesthesia is a practical phase. It involves the intentional doing alluded to above. It involves prioritizing individuality and uniqueness of experience above traditionalized instructional goals. Music education is, by definition, a traditionalized discipline. Although there has been consistent deconstruction of ineffective music-educational pedagogies in the twentieth century (Elliot, 2005; 2014), tradition-based approaches still pervade music education.

The experiences of participants in this study have shown many commonalities and points of resonance, but these lived experiences remain distinct and unique in quality and 
quantity. The extent of synesthetic experience is a phenomenological issue. Endeavors

toward the acknowledgment of individuality can be as simple as asking students a

question. The following short passages from the narratives speak to these unique

experiences:

I think what I would probably do for my student, or what I would have wanted a teacher to have done for me would [be to] just give me the staff and a bunch of pencil crayons and color (in the colors of the notes). And I would, like, draw whole notes, but in the same color, or quarter notes in the color of what they are for you. Debbra

And I think, like, if I had a student who did have that, I would try to kind of learn about their type and make reference to that in a way that would help them, you know, maybe learn or memorize or something like that, to understand a concept. (...) And also not giving, not trying to impose a system that would be similar to synesthesia. Alba

\section{Validation and Encouragement}

Finally, a workable framework would also need to prioritize an ongoing validation and encouragement of synesthetes' perception. The bullying, discredit, and indifference mentioned by synesthetes is disheartening. Their plea and need for validation are evident in the following passages:

Yeah. And then also, like, for the student to know that the teacher understands what they're thinking. I think that'd be so cool. Because, like, I definitely did not have that when I was a kid. I just thought I was weird. Debbra

Well, I guess validating it at the time or in trying to use it would have helped us all, I guess. Esther

Because I try to talk about this very vocally with my students... because I know there's kids out there that have this they like me... a few students that have clued in and, you know, come to me privately like they have some secret, "I think I have this," (...) she was embarrassed and she just was like, "I hope nobody finds out." She talked to me about it. I'm going "but this a superpower!" (Chuckles). Like "why are you embarrassed about this?" So, yeah, it's funny. It is. It's like they look at it like it is like an autism... like something's wrong with your brain and I think it's the opposite. I put it out there. (...) But I always did have a wish that... I wish kids knew 
it's okay to have it... plus, how do you actually use it as a superpower? Not as a detriment! Because as a kid, I thought it and I'm sure you too... you are wrong in your brain because you're categorizing things. Kailey

So, if I were to tell a young student who has no idea what they're experiencing, except that they see something, they see a color, they see a shape, or they see a thing. It's fantastic! Because it means that there's a part of that brain that's incorporated within the music and I would definitely encourage that. Daisy

Validation, thus, stands at the heart of this second and practical phase.

Finally, the role of intentionality transferring between this and the third phase in the process remains the same as between the first and second phases. Once more, intentionality grounded in awareness is the moving force between the three stages in this proposed educational approach.

\section{Phase 3: Methodological Considerations}

In approaching the third and last phase, I propose three methodological considerations that may be transformative. Curricular reform can only take place if a workable framework and feasible methodologies are carefully planned, calculated, and budgeted accordingly. In starting the conversation about methodological considerations as surfacing from the narratives in this study, the following paragraphs aim at sparking further curiosity and inventiveness on the part of educators and students alike in order to move this discussion to the next steps. They involve the reinforcement of individuality, creativity and imagination, and community building.

Even if they might not have been entirely cognizant, participants have mentioned compelling methodological ideas that foster individuality.

Or maybe, I think, like, just keep associating and let the person keep associating the color that makes sense for this person. Iria 
...but I would encourage them to come up with mnemonic devices, like I have done with their colors or whatever.... Um, and even if it's something just completely silly... it doesn't matter if it doesn't make any sense to other people as long as it makes sense to you and helps you retain the information. That's what matters. So yeah, I would... I would encourage that. Heidi.

I guess me, I don't know... it would be interesting to know that if you had printed the notes in the colors that I see, would that have helped me learn faster because... again, it would have been, you know, another prompt that... "it looks like that and it feels like that and I put my mouth like that to make that..." [indistinct] or even if I tried to play the piano with two hands if I had a color, you know... in the... in my peripheral vision that my left hand in it to be making a green... might have been easier for me than trying to, you know, yeah... Zoe

It seems as though these simple methodological adaptations - based on awareness and priority for individuality (and mediated by intentionality) would already bring about change to the current paradigms and make synesthete's experience of music more meaningful.

Lastly, in thinking of creativity, imagination, and community, Kailey and Daisy seem to think that awareness about synesthesia brings people together. Awareness about (and intentional inclusion of) synesthesia may spark a community collaboration that may involve synesthetes and non-synesthetes alike.

We painted a lot in class, I try to bring those things in. And they would share with each other what they saw, and I think it was valid for them to see that "oh, what I imagined was totally different than another kid". Kailey

So, anything that would connect you more with your fellow musicians, I think it's fantastic. Daisy

In early or advanced stages of music education, respect and intentionality in welcoming synesthesia as a valid form of perception could go a long way. 


\section{Chapter 10 Summary}

This dissertation has collected narratives cross-culturally from 12 participants with music notation-to-color synesthesia. The collection of data and analysis were framed around and addressed the proposed research questions. The participants' perspectives have been analyzed by means of qualitative methodology and the main themes and commonalities were identified and reported.

These commonalities were used to build two theoretical models. The first addresses the synesthetic perception of music notation on the part of these participants. The second offers a three-phase educational approach based on inclusive dispositions and attitudes.

Chapter 11 builds on the third and final phase of this theoretical model, suggesting overarching practical implications for music educators inside and outside the classroom, with attention to realities in music instruction in North America. It also fosters general pedagogical techniques that envision the ultimate transfer of music notation-tocolor synesthetes to real-life scenarios. 


\section{CHAPTER 11}

\section{PRACTICAL IMPLICATIONS}

\section{Overview}

The green color make sense for you, right?

-Iria (participant)

Chapter 10 has suggested the ideal condition for the development of fruitful efforts to educate music notation-to-color synesthetes. In specific, this educational effort concerns the teaching of graphic symbols involved in music documentation. In proposing a three-phase theoretical approach to music-curricular reform grounded in intentionality, this research has identified the need for (1) a philosophical foundation based on awareness and (2) a workable framework, thus allowing for (3) methodological considerations. This chapter explores preliminary—albeit in no way exhaustiveoverarching practical implications of this theoretical model.

The sections that follow elaborate on practical strategies for individualized instruction within and without the school setting as well as general pedagogical approaches that can be transformative in synesthetes' learning of music notation. They also discuss the elimination of sensory overload and the priority for transfer as a central indicator of student success. 
It is essential to reiterate that this research involves early stages of instruction in music notation. Hence, the practical implications and embedded recommendations in this chapter concern novice students who possess music notation-to-color synesthesia. In other words, these practical suggestions may benefit various groups of students regardless of the age and setting in which these elementary stages of music education are taking place. They may benefit a kindergarten student with synesthesia learning the notes on the staff as well as a college student with synesthesia learning to play the piano for the first time as an elective course. Yet, although the focus on elementary music instruction has been a priority in this study, these strategies may also benefit advanced musicians with this mode of synesthesia.

In light of the germinal nature of this dissertation, this final chapter only starts to map out practicalities involving the teaching of synesthetes in music. The initial suggestions contained here involve synesthetes' learning of basic music notation-a specific and rather hermetic aspect of music-making in Western culture-but may be expanded, adapted, and transformed to include other forms of synesthesia and broader cultural contexts. Similarly, the principles behind these practical considerations can be imported, replicated, and modified to suit other disciplines outside music, such as the learning of languages and mathematics, to name a few fields of study that could benefit from these suggestions in teaching synesthetes.

\section{Individualized Instruction}

The workable framework (Phase 2) discussed in the previous chapter has advocated for an intentional outlook at individuality on the part of instructors. Given the different scenarios in which music instruction can take place-usually the one-on-one 
lesson or the collective music class - the feasibility of a priority for individuality on the part of teachers may vary according to context. Regardless of the age of students, instructors in both the one-on-one and the classroom settings would need a considerable degree of time with each synesthete student to learn about their individual perception of music notation. In so doing, instructors would have an initial direction on how to adapt their methodology accordingly for effective teaching and meaningful results.

In chapter 8, participants broached two distinct modes of music instruction: private, one-on-one teaching and collective teaching. The ensuing subsections offer practical considerations for both these scenarios separately. Not only were these modes of instruction referenced in the collected narratives of this study, but they account for the most common forms of music instruction in a Western cultural context.

Regardless of the educational scenario, an individual approach stands as a fundamental element of pedagogical adaptation and surfaced among participants' responses. The following passages from the narratives allude to ways in which instructors could engage with students who have music-to-color synesthesia at an individual and specialized level.

[Teachers could ask] kids or the person who is learning music: "let's put here all the notes, so, can you tell me what color is this note for you? "If the personal says, like, whatever or can't really associate a color to a note or song, [fine]. But, if the person does, I think that the teacher can take note, right? So, put everything there, each color with each note and then start, for example, with sheet music on paper. Yeah, for example, "this is a song in D major. Does the green color make sense for you, right?" "Oh, yes." "So, I'll put like a sticker here with green color in the front of the page." So you can, like, I don't know, it will help you. Iria

So, I think I... I could use it in that way... like, what the student is. But it would require me learning their colors. Which could be... like, so first of all, like, not all my students have it. Like, if I found out that one of my students did have it, I would want to learn their colors. But then, like a different student might have different colors. So, um, yeah. (...) Yeah. Like I would want them to make that for me. And then I could 
like keep it in a binder somewhere so that when they were in my class, I could be like, "Oh, yeah, this person thinks about it like this." ... I was gonna say, I think [it] would work really well for private teaching. Debbra

And I think, like, if I had a student who did have that I would try to kind of learn about their type and make reference to that in a way that would help them to, you know, maybe learn or memorize or something like that, to understand a concept. Alba

It is precisely because synesthesia poses a unique perception for each individual synesthete that these students would highly benefit from this type of focused and specialized approach. Before discussing the different implications for one-on-one and classroom teachers separately, it is crucial to understand that the idea of addressing synesthesia intentionally (a direct consequence of heightened awareness about the condition, as discussed in chapter 10) is necessarily preceded by identifying and verifying the presence of the condition. Both identification and verification are diagnostic processes.

Intentionality on the part of diverse stakeholders involved in education, from administrators, to curriculum planners, to educators, was discussed in chapter 10 as the connective link between different stages involved in engaging synesthetes (three-phase theoretical model). This theoretical approach aims to ensure the best learning outcomes for this group of students. When music instructors are aware of notation-to-color synesthesia and its mechanisms, even if at a more generalized level, they would need to (1) identify students who potentially have music notation-to-color synesthesia, (2) verify the presence of synesthesia in their perception, and (3) take steps to address these individuals (figure 14). 
Figure 14. Instructional intentionality in practice.

Identification and verification of synesthesia are used here as neutral alternative terms to what has been often called "diagnosis" or "testing" in synesthesia literature. They also denote conceptually distinct and successive steps in the process of testing for students' synesthesia, rather than part of one and the same diagnostic procedure. The literature review of this study pointed to various methods currently used to diagnose synesthesia (Rothen et al., 2013), according to the demands of different research designs. This research prioritizes the quality of synesthesia, which is phenomenologically defined (Sagiv \& Frith, 2013) and not observable in laboratory-based tests such as fMRI scans. Besides, the latter's high cost and difficulty of replication poses a methodological problem. In particular, it would be challenging, if not impossible, to use this specific form of testing to identify and verify synesthesia in educational contexts, which often involve school sites as the research/application locus and larger groups of children as the target population.

Carmichael et al. (2015) propose alternative forms of synesthesia testing that may prove just as significant in identifying and verifying synesthesia, albeit at a much lower cost and much higher replication viability within educational settings. Given synesthesia's automaticity, consistency, reality, and involuntary-basis (Ward, 2013), it 
can be identified and verified through qualitative means. The tripartite process illustrated in figure 14 imports some of the strategies used in the interviews conducted in this study (Appendix D), yet framed in a more systematic way:

1. Identify: The identification of a student's music notation-to-color synesthesiaor, at this point, the identification of the potential for synesthesia—is perhaps the most uncomplicated stage in this intentional process. It can be achieved by simply inquiring whether students make such associations and asking them to elaborate further on their nature (frequency, consistency, etc.). In Iria, Debbra, and Alba's words quoted above, there seems to be an indication that a dialogical interaction with students would be sufficient in surfacing the potential for synesthetic associations.

2. Verify: Confirmation of synesthesia through verification would take repeated testing over extended periods of time. Since one of the characteristics of synesthetic associations is their consistency over time, students who report having the same color associations every time a check for consistency is done are likely to have synesthesia. During participants' interviews for this research, two formal consistency checks for synesthetic associations (Appendix D). These checks can be done on the part of the instructor over longer periods of time and potentially at a more spaced rate. For example, when identifying the potential for color associations in a particular student, teachers could ask for the specific concept-color pairs once every month for a period of four months. With younger students, who may be more likely to forget made-up, deliberate color associations they may mention when asked, weekly checks for consistency might be fruitful as well. The overarching objective of this verification is to detect whether the associations remain consistent while maintaining certain control over truthfulness on the 
part of the students' responses. Moreover, given the reality, involuntary-basis, and automaticity of synesthetic associations (Ward, 2013), synesthetes usually respond to these questions promptly. In particular, they are often overly specific about the shade, hue, and quality of the color associated to a given concept — which points to the reality of these associations. For instance, participants in this study described their notated-pitch associations as "dark purple, occasionally a bit indigo", "warm pink, kind of mediumlight", "beautiful gold", "yellow, but changes into light green", "rusty orange”, "grass green", and "pale orange", to name a few examples. Participants have also indicated ways in which teachers can keep track of these associations, by maintaining a record of the responses.

3. Address: From participants' suggestions, it is also possible to derive the idea of developing a chart of the final list of associations after the verification stage of the process is complete:

And then I could like keep it in a binder somewhere so that when they were in my class, I could be like, "Oh, yeah, this person thinks about it like this." Debbra ...try to kind of learn about their type and make reference to that in a way that would help them... Alba

These are preliminary procedures, however. Addressing music notation-to-color synesthesia, or any other form of the condition, may not prove to be just as simple. It may involve different levels of engagement on the part of both the instructor and student. Yet, in general lines, it may benefit from the two overarching approaches explored in later portions of this chapter.

This linear process of identifying, verifying, and intentionally beginning to address synesthesia may look different in the two settings brought up by participants: the 
one-on-one lesson and the classroom. While the directional linearity proposed in this study (figure 14) would have to be maintained almost invariably, the implications of these steps are different for one-on-one music instruction and collective instruction (classroom). The following paragraphs discuss these settings independently in more detail.

\section{One-on-one Music Instruction}

Although North American schools may incorporate both curricular and extracurricular music programs, individual music instruction is most common outside the school environment. To be sure, specific music programs such as El Sistema and other analogous extra-curricular efforts to teach music to children at a high level of excellence feature both group and individual lessons (Majno, 2012). These can be private and public initiatives. Nonetheless, the majority of children involved in school-based music programs would not be exposed to individualized instruction substantially, save for opportunities to enroll in such a program (Majno, 2012).

Participants in this study have suggested that fostering individuality in getting to know a student at a time may prove much easier and viable in one-on-one lesson time. In addressing the need to know each synesthete's set of colors and how their perception of music notation works, Debbra says:

\section{I think [it] would work really well for private teaching.}

She is a music teacher both inside and outside the classroom and recognizes that this approach would be highly suitable for "private teaching" - an alternative term for extracurricular, one-on-one instrument lessons subsidized privately, often by the student's own family. In such lessons, the teacher has the time and flexibility to devote to 
methodological considerations and needed adaptations to each student. The other participants quoted above also attest to a dialogical element. They suggest conversing with the students individually and collecting information from their unique perspective prior to crafting the appropriate pedagogy used thereafter.

Private instrument teachers usually have a high degree of knowledge about their musical instrument and the notation involved in its performance. These instructors frequently have to cater for different levels of ability and adapt to diverse learning aptitudes while maintaining the same performance standards across all students. With one-on-one time on their side, adaptations to synesthetes' needs are both more easily achievable and manageable. In fact, the process of identification discussed above should take little time. Verifying consistency may take longer periods of time, on the other hand, but would still consume a minimal amount of time during each lesson. Likewise, addressing synesthesia by keeping association charts for each independent student would be manageable with no salient challenges.

\section{Reality: the Classroom Music Teacher}

This level of individual attention, however, can be a challenge for classroom teachers. The ability to focus time and apply specialized methodologies with each student frequently depend heavily on available resources, which vary greatly from school to school. In particular, classroom music teachers working in larger classes with limited resources may not be able to invest as substantial an amount of time in each individual student to discover their unique synesthetic capabilities.

Moreover, classroom teachers may already feel undertrained to address learning differences (Rowley, 2008; Thompson, 2013), let alone to undertake the task of having to 
identify, verify, and address individual music students with notation-based synesthesiaa specific neurological phenomenon. This may be compounded with a decreased confidence to teach music (Seddon, 2008), in spite of its inclusion in the North American $\mathrm{K}-12$ various curricula. In other words, the basic music instruction offered in teacher training professionalizing programs may not be sufficient for teachers to feel confident in teaching music notation in the classroom, in the first place. Lack of confidence, in turn, derives from a lack of proficiency in the language of music. This may result in students with notation-based forms of synesthesia falling through the cracks in elementary stages of music instruction — stages that are foundational in their journey.

Given these challenges and assuming that awareness about synesthesia has been raised, classroom teachers can identify students who may have it by using general-toindividual versions of the linear process discussed here (figure 14). Identifying synesthetes in this context means singling-out students who may potentially have notation-to-color synesthesia from the totality of students in a classroom setting. The identification step needs, however, to be less time consuming than entering in a lengthy dialogue with each student. In this sense, teachers would not need to meet individually with students, to begin with. Open-ended dynamics targeting all students alike but allowing for individual expression may be particularly beneficial in singling out individuals who have synesthesia. Kailey and Daisy alluded to examples of such openended classroom activities.

So, I get my students to really listen to a lot of music and I say, "Okay, what colors are [hearing] you here?" "What are you seeing?" And if I allow them to open up that amount of imagination - which I don't think a lot of teachers talk about muchthey talk about, you know, the finite, period, the eighth notes, and here are the notes and here's [indistinct], but you get more into the abstract, which really what is 
synesthesia, then they can experience music or on their own whether or not they have synesthesia. I just wish there was a way to talk about students more openly with it. (...) Because I try to talk about this very vocally with my students... because I know there's kids out there that have this they like me... a few students that have clued in and you know, come to me privately like they have some secret, "I think I have this". It's been fun to watch them experience music more in a joyful way because they finally understand, like, "Oh, I'm experiencing something that other people in the room aren't getting." And so, I wish, you know, I'd had as a kid... to be able to understand that... but I just, I didn't know. So, yeah... Kailey

I think I would definitely want to encourage people to... not only just students, but any adults that I would... that I would work with ... to really allow themselves to be free in their thinking when it comes to music because we're... we're visual learners, like, everyone is either kinesthetic, or visual, or auditory... like, everything is incorporated when you play music. So, if I were to tell a young student who has no idea what they're experiencing, except that they see something... they see a color, or they see a shape, or they see a thing. It's fantastic! Because it means that there's a part of that brain that's incorporated within the music and I would definitely encourage that. Daisy

Unfortunately, since synesthesia is characterized by personal differences in the way it manifests, the two subsequent stages in this process (verification and addressing) cannot be achieved unless instructors get more involved with students individually. Yet, after having identified synesthesia through open-ended, general activities targeting multiple students, especially in larger classrooms, teachers can proceed to verification and addressing strategies catered specifically to the identified synesthetes. This general-toindividual approach may prove more manageable in the classroom-especially in school settings in which time and resources may be limited or restricted.

\section{Eliminating Excessive Notational Information}

When individualized teaching can be achieved successfully on the part of instructors in identifying, verifying, and addressing synesthesia intentionally, more specific methodological considerations can be carried out with each individual student in 
mind. Eliminating excessive information, as a rule of thumb, may prove an effective way to begin pedagogical adaptations in this direction.

Although pedagogical adaptations of this kind may be quotidian procedures and well-known to experienced educators, there are methods and textbooks still used by instructors today that suggest a standing need for heightened awareness in regards to teaching concepts clearly and systematically. I will use examples from teaching methods used with violin students in North America to exemplify this need, since I have been engaged in the activity of instructing violin for many years. The characteristics of this example may, however, find analogous manifestations in other music-instructional texts/methods.

There are music methods such as older versions of the Suzuki Method (Suzuki, 1978) and the Rubank Elementary Method (Potter, 1990) that introduce multiple concepts at the same time, often in the same lesson. The Rubank Elementary Method (Potter, 1990), in particular, uses several notational elements concurrently and in the very first lesson of the book, namely: numbers denoting beats, numbers denoting fingerings, letters and numbers denoting violin strings, bowings, open string signs (which beginners can easily confuse with the number " 0 " or the letter "o"), etc. A non-synesthete might already be negatively affected by the excess of information. Yet, synesthetes may experience additional incongruence between the colors triggered by these different preceptsespecially if they are related to the one and the same musical event—as some of the participants of this study have expressed substantially (chapter 6).

The Suzuki Method (Suzuki, 1978) for the violin, in turn, does not focus primarily on the reading of notational concepts - at least as a pedagogical philosophy. Rather it 
focuses on the development of a reliable musical ear and on the ability to hear and reproduce on the part of the student. These are indeed foundational skills to be emphasized during these early stages. However, the absence of emphasis on reading musical notation has met opposition from many music educators over the years. Reading musical notation is as important for the instrumentalist to understand musical discourse as reading letters and words is to understand verbal-linguistic discourse. In fact, many instructors use the excellent choice of repertoire in the Suzuki Method in combination with a strong emphasis on note-reading, sight-reading, and attention to notational elements such as dynamics, tempo indications, alternative fingerings, etc.

The elimination of excessive information as it appears on the page is, hence, an important first step. Learning tools targeting music notation should look as clean as possible and should introduce concepts individually. A gradual combination of new concepts with previously learned material may also prove effective in teaching them successfully to synesthetes. If information is laid out clearly for synesthetes during early stages of music notation instruction, these novice musicians may be able to take further learning steps more confidently, rather than feel overwhelmed by incongruence or sensory overload. There are systematic ways in which this gradual infusion can be done. The next section elaborates on one of them. It explores how various levels of musicnotational knowledge can be infused gradually in lesson plans without compromising learning standards and desired skills.

\section{Gradual Learning for Transfer}

The idea of gradual learning is fundamental in addressing music notation-to-color students who are first exposed to notational concepts. Given the multiplicity of 
synesthetic sensations they may experience when exposed to different notational concepts (discussed in the previous section), it may be highly beneficial to these students if they are introduced gradually and systematically. Vygotsky (1978) proposes the concept of instructional scaffolding, suggesting that novel knowledge should be gradually "built on" previously learned and mastered foundational material. This concept requires careful planning not only from instructors, but from curricularists and method/textbook designers.

Zone of Proximal Development (ZPD)

In particular, Vygotsky (1978) recommends that instructors should be mindful of potential linking elements that could seamlessly connect already learned information to the new knowledge the student should acquire next. In this sense, rather than introducing several notational concepts at once, instructors should add new concepts sparingly and only when they have observed students' mastery of previous material. Vygotsky (1978) calls this linking area "zone of proximal development" (ZPD). Figure 15 illustrates the relationship between content that the student already knows and content that the student does not yet know. The communication between these niches of content should be mediated by the ZPD. 


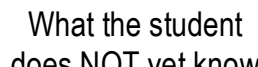

does NOT yet know

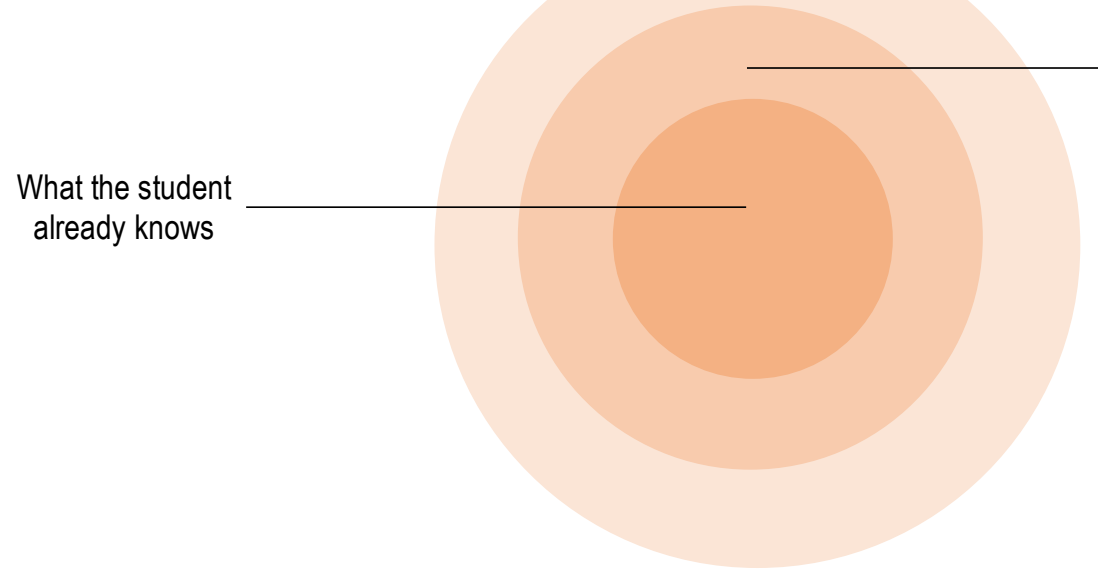

Zone of Proximal

Development (ZPD)

Figure 15. Vygotsky’s (1978) Zone of Proximal Development (ZPD).

The ZPD is comprised of linking elements that mediate any two niches of content. Hence, an additional, novel ZPD would need to be added after every new concept is learned in order to ensure that the student can be transferred effectively to the next one. It follows that teaching music notation to synesthetes may involve multiple niches of content, interpolated by carefully crafted ZPDs.

Synesthete students undergoing this methodology would end up exposed to the same concepts as a non-synesthete, albeit in a more intentionally gradual manner on the part of the instructional technique used. In fact, the very objective of this pedagogical approach is to ensure that synesthetes can transfer just as successfully as non-synesthetes to complex forms of music notation, yet without the behavioral delay in responding to notational concepts or the annoyance voiced by some of the participants in this study. In higher levels of learning and professional scenarios, music scores and sheet music would certainly not be adapted to synesthetes. Besides, they would not feature specific 
synesthetic associations or modes of perception, most likely. The addressing of this issue during early stages may eliminate the frustration mentioned by some of the participants in subsequent years.

So it just made me have to practice more and after many years, like, after a long time of practicing and playing and, you know... eventually now, like, that $A$ is blue... but it took like over 10 years to kind of... and there are still some notes like ledger lines... don't even get me started. (Chuckles). Debbra

Instruction is effective and successful when it can transfer every student to real-life situations (Wiggins \& McTighe, 2005) and when it ensures that they feel confident to approach and overcome new challenges.

\section{Chapter 11 Summary}

This concluding chapter elaborated on practical implications resulting from the theoretical model advanced in chapter 10. Firstly, in reiterating the role of intentionality discussed in chapter 10, it suggested a linear process for the identification, verification, and addressing of color-based synesthesia among students learning music notation. These final recommendations have considered essential differences in approaching individual students in one-on-one and classroom settings. These settings and their characteristics were discussed independently, but the linear process of identification, verification, and addressing of synesthesia remained the same. Additionally, this chapter has proposed the elimination of excessive information as a potentially effective first step in addressing synesthetes' needs. It has also drawn upon Vygotsky's (1978) zone of proximal development (ZPD), recommending that instructors interpolate these linking zones between any two niches of content. This may result in a multilayered, complex lesson 
plan aiming at transfer on the part of synesthetes in comparison to their non-synesthete peers.

\section{Closing Thoughts}

This study has relied on qualitative methodology to arrive at two theoretical models that describe and try to understand (rather than explain) the synesthetic experiences of music notation-to-color synesthetes. The study has also demonstrated robust validation procedures in analyzing participants' narratives. Results and findings have addressed and answered the three proposed questions of the study. Firstly, the results of this research have pointed to ways in which synesthetes with music notation-tocolor synesthetes experience graphic/symbolic musical concepts. Secondly, they have addressed the role of synesthesia in the early stages of music education. Thirdly, they have explored alternative ways in which music notation can be taught to synesthetes from the perspectives of the participants, through the creation of two grounded theories. In answering the three proposed research questions, this study also addressed the two proposed sub-questions, which involved consistently emerging themes and similarities within those narratives.

Moreover, in expanding the theoretical model that proposes a novel approach to teaching music notation to synesthetes, the study has elaborated on methodological considerations and their general practical implications. These involve suggestions on the process of identification/verification/addressing of music notation-to-color synesthesia. The study also offers conclusory considerations such as the elimination of sensory overload from music-educational textbooks and gradual learning envisioning successful transfer of synesthetes to real-life scenarios. 
APPENDIX A

RECRUITMENT LETTER 


\section{RECRUITMENT LETTER}

Eduardo Sola

Burman University/Andrews University

$+14168357078$

eduardosola@burmanu.ca solachagas@andrews.edu

Dear prospect participants,

This is a letter of invitation and recruitment for participation in a unique mixed-methods study (with a mostly qualitative flavor) investigating the nature of synthetic experiences of music notation and color and their impact on early stages of music education. Scholarly literature on music forms of synesthesia is still in the process of development. A study like this would enormously benefit the field and make further research possible in terms of understanding what questions to ask next and which directions to take.

Furthermore, this research is part of my doctoral dissertation, which I am writing in partial fulfilment of a Ph.D. in Curriculum \& Instruction at Andrews University, Michigan. This research is also closely related to my scholarly work and has a significant bearing on my own teaching both at the secondary level (Burman University) and within my private music studio. Besides, as a synesthete myself, I have an intrinsic motivation to carry out this study systematically.

The research consists of two parts:

1. Completion of a brief survey form online at your convenience (link below). The survey includes thorough information on the study and an informed consent form.

https://forms.gle/Y5ESaD94Qh64TfhH6

2. Participation in a 20-30 minute interview with the researcher (myself) conducted either in person or via Zoom video conference. Interviews will be highly informal in that I am interested in hearing on your experience in detail. They will also be recorded for coding and analytical purposes. No personal information will be disclosed at any point in the study and will be recoded with pseudonyms (please refer to the link above for a full disclosure of the terms and conditions of the study).

Participants will be given a guaranteed token of appreciation of an amazon.com gift card in the amount of USD $\$ 25.00$. 
The deadline for participation in the study is January 30, 2020.

If you experience music notation > color synesthesia (if you see colors when you look at a page of sheet music), are above 18 years of age, and have undergone some level of music instruction, please contact me informing me of your availability and willingness to participate!

Thank you very much in advance for your valuable contribution to this study. Should you have any questions or need further information, please do not hesitate to contact me using the addresses and phone number provided above.

Sincerely yours,

Eduardo Sola

Assistant Professor, Burman University

Ph.D. candidate, Andrews University 
APPENDIX B

INFORMED CONSENT DISCLAIMER/FORM 


\title{
INFORMED GONSENT DISCLAIMER
}

\author{
Eduardo Sola \\ Burman University/Andrews University \\ $+14168357078$ \\ eduardosola@burmanu.ca \\ solachagas@andrews.edu
}

With this research, I am seeking to find out more about individual experiences of music notation-to-color synesthesia and their impact on music education. Your participation and unique contribution to this study is both valued in appreciated.

Title: Music notation-to-color synesthesia and early stages of music education: a grounded theory study

Aim of the study: To better understand the quality of the synesthetic experience of music notation $>$ color and its influence on music education.

Selection criteria: You were selected to participate in this study because you are self-reported synesthete with music notation > color synesthesia and have undergone music education at some point in your life within a Western cultural context.

Duration of study participation: The participants of this study understand their contribution consists in answering an online survey and taking part in an in-person or Zoom-based interview of between 20-30 minutes a possible follow-up interview. The participants understand that the interviews will be recorded for analytical and coding purposes.

Procedure: The survey portion of the participant's contribution will take place online and individually via the link provided above. Interviews will take place at a mutually convenient location and time or scheduled via Zoom according to the participant's and the researcher's convenience.

Benefits: This interview will help identify the emerging themes in this phenomenological process as well as its direct influences on the learning of music. Scholarly literature on synesthesia currently needs improvement in this respect and your contribution is of utmost value and importance for the research community at a global scale.

Risks: Participants have been informed that there are not any anticipated risks associated with collaboration in the study. 
Voluntary Participation: Participants have been informed that her/his participation in this study is completely voluntary. Participants have right to abstain from answering any questions. Participants have the right to withdraw from the study at any point. There are no penalties for withdrawing from the study.

Confidentiality: Personal information about the participants (such as name) will not be used for statistical analysis and publications. The confidentiality of personal data is maintained at all times. Any publication of the data generated from the questionnaires will not contain personal information about participants that could be used to identify them. In the event that any personal information identifiers become available, such will be coded to comply with subject confidentiality, such as the translated by using pseudonyms. Participants also understand that the researchers will maintain records of any personal information in files with restricted access, for a minimum period of three years.

Contact: Participants are encouraged to contact the researcher at any point with any potential questions and/or concerns. The researcher (Eduardo Sola) can be contacted via email (eduardosola@,burmanu.ca) or phone (+1-416-835-7078).

\section{$* * *$}

\section{Consent Statement:}

I have read the content of this Informed Consent. Any questions that I had have been answered to my satisfaction. I voluntarily consent to participate in the study.

Participant's Signature

Date 
APPENDIX C

SURVEY AND SEMI-STRUCTURED

INTERVIEW PROTOCOLS 


\section{MUSIC NOTATION-TO-COLOR SYNESTHESIA \\ IN EARLY STAGES OF MUSIC EDUCATION \\ SURVEY AND SEMI-STRUCTURED INTERVIEW PROTOCOL}

\section{PRELIMINARY INFORMATION (Quantitative Data): Google Forms}

- Name

- Gender

- Age

- Nationality/cultural background

- Ethnicity

- Native language

- Other languages spoken

- Level of instruction

- Level of music instruction

- Types of synesthesia possessed

\section{DETAILED NARRATIVE DESCRIPTIONS (Qualitative Data): Interviews and Video Recording (in person or via Zoom)}

\section{Introduction:}

During this preliminary phase, the researcher set the Zoom application to record (or the recording device if in person), thanked the participant for engaging in the study, and informed the participant that the session is being recorded for research purposes. Subsequently, the researcher summarized the purpose of the study and the format of the research.

\section{Questions:}

The questions were organized and ordered according to a flowchart (Appendix D). Questions were asked in an organic and natural manner.

\section{Postlude:}

At this stage, the researcher thanked the participant again and indicated that the token of appreciation (www.amazon.com gift card in the amount of USD\$25.00) would be sent to the participant's email following the interview. 
APPENDIX D

INTERVIEW FLOWCHART 


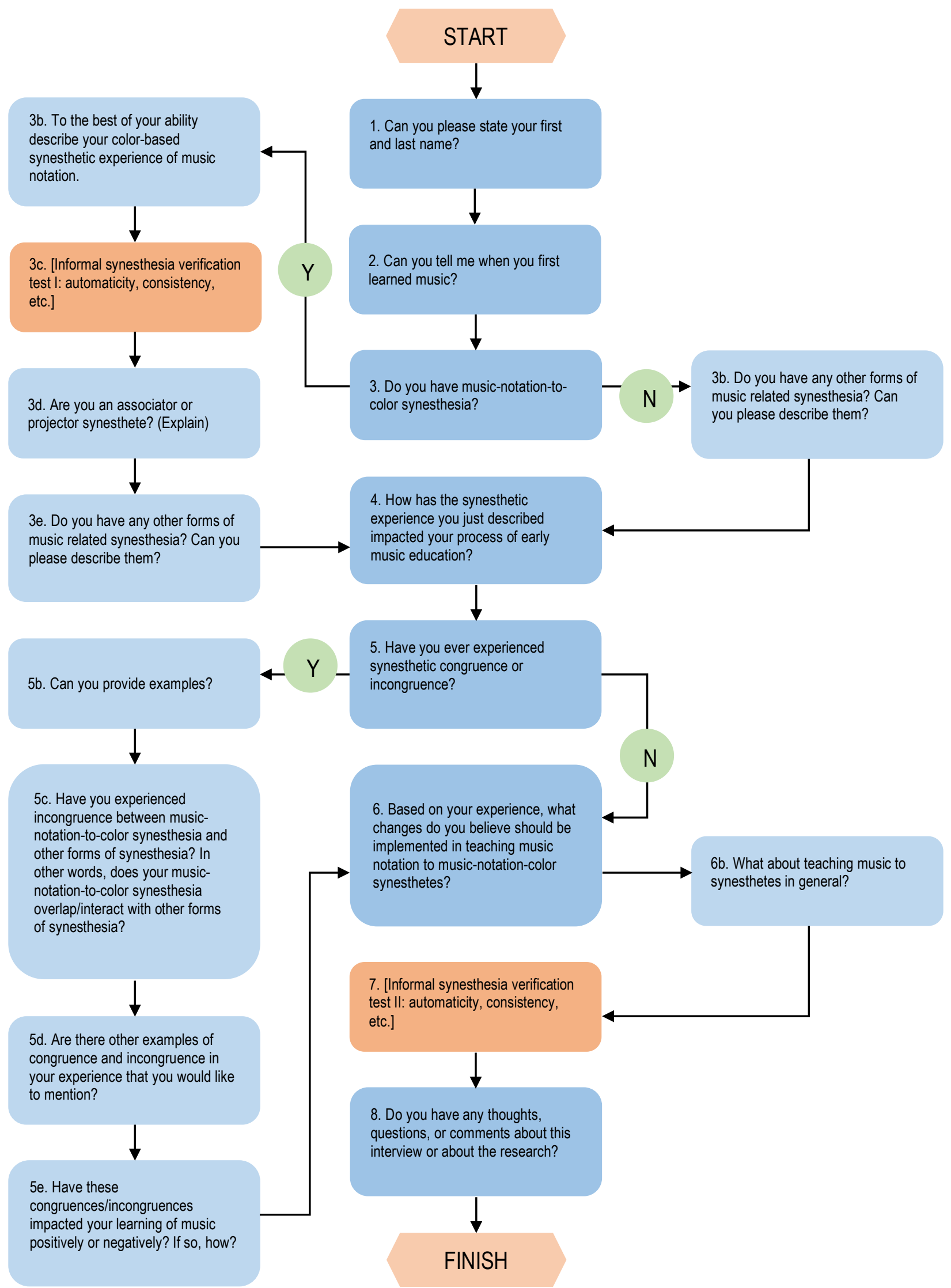


APPENDIX E

CODING CATEGORIZATION/HIERARCHY 


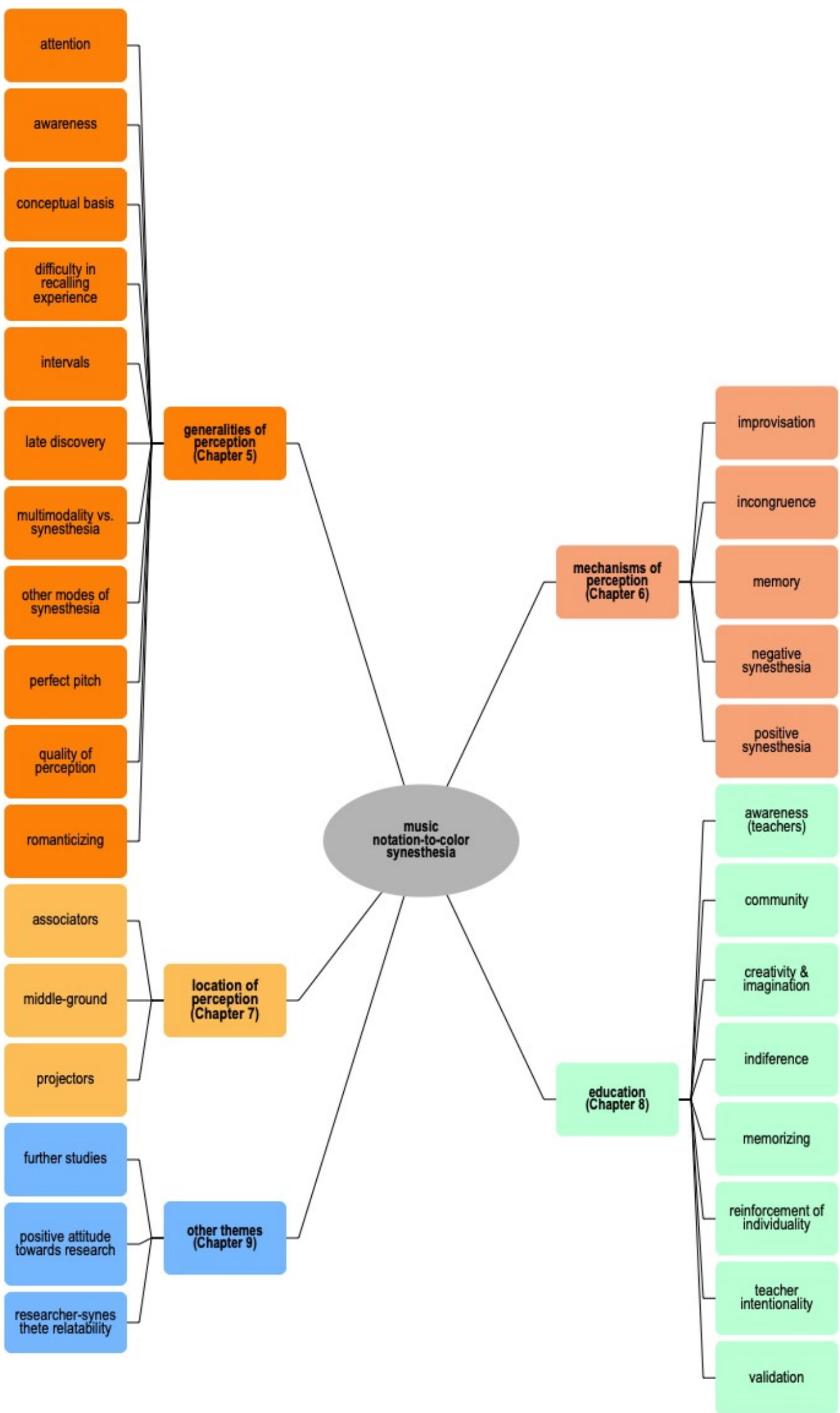


APPENDIX F

RESEARCH CYCLE 


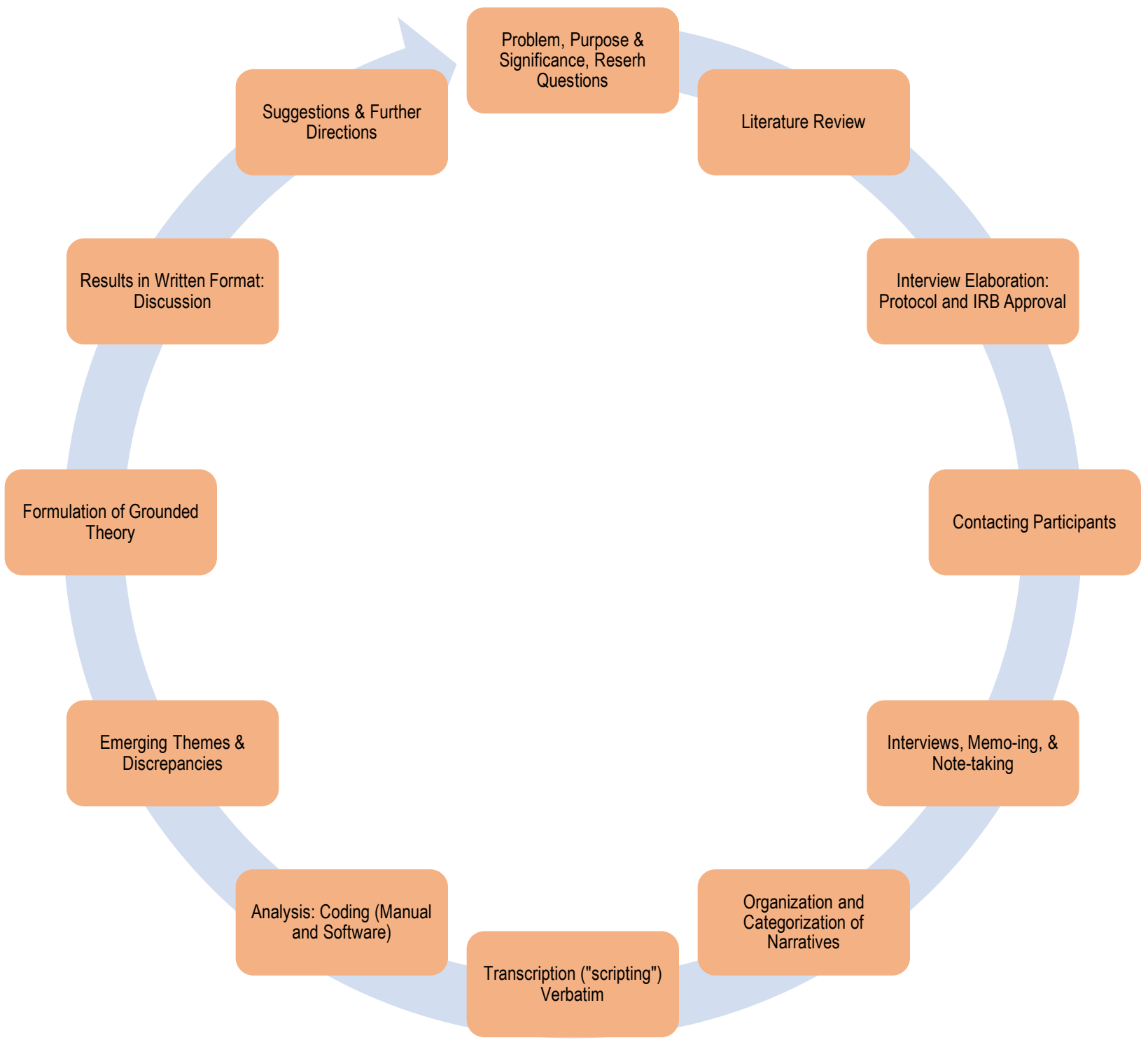


APPENDIX G

IRB APPROVAL 


\title{
Andrews 0 University
}

December 13, 2019

Eduardo Sola Chagas

Tel. 416-835-7078

Email: solachagas@andrews.edu

\begin{abstract}
RE: APPLICATION FOR APPROVAL OF RESEARCH INVOLVING HUMAN SUBJECTS
IRB Protocol \#:19-134 Application Type: Original Dept.: Curriculum \& Instruction

Review Category: Exempt Action Taken: Approved Advisor: Anneris Coria-Navia

Title: Music notation-to-color synesthesia and early stages of music education: A grounded theory study.
\end{abstract}

Your IRB application for approval of research involving human subjects entitled: "Music notation-to-color synesthesia and early stages of music education: A grounded theory study" IRB protocol \# 19-134 has been evaluated and determined Exempt from IRB review under regulation CFR 46.101 (b) (2). You may now proceed with your research.

Please note that any future changes made to the study design and/or informed consent form require prior approval from the IRB before such changes can be implemented. Incase you need to make changes please use the attached report form.

While there appears to be no more than minimum risks with your study, should an incidence occur that results in a research-related adverse reaction and/or physical injury, this must be reported immediately in writing to the IRB. Any research-related physical injury must also be reported immediately to the University Physician, Dr. Katherine, by calling (269) 473-2222.

We ask that you reference the protocol number in any future correspondence regarding this study for easy retrieval of information.

Best wishes in your research.

Sincerely,

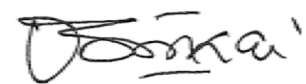

Mordekai Ongo, Ph.D.

Research Integrity and Compliance Officer 


\section{APPENDIX H}

THEORETICAL PLAN: PERCEPTION 


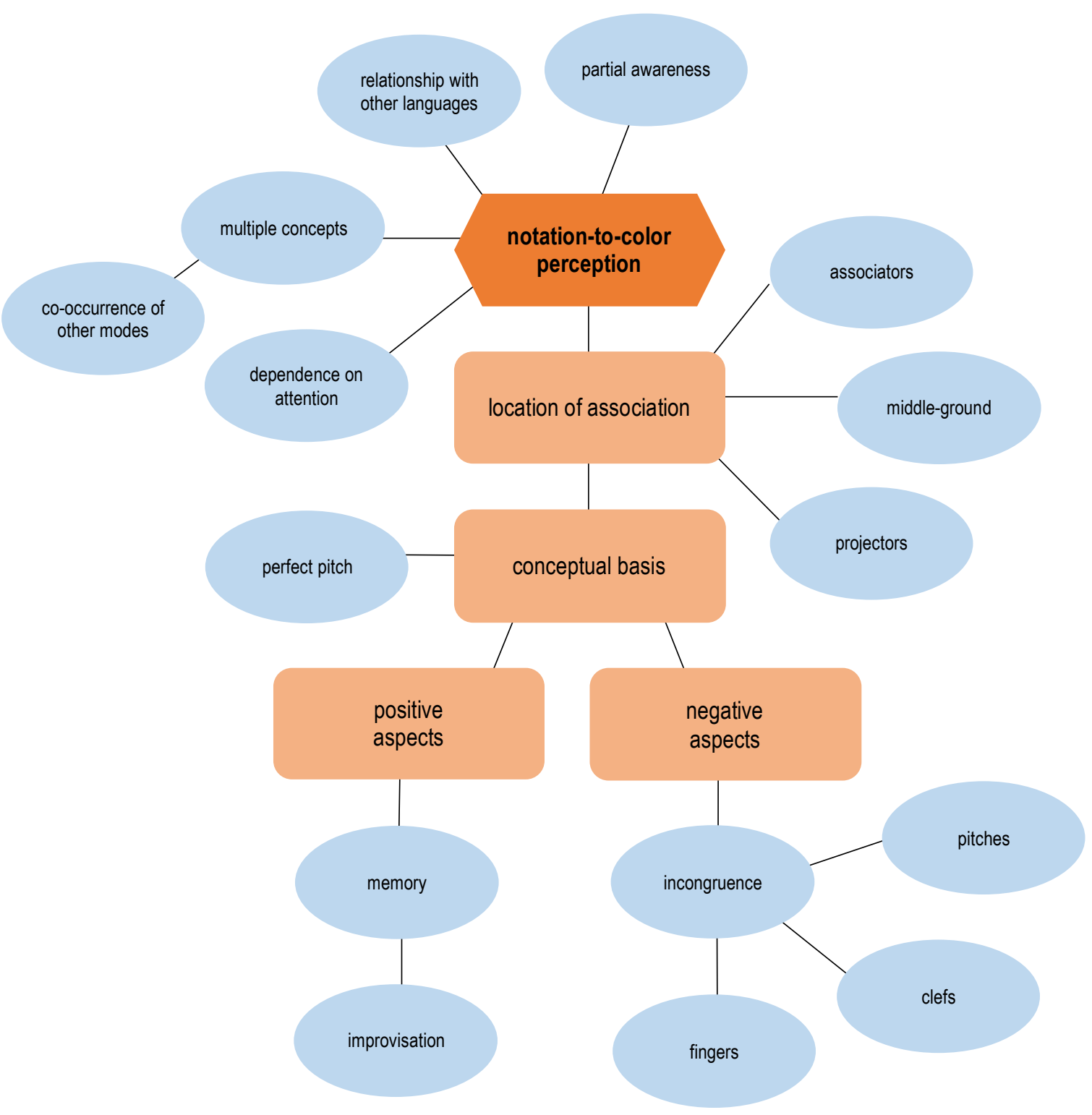




\section{APPENDIX I}

THEORETICAL MODEL: EDUCATIONAL APPROACH 
Phase 1:

Philosophical Foundation

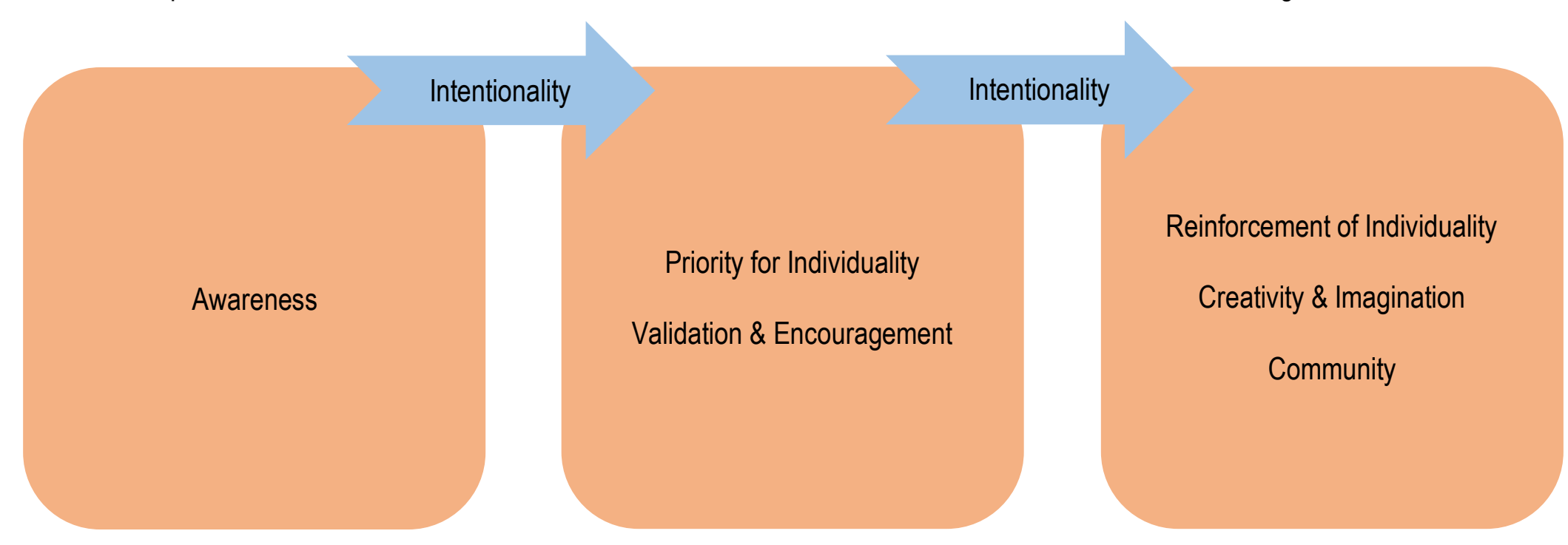

\section{Phase 2:}

Framework

Phase 3:

Methodological Considerations

Community 


\section{REFERENCE LIST}

Adler, M. J. (2013) The Paideia Proposal. In D. J. Flinders, \& S. J. Thornton (Eds.), Curriculum Studies Reader (4th ed.) (159-162). New York, NY: RoutledgeFalmer.

Afra, P., Funke, M., \& Matsuo, F. (2009). Acquired auditory-visual synesthesia: A window to early cross-modal sensory interactions. Psychology Research and Behavior Management, 2, 31.

Asano, M., \& Yokosawa, K. (2012). Synesthetic colors for Japanese late acquired graphemes. Consciousness and Cognition, 21(2), 983-993.

Asano, M., \& Yokosawa, K. J. (2013). Grapheme learning and grapheme-color synesthesia: toward a comprehensive model of grapheme-color association. Frontiers in Human Neuroscience, 7, 757.

Asher, J. E., \& Carmichael, D. A. (2013). The Genetics and Inheritance of Synesthesia. In Simner, J., \& Hubbard, E. M. (Eds.), The Oxford Handbook of Synesthesia (2345). Oxford: Oxford University Press.

Baron-Cohen, S., Bor, D., Billington, J., Asher, J., Wheelwright, S. \& Ashwin, C. (2007). Savant memory in a man with colour form-number synaesthesia and Asperger Syndrome. Journal of Consciousness Studies, 14(9, 10), 237 - 251.

Bédard, A.-C. V., Trampush, J. W., Newcorn, J. H., \& Halperin, J. M. (2010). Perceptual and motor inhibition in adolescents/young adults with childhood-diagnosed ADHD. Neuropsychology, 24(4), 424-434.

Beethoven, L. v. (1923). Klaviersonaten Band I. Leipzig: Breitkopf und Härtel.

Bent, I. D., Hughes, D. W., Provine, R. C., Rastall, R., Kilmer, A., Hiley, D., Szendrei, J., Payne, T. B., Bent, M., \& Chew, G. (2014). Notation. Oxford Music Online. https://doi.org/10.1093/gmo/9781561592630.article.20114

Blair, C. D., \& Berryhill, M. E. (2013). Synesthetic grapheme-color percepts exist for newly encountered Hebrew, Devanagari, Armenian and Cyrillic graphemes. Consciousness and Cognition, 22(3), 944-954.

Bloomberg, L. D. \& Volpe, M. (2019). Completing your qualitative dissertation: A roadmap from beginning to end. ( $4^{\text {th }}$ ed.). Thousand Oaks, CA: Sage.

Bowers, F. (1996). Scriabin: A bibliography. Toronto: Dover Publications. 
Brang, D., Ghiam, M., \& Ramachandran, V. S. (2013). Impaired acquisition of novel grapheme-color correspondences in synesthesia. Frontiers in Human Neuroscience, 7, 717.

Brang, D., \& Ramachandran, V. S. (2010). Visual field heterogeneity, laterality, and eidetic imagery in synesthesia. Neurocase, 16(2), 169-174.

Brang, D., Rouw, R., Ramachandran, V. S., \& Coulson, S. (2011). Similarly shaped letters evoke similar colors in grapheme-color synesthesia. Neuropsychologia, 49(5), 1355-1358.

Bruner, J. S. (1960). The process of education. New York: Vintage Books.

Counts, G. S. (2013) Dare the school build a new social order? In D. J. Flinders, \& S. J. Thornton (Eds.), Curriculum Studies Reader (4th ed.) (29-35). New York, NY: RoutledgeFalmer.

Carmichael, D., Down, M., Shillcock, R., Eagleman, D., \& Simner, J. (2015). Validating a standardised test battery for synesthesia: Does the synesthesia battery reliably detect synesthesia? Consciousness and Cognition, 33, 375-385.

Creswell, J. W. (2018). Educational research: Planning, conducting, and evaluating quantitative and qualitative research ( $6^{\text {th }}$ ed.). Upper Saddle River, NJ: Pearson.

Creswell, J. W., \& Poth, C. N. (2018). Qualitative inquiry \& research design. Fourth Edition: Thousand Oaks, CA: SAGE Publications.

Cytowic, R. E. (2018). Synesthesia. Cambridge, MA: MIT Press.

Curwen, C. (2018). Music-colour synaesthesia: Concept, context and qualia. Consciousness \& Cognition, 61, 94-106.

Day, S. A. (2013). Synesthesia: a first-person perspective. In J. Simner, \& E. M. Hubbard (Eds.), The Oxford Handbook of Synesthesia. Oxford: Oxford University Press.

Day, S. A. (2016). Synesthetes: a handbook. North Charleston, SC: CreateSpace.

Day, S. A. (2008). Regarding types of synesthesia and color-music art. In Bulat M. Galeyev (Eds.); СИНЕСТЕЗИЯ: СОДРУЖЕСТВО ЧУВСТВ И СИНТЕЗ ИСКУССТВ, $282-288$.

De Thornley Head, P. (2006). Synaesthesia: Pitch-colour isomorphism in RGB-space. Cortex, 42(2), 164-174. 
Dewey J. (2008). Democracy and Education (1916). New York: The Macmillan Company.

Dewey, J. (1902). The child and the curriculum. Chicago: University of Chicago Press.

Dewey, J. (1934). Art as experience. New York, Perigee Books.

Dickens, C. (1854). Hard times. London: Bradbury \& Evans.

Dixon, M. J., Smilek, D., Duffy, P. L., Zanna, M. P., \& Merikle, P. M. (2006). The role of meaning in grapheme-colour synaesthesia. Cortex, 42(2), 243-252.

Elliot, D. J. (Ed.). (2005). Praxial music education: reflections and dialogues. New York: Oxford University Press.

Elliott, D. J., \& Silverman, M. (2014). Music matters: A philosophy of music education. New York: Oxford University Press.

Freire, P. (2013) Pedagogy of the oppressed. In D. J. Flinders, \& S. J. Thornton (Eds.), Curriculum Studies Reader (4th ed.) (125-133). New York, NY: RoutledgeFalmer.

Glaser, B. G., \& Strauss, A. L. (1967). The discovery of grounded theory: Strategies forqualitative research. Chicago, IL: Aldine.

Goller, A. I., Otten, L. J., \& Ward, J. (2009). Seeing sounds and hearing colors: an eventrelated potential study of auditory-visual synesthesia. Journal of Cognitive Neuroscience, 21(10), 1869-1881.

Gregersen, P. K., Kowalsky, E., Lee, A., Baron-Cohen, S., Fisher, S. E., Asher, J. E., Ballard, D., Freudenberg, J., \& Li, W. (2013). Absolute pitch exhibits phenotypic and genetic overlap with synesthesia. Human Molecular Genetics, 22(10), 20972104.

Gsöllpointner, K., Schnell, R., \& Schuler, R. K. (2016). Digital Synesthesia: A Model for the Aesthetics of Digital Art: Walter de Gruyter GmbH \& Co KG.

Hänggi, J., Beeli, G., Oechslin, M. S., \& Jäncke, L. (2008). The multiple synaesthete ES-Neuroanatomical basis of interval-taste and tone-colour synaesthesia. NeuroImage, 43(2), 192-203.

Heidegger, M., Macquarrie, J., \& Robinson, E. (1962). Being and time. Malden, MA: Blackwell. 
Hubbard, E. M., Arman, A. C., Ramachandran, V. S., \& Boynton, G. (2005). Individual differences among grapheme-color synesthetes: brain-behavior correlations. Neuron, 45, 975-985.

Hubbard, E. B. (2007). Neurophysiology of synesthesia. Current Psychiatry Report, 9 , 193-199.

Hubbard, E. M. (1996). Synesthesia-like mappings of lightness, pitch, and melodic interval. American Journal of Psychology, 109, 219-238.

Hupé, J.-M., Bordier, C., \& Dojat, M. J. C. C. (2011). The neural bases of graphemecolor synesthesia are not localized in real color-sensitive areas. Cerebral Cortex, 22(7), 1622-1633.

Husserl, E. (1964). The Phenomenology of Internal Time-Consciousness. Churchill, J. S. (Trans.) \& Heidegger, M. (Ed.). Bloomington: Indiana University Press.

Itoh, K., Sakata, H., Kwee, I. L., \& Nakada, T. (2017). Musical pitch classes have rainbow hues in pitch class-color synesthesia. Scientific Reports, 7(1), 17781.

Jewanski, J. (1999). Ist C = Rot?: Eine Kulturund Wissenschaftsgeschichte zum Problem der wechselseitigen Bezeihung zwischen Ton und Farbe. Von Aristoteles bis Goethe. Berlin: Berliner Musik Studien, Sinzig: Studio.

Jewanski, J. (2013). Synesthesia in the nineteenth century: Scientific origins. In J. Simner, \& E. M. Hubbard (Eds.), The Oxford Handbook of Synesthesia. Oxford: Oxford University Press.

Jewanski, J., Day, S. A., \& Ward, J. (2009). The First Documented Case of Synesthesia, by George Tobias Ludwig Sachs in 1812. Journal of the History of the Neurosciences, 18(3), 293-303.

Kadosh, R. C., \& Henik, A. J. C. (2006). Color congruity effect: where do colors and numbers interact in synesthesia? Cortex, 42(2), 259-263.

Kliebard, H. M. (2013). The rise of scientific curriculum-making and its aftermath. In D. J. Flinders, \& S. J. Thornton (Eds.), Curriculum Studies Reader (4th ed.) (37-46). New York, NY: RoutledgeFalmer.

Kliebard, H. M. (2004). The struggle for the American curriculum, 1893-1958 (3rd ed.). RoutledgeFalmer.

Lacey, S., Martinez, M., McCormick, K., Sathian, K., \& Molholm, S. (2016). Synesthesia strengthens sound-symbolic cross-modal correspondences. European Journal of Neuroscience, 44(9), 2716-2721. doi:10.1111/ejn.13381 
Lima, E. S. C. (2019). Cross-sensory experiences and the Enlightenment: music synesthesia in context. Revista Musica Hodie, 19, 1-14.

Lima, E. S. C. (2015). Developmental synesthesia, perception, and performance: challenges and new directions in music education and research. Anais do $X X V$ Congresso da Associacao Nacional de Pos-Graduacao e Pesquisa em Musica. Salvador: Universidade Federal do Espirito Santo.

Lincoln, Y. S., \& Guba, E. G. (1985). Naturalistic inquiry. Beverly Hills, CA: Sage.

Loftus, E., \& Ketcham, K. (1994). The myth of repressed memories: false memories and allegations of sexual abuse. St. Martin's Press.

Lovelace, C. T. (2013) Synesthesia in the Twenty-First Century: Synesthesia's Ascent. In Simner, J., \& Hubbard, E. M. (Eds.), The Oxford Handbook of Synesthesia (409439). Oxford: Oxford University Press.

Mahler, G. (1904). Symphony No. 5 für grosses Orchester. Leipzig: C. F. Peters

Magrini, J. M. (2016). The Language of Teaching in Dwayne Huebner's Phenomenology: the poetic essence of language for the new re-conceptualization of curriculum. Journal of the American Association for the Advancement of Curriculum Studies, 11(1), 1-23.

Majno, M. (2012). From the model of El Sistema in Venezuela to current applications: Learning and integration through collective music education. Annals of the New York Academy of Sciences: The Neurosciences and Music IV, 1252(1), 56-64.

Marshall, J.D., Sears, J.T., Allen, L.A., Roberts, P.A., \& Schubert, W.H. (Eds.). (2007). Turning points in curriculum (2nd ed.). Upper Saddle River, NJ: Pearson.

Merleau-Ponty, M. (1962). Phenomenology of perception. London: Routledge.

Mottron, L., Dawson, M., Soulières, I., Hubert, B., \& Burack, J. (2006). Enhanced Perceptual Functioning in Autism: An Update, and Eight Principles of Autistic Perception. Journal of Autism Development Disorders, 36, 27-43.

Mroczco-Wasowicz, A., \& Nikolic, D. (2013) Colored Alphabets in Bilingual Synesthetes. In Simner, J., \& Hubbard, E. M. (Eds.), The Oxford Handbook of Synesthesia, (165-180). Oxford: Oxford University Press.

Neufeld, J., Sinke, C., Dillo, W., Emrich, H., Szycik, G., Dima, D., .Bleich, S., \& Zedler, M. (2012). The neural correlates of coloured music: A functional MRI investigation of auditory-visual synaesthesia. Neuropsychologia, 50(1), 85-89. 
Newton, I., \& Turnbull, H. W. (1959). Correspondence. Cambridge: Published for the Royal Society at the University Press.

Ofshe, R. (1994). Making monsters; False memories, psychotherapy, and sexual hysteria. Los Angeles: University of California Press.

Paffen, C. L., Van der Smagt, M. J., \& Nijboer, T. C. (2015). Cross-modal, bidirectional priming in grapheme-color synesthesia. Consciousness and Cognition, 33, 325333.

Pinar, W. F. (1994). Autobiography, politics, and sexuality: Essays in curriculum theory 1972-1992. New York: P. Lang.

Pfeifer, G., Rothen, N., Ward, J., Chan, D., \& Sigala, N. (2014). Associative memory advantage in grapheme-color synesthetes compared to older, but not young adults. Frontiers in Psychology, 5, 696.

Pfeifer, G., Rothen, N., Ward, J., Chan, D., \& Sigala, N. (2016). Representational account of memory: Insights from aging and synesthesia. Journal of Cognitive Neuroscience, 28(12): $1987-2002$.

Pritchard, J., Rothen, N., Coolbear, D., \& Ward, J. (2013). Enhanced associative memory for colour (but not shape or location) in synaesthesia. Cognition, 127, $230-234$.

Rachlin, H. (2005). What Müller's law of specific nerve energies says about the mind. Behavior and Philosophy, 33, 41-54.

Ramachandran, V. S., \& Seckel, E. (2011). Graphemes evoke synesthetic colors even before they are consciously recognized. Perception, 40(4), 490-492.

Rogers, G. L. (1987). Four cases of pitch-specific chromesthesia in trained musicians with absolute pitch. Psychology of Music, 15(2), 198-207.

Rothen, N., \& Meier, B. (2009). Do synesthetes have a general advantage in visual search and episodic memory? A case for group studies. PLoS ONE, 4(4), 5037.

Rothen, N., \& Meier, B. (2010). Grapheme-colour synaesthesia yields an ordinary rather than extraordinary memory advantage: evidence from a group study. Memory, 18(3), 258-264.

Rothen, N., Meier, B., \& Ward, J. (2012). Enhanced memory ability: Insights from synaesthesia. Neuroscience and Biobehavioral Reviews, 36, 1952 - 1963. 
Rothen, N., Seth, A. K., Witzel, C., \& Ward, J. (2013). Diagnosing synaesthesia with online colour pickers: maximising sensitivity and specificity. Journal of Neuroscience Methods, 215(1), 156-160.

Rowley, J. L. (2008). Teaching strategies to facilitate learning for gifted and talented students. Australasian Journal of Gifted Education, 17(2), 36-42.

Potter, L. C. (1990). Rubank Elementary Method: violin. Hal Leonard Corporation.

Sagiv, N., Frith, C. D. (2013). Synesthesia and Consciousness. In J. Simner, \& E. M. Hubbard (Eds.), The Oxford Handbook of Synesthesia (924-940). Oxford: Oxford University Press.

Saldaña, J. (2016). The Coding Manual for Qualitative Researchers. Fourth Edition: Thousand Oaks, CA: SAGE Publications.

Saldaña, J. (2015). Thinking qualitatively. Thousand Oaks, CA: SAGE Publications.

Sartre, J. (1992). Being and nothingness. New York: Washington Square Press.

Seaberg, M. (2011). Tasting the universe. Pompton Plains: The Career Press.

Sedikides, C., \& Skowronski, J.J. (2020). In human memory, good can be stronger than bad. Current Directions in Psychological Science, 29(1), 86-91.

Seddon, F. (2008). Non-music specialist trainee primary school teachers' confidence in teaching music in the classroom. Music Education Research, 10(3), 403-421.

Simner, J., \& Bain, A. E. (2018). Do children with grapheme-colour synaesthesia show cognitive benefits?, British Journal of Psychology, 109(1), 118-136.

Simner, J., Sagiv, N., Mulvenna, C., Tsakanikos, E., Witherby, S. A., Fraser, C., Scott, K., \& Ward, J. (2006). Synaesthesia: the prevalence of atypical cross-modal experiences. Perception, 35(8), 1024-1033.

Simner, J., \& Hubbard, E. M. (Eds.) (2013). The Oxford Handbook of Synesthesia (924940). Oxford: Oxford University Press.

Suzuki, S. (1978). Suzuki violin method: Violin part. Miami: Sunny-Birchard Inc.

Taruskin, R. (2010). Oxford history of Western music: A complete five-volume set. Oxford: Oxford University Press.

Thompson, M. (2013). Inclusive practices for the general music classroom [Master's thesis, Southern Illinois University Carbondale]. ProQuest Dissertations Publishing. 
University of Basel. Neumatic Notation. Retrieved Februrary 13, 2020, from http://wordpress.redirectingat.com/?id=725X1342\&isjs $=1 \& \mathrm{jv}=13.26 .2$ stackpath\&sref $=$ https $\% 3 \mathrm{~A} \% 2 \mathrm{~F} \% 2 \mathrm{Fcanvas}-$ shaped-ofsilence.blog\%2F 2017\%2F03\%2F05\%2Fexample-1-research-part-3a-earlyneumatic-

notation $\% 2 \mathrm{~F} \&$ url $=$ https $\% 3 \mathrm{~A} \% 2 \mathrm{~F} \% 2 \mathrm{Fwww}$.futurelearn.com $\% 2 \mathrm{Fcourses} \% 2 \mathrm{~F}$ from -ink-to-

sound $\% 2 F 0 \% 2$ Fsteps $\% 2 F 25996 \& x g u i d=\& x s=1 \& x t z=420 \&$ xuuid $=45 \mathrm{c} 70 \mathrm{~b} 116 \mathrm{e} 13$ dc1b37972ee73da01fc8\&xcust $=8982$

Van Leeuwen, T. M. (2013). Individual differences in synesthesia. In J. Simner, \& E. M. Hubbard (Eds.), The Oxford Handbook of Synesthesia. Oxford: Oxford University Press.

Van Campen, C. (2009). How does the memory of synesthetes work? In de Córdoba, M. J., Hubbard, E. M., Riccò, D., \& Day, S. (Eds.), Actas del III Congreso Internacional de Sinestesia, Ciencia y Arte. Granada: Ediciones Fundación Internacional Artecittè.

Van Waesberghe, J. S. (1951). The musical notation of Guido of Arezzo. Musica Disciplina, 5, p. 15-53.

Vygotsky, L. S. (1978). Mind in society: The development of higher psychological processes. Cambridge, Mass.: Harvard University Press.

Ward, J., Hovard, P., Jones, A., \& Rothen, N. (2013). Enhanced recognition memory in grapheme-color synaesthesia for different categories of visual stimuli. Frontiers in Psychology, 4, 762.

Ward, J. (2013). Synesthesia. Annual Review of Psychology, 64(1), 49-75.

Ward, J., Tsakanikos, E., \& Bray, A. (2006). Synaesthesia for reading and playing musical notes. Neurocase, 12, 27-34.

Ward, J. (2008). The Frog Who Croaked Blue: Synesthesia and the Mixing of the Senses. New York: Routledge.

Wiggins, G., \& McTighe, J. (2005). Understanding by Design. Alexandria: Association for Supervision and Curriculum Development.

Witthoft, N., \& Winawer, J. (2013). Learning, memory, and synesthesia. Psychological Science, 24(3), 258-265.

Yin, R. K. (2009). Case study research: Design and methods (4th ed.). Thousand Oaks, CA: Sage. 
VITA

NAME: $\quad$ Eduardo Sola Chagas Lima

EDUCATION:

2020

Doctor of Philosophy (Curriculum and Instruction)

Andrews University, Berrien Springs, Michigan, USA

2015

Master of Arts (Musicology, Music Theory)

University of Toronto, Ontario, Canada

2012

Bachelor of Music (Baroque Violin Performance)

Royal Conservatoire, The Hague, The Netherlands

2009

Bachelor of Music (Violin Performance)

Parana State University, Curitiba, Brazil

PROFESSIONAL EXPERIENCE:

2018 - Present Assistant Professor, Music Department

Burman University, Alberta, Canada

$2017-2018$

Choir Director

Kingsway College, Ontario, Canada

$2015-2018 \quad$ Choir Director

College Park Elementary School, Ontario, Canada

$2015-2018$

Choir Director, Violin Instructor

Sistema Toronto, Ontario, Canada

2012 - $2014 \quad$ Teacher Assistant "Music History Survey I", "Music for the

Theater", University of Toronto

$2006-2009 \quad$ Section Violinist

Paraná Symphony Orchestra

$2005-2009$

Section Violinist

PUC-PR Chamber Orchestra 